\title{
Investigaciones arqueológicas en Anfama. 2014-2015.
}

Book · January 2019

CITATIONS

0

3 authors:

Francisco Franco

National University of Cordoba, Argentina

18 PUBLICATIONS 2 CITATIONS

SEE PROFILE

Julián Salazar

National University of Cordoba, Argentina

18 PUBLICATIONS 29 CITATIONS

SEE PROFILE
READS

14

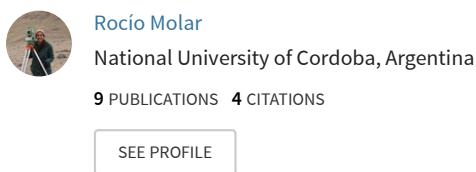

Some of the authors of this publication are also working on these related projects:

Project Equipo de Arqueología del Sur de las Cumbres Calchaquíes View project 


\section{SERIE REPORTES}
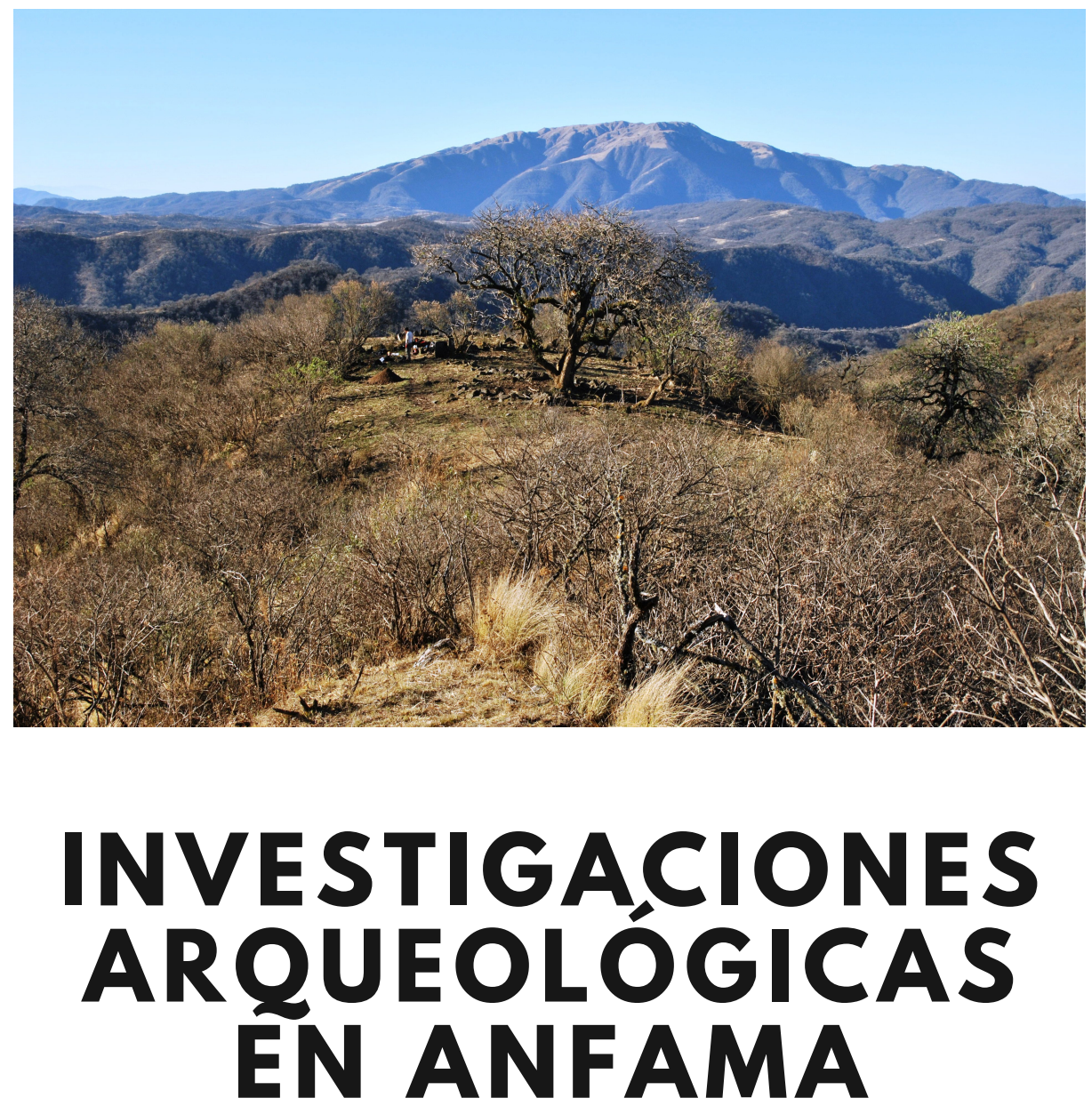

2014-2015

Proyecto "Arqueología de Anfama. Antepasados, Memoria e Identidad"

EQUIPO DE ARQUEOLOGÍA DEL SUR DE LAS CUMBRES C A L C H A Q U Í E S

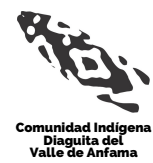

ISBN: 978-987-86-1104-4 


\title{
SERIE REPORTES
}

\section{Investigaciones}

\section{Arqueológicas en Anfama}

\section{4-2015}

\author{
Francisco Franco, Rocío M. Molar y Julián Salazar
}

Tareas de campo: Carolina Andreis, Cecilia Argañaraz, Dana Carrasco, Celeste Chávez, Stefanía Chiavassa Arias, Francisco Franco, Valeria Franco Salvi, Jordi López Lillo, Rocío Molar, Juan Montegú, Gonzalo Moyano, Paula Páez, Julián Salazar, Molly Seidel, Agustina Vázquez Fiorani. 
Salazar, Julián

Investigaciones / Francisco Franco; Rocío M. Molar; Julián Salazar - 1a ed. ampliada. - Córdoba: Julián Salazar, 2019.

Libro digital, PDF - (Serie reportes / Salazar, Julián. Serie reportes Anfama ; 1)

Archivo Digital: descarga y online

ISBN 978-987-86-1104-4

1. Arqueología. I. Franco, Francisco. II. Molar, Rocío M. III. Título. CDD 930.1 
Esta serie de publicaciones apunta a facilitar el acceso a información y datos que hemos generado a lo largo de distintas campañas arqueológicas realizadas en sur de las Cumbres Calchaquíes (Tucumán, Argentina). El relativo desconocimiento que hay hasta la actualidad sobre la arqueología pedemontana de la región amerita un esfuerzo por facilitar el acceso a las descripciones de sitios y materiales allí identificados.

Buena parte de las investigaciones no se materializan en publicaciones académicas o tardan en hacerlo, con lo cual una gran cantidad de información permanece inaccesible para otros equipos, e incluso para las comunidades locales. Esperamos que esta serie de informes ayude a rellenar parcialmente los intersticios entre trabajos de campo y publicaciones, y que los datos originales generados queden públicamente disponibles. Aprovechamos la posibilidad que nos brinda este tipo de formato para incluir abundante material gráfico que complementa las descripciones realizadas, $y$, que en ocasiones no puede ser incluido en su totalidad en los trabajos de divulgación científica.

Si bien el informe se centra en la descripción de los sitios y materiales trabajados, también hemos incluido algunas interpretaciones breves de carácter teórico a fines de otorgar una visión integradora del registro. Parte de las hipótesis que planteábamos en estos primeros pasos han sido corroboradas, mientras que otras fueron descartadas, sin embargo, preferimos exponerlas de la forma en la que las pensábamos hace algunos años atrás, intentando que este material también sirva como mapa de ruta de la evolución de nuestras interpretaciones. Adicionalmente, esperamos poder editar en el corto plazo los avances correspondientes a los años 2016, 2017 y 2018 a fines de brindar un panorama más completo y actualizado de nuestra labor en Anfama.

Córdoba, julio de 2019 


\section{Contenido}

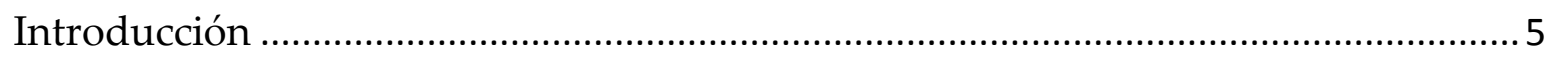

Breve caracterización geoespacial de Anfama .................................................. 6

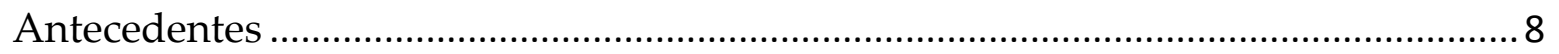

Investigaciones arqueológicas realizadas ........................................................ 12

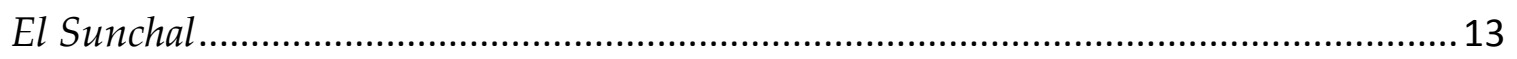

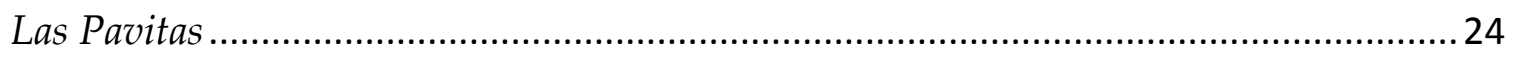

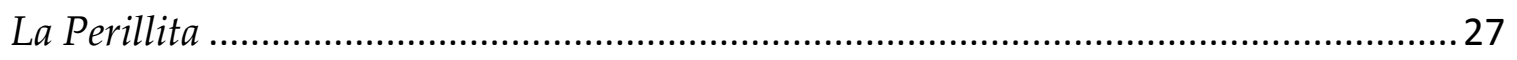

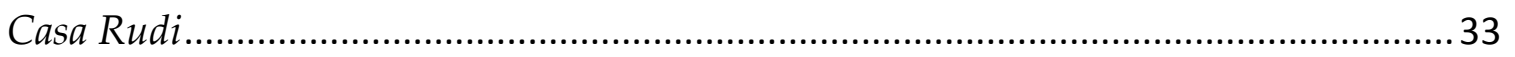

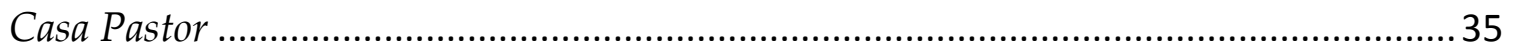

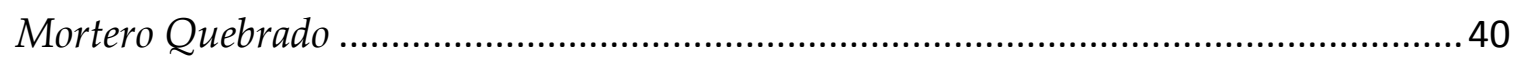

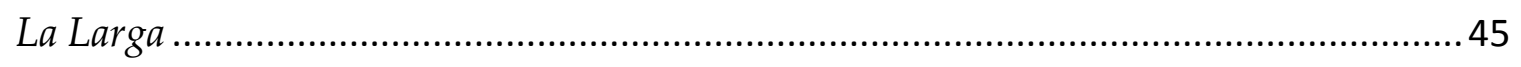

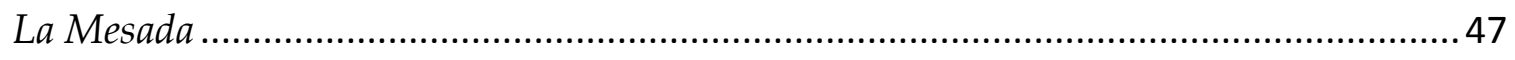

Aspectos cronológicos de la materialidad ........................................................ 48

Algunas reflexiones iniciales ......................................................................... 51

Entrevistas para el registro de la Historia Oral y el Saber Comunitario. ..................53

Entrevista a Daniel Chocobar (Julio de 2014) .............................................................53

Entrevista a Teresa Monasterio y Desiderio Maza (Julio de 2015) ................................59

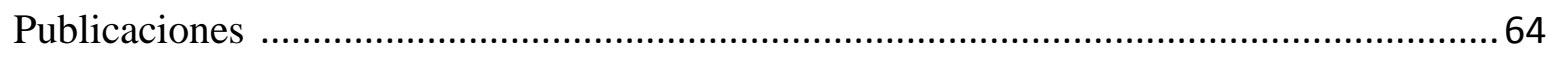

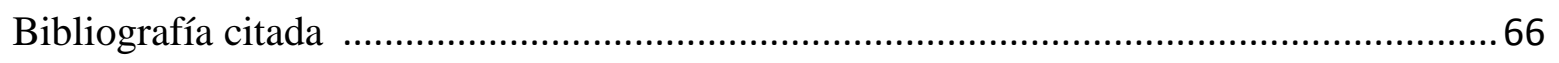




\section{Introducción}

El valle de Anfama $\left(26^{\circ} 42^{\prime}\right.$ a $26^{\circ} 47^{\prime} \mathrm{S} ; 65^{\circ} 31^{\prime}$ a $65^{\circ} 38^{\prime} \mathrm{O} ; 1800$ a $\left.2400 \mathrm{msnm}\right)$, se encuentra ubicado en la vertiente oriental de las Cumbres Calchaquíes en el noroeste de la provincia de Tucumán (Argentina); y puede entenderse como un área de transición entre valles y yungas, e incluso como una vía de acceso desde los sectores de valles pre cordilleranos al piedemonte oriental (Figura 1). Recientemente las tierras del valle han sido recuperadas por la Comunidad indígena diaguita local, entidad con la cual suscribimos desde julio de 2014 proyectos de cooperación mutuos para la realización de investigaciones arqueológicas en la cuenca.

De esta manera, el Equipo de Arqueología del Sur de las Cumbres Calchaquíes (EASCC), de la Universidad Nacional de Córdoba y el Centro de Estudios Históricos Profesor Carlos S. A. Segreti (CONICET), y la Comunidad Indígena del Pueblo Diaguita de Anfama, Personería Jurídica 740/08, firmaron un primer acuerdo de trabajo materializado en el proyecto "Arqueología de Anfama. Antepasados, Memoria e Identidad", y el cual se constituyó con los objetivos de:

1. Investigar la dinámica histórica de los habitantes originarios que ocuparon la región, desde su poblamiento original hasta la actualidad.

2. Identificar y relevar los vestigios arqueológicos distribuidos en el paisaje a fin de generar un inventario patrimonial de la Comunidad.

3. Registrar, a través de entrevistas a comuneros, la historia reciente de Anfama y su gente, la memoria colectiva, los mitos y las leyendas, a fin de construir una base escrita y audiovisual de los saberes tradicionales comunitarios.

4. Asegurar que todas las actividades realizadas en el marco de trabajo sean acordadas con la comunidad considerando la voluntad general, el respeto a las creencias locales y la ética profesional. 
5. Difundir la totalidad de conocimientos generados en el marco del proyecto a la comunidad a través de distintos medios: informes escritos, libros, documentales audiovisuales, exposiciones, charlas y talleres.

6. Asegurar que la totalidad de los bienes culturales recuperados sean resguardados y protegidos de la mejor manera posible (según los conocimientos y recursos disponibles) en un depósito de la localidad de Anfama.

El contenido que presentamos aquí es una versión ampliada del primer informe de actividades arqueológicas realizadas en Anfama (cinco campañas entre mayo de 2014 y octubre de 2015), en el cual se detallaron las tareas de campo y los resultados iniciales de los trabajos estipulados en el convenio firmado.

\section{Breve caracterización geoespacial de Anfama}

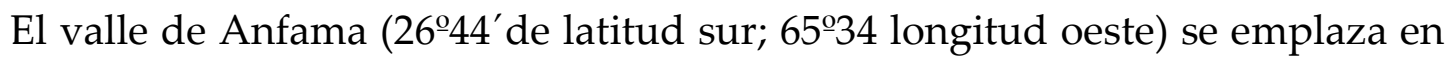
la vertiente oriental de las Cumbres Calchaquíes. Este espacio, de alturas que oscilan entre los 1300 y 2800 msnm, une la llanura tucumana con el valle de Tafí a través del recorrido El Siambón (920 msnm)- Las Juntas (1100 msnm)- Anfama- La Ciénega (2700 msnm)- Tafí del Valle (2050 msnm).

El borde oriental de las Cumbres Calchaquíes, el cual se funde progresivamente hacia el este con la llanura tucumana, no presenta una vertiente simple, sino un cuerpo en bloque subdividido por regiones de hundimiento. Como resultado de estos procesos la topografía de Anfama es muy escarpada, combinando quebradas muy profundas con estrechas zonas de cumbres las cuales son levemente planas y dan asiento a la mayoría de las estructuras arqueológicas identificadas. En algunos sectores, especialmente en aquellos próximos a los 
fondos de la cuenca, se extienden terrazas aluviales de menores pendientes con mayor depositación de sedimentos.

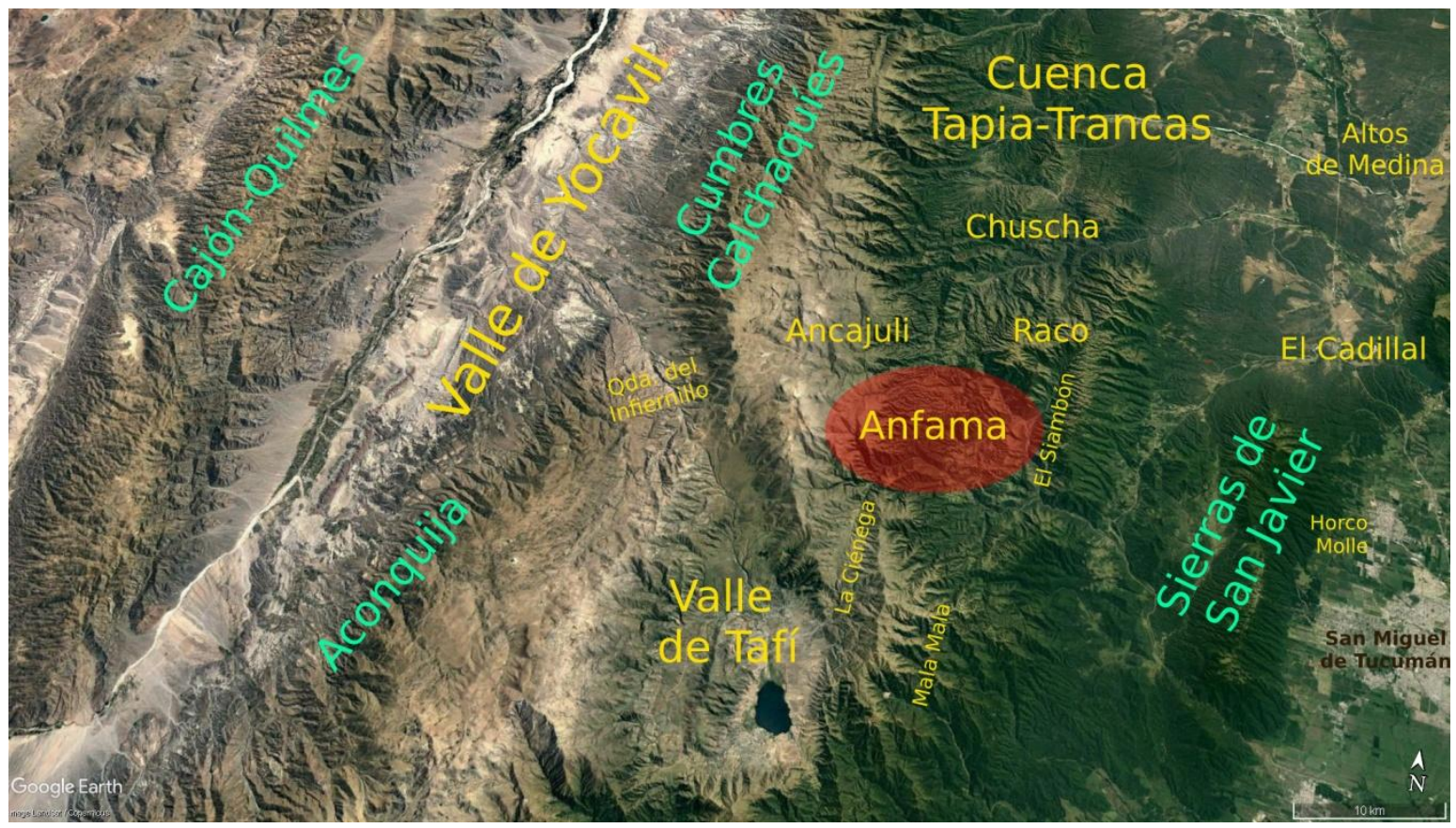

Figura 1. Ubicación espacial de Anfama.

Anfama recibe precipitaciones regulares (del orden de los 800 a $2000 \mathrm{~mm}$ anuales) que se concentran fundamentalmente en la época estival, debido a los cordones orográficos que impiden el paso hacia el oeste de vientos húmedos, provocando su condensación y descarga en la ladera oriental. Dicha situación provoca a su vez la formación de ríos estacionalmente torrentosos y de amplio caudal (Capllonch et al., s/f).

El valle forma parte del piso más elevado de la eco-región de las Yungas, el bosque montano (Cabrera, 1976). Esta franja altitudinal, lindante con los pastizales de neblina hacia arriba y con la selva montana hacia abajo, muestra la mayor heterogeneidad estructural de las yungas (Rohmeder, 1945; Antelo y Navarro, 2017; Capllonch et al., s/f). Y constituye un espacio de transición en el que se intercalan extensas praderas (que forma grandes extensiones de césped, propicias 
para el pastoreo en la actualidad de ganado ovino, equino y vacuno) y numerosos bosques de alisos (Alnus acuminata y Alnus jorullensis var. spachii, que proveen de madera de buena calidad), sauco y molles del cerro.

Adicionalmente, el clima templado, la alta pluviosidad y la presencia de suelos fértiles posibilitan la realización de actividades agrícolas sin la necesidad de recurrir a métodos de regadío artificial.

\section{Antecedentes}

Los primeros acercamientos al registro arqueológico de Anfama incluyeron prospecciones iniciales y la realización de sondeos exploratorios en seis sitios arqueológicos multicomponentes, acompañados de los primeros tres fechados radiocarbónicos para el área de trabajo. La apertura de la Comunidad a nuestra labor, permitió que pudiéramos realizar entrevistas tendientes a recuperar la historia y memoria del valle en las décadas precedentes. Adicionalmente, la amistad y apertura de algunas de las familias facilitó desde el inicio nuestra labor, y posibilitó que conociéramos parte de sus prácticas tradicionales, las trazas materiales que las mismas generan, y un acercamiento inicial a la arqueología de la zona.

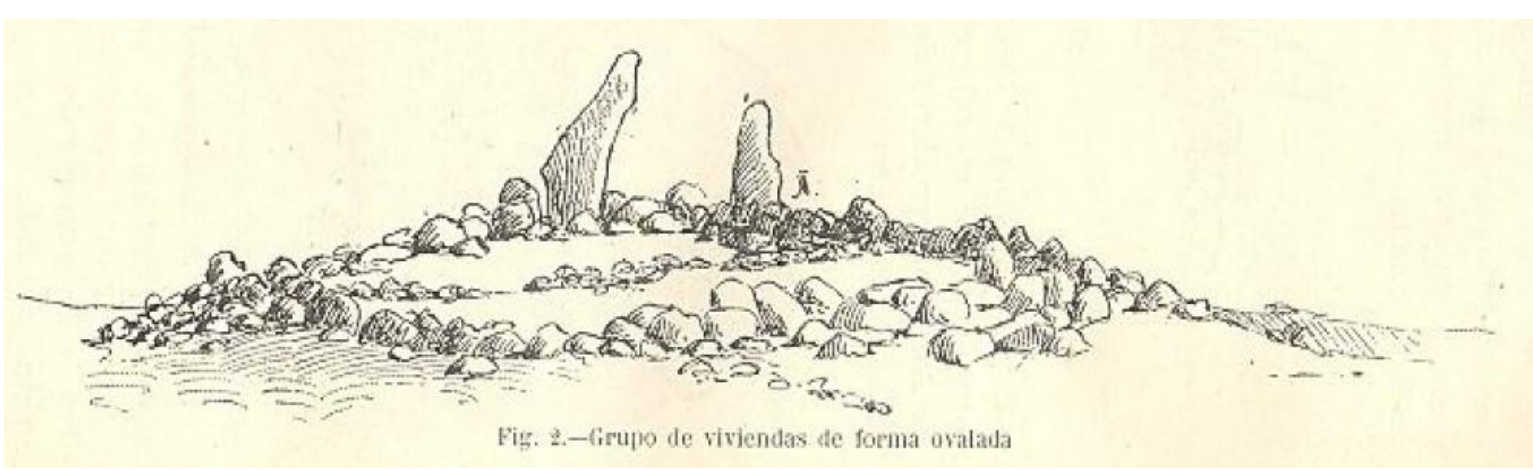

Figura 2. Estructuras circulares registradas por Quiroga (1899: 97). 
Hasta el inicio de las tareas de campo del EASCC (Equipo de Arqueología del Sur de las Cumbres Calchaquíes), ningún proyecto arqueológico sistemático había sido puesto en marcha para identificar y analizar las ocupaciones humanas prehispánicas de Anfama. Solo contábamos en ese momento con una breve reseña de Quiroga (1899), y la descripción de una serie de sondeos en el sudeste de Anfama realizados por Cremonte (1996) en el marco de su tesis doctoral centrada en el vecino valle de La Ciénega.

Quiroga relata haber observado algunas "ruinas" en los sectores altos de las serranías, que se encontraban a salvo de la acción del agua. Presenta algunos croquis y dibujos, destacando la presencia de estructuras circulares asociadas a menhires (Figura 2), de conjuntos de estructuras rectangulares (Figura 3) que denomina "tamberías", de algunos monolitos dispersos y la presencia de una escultura lítica que, según su interpretación, representaría una tortuga. La misma pasó a formar parte de la colección personal del viajero (Figura 4).

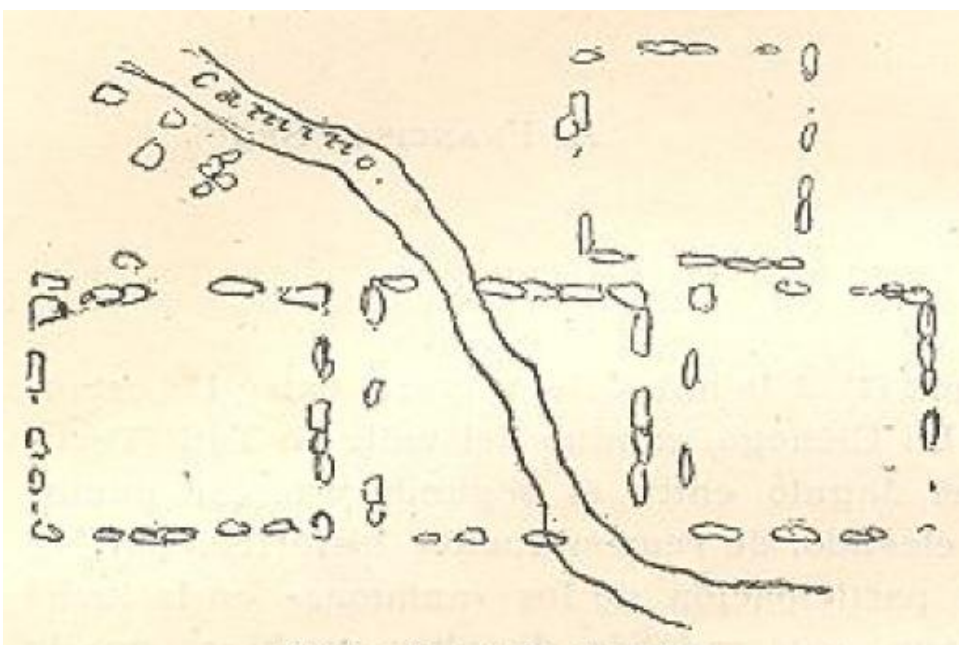

Fig. 1.-Grupo de viriendas

Figura 3. Estructuras rectangulares registradas por Quiroga (1899: 96). 
Cremonte (1996: 147-150) detalla la arquitectura superficial de los sitios El Potrerillo y La Cañadita, así como los materiales recuperados en los sondeos realizados. A partir de distintos estudios composicionales de pastas cerámicas, esta autora observó diferencias en las formas de producción, destacando la mayor presencia de inclusiones tabulares de rocas metamórficas en El Potrerillo, y de biotita, feldespato y cuarzo en La Cañadita.

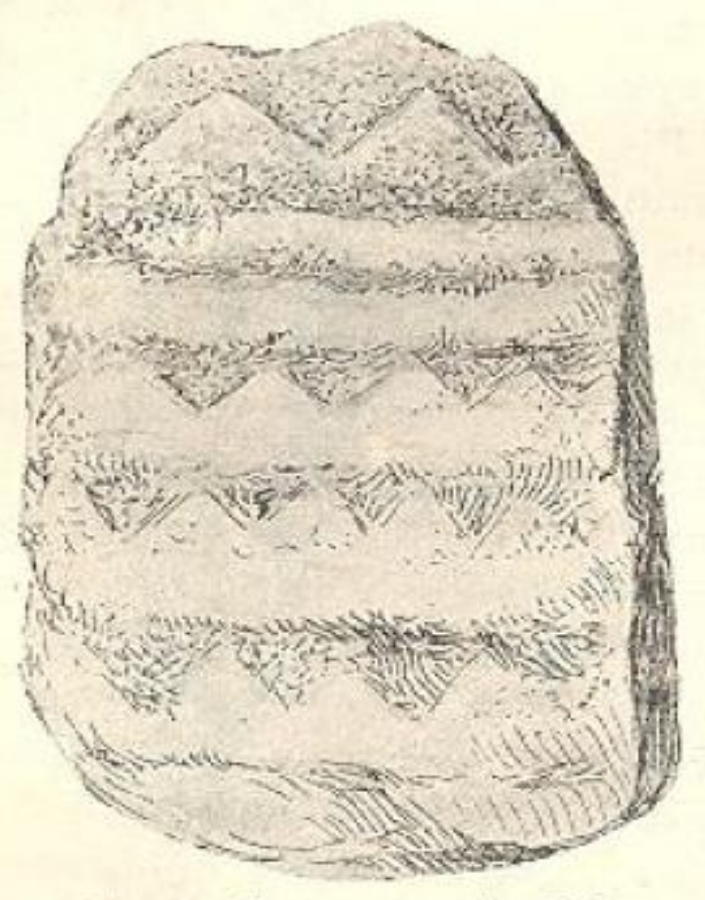

Fiz. 3.-Gran tortuga de piedrat

Figura 4. Bloque lítico grabado interpretado como una tortuga. Quiroga (1899: 98).

Los fragmentos recuperados en El Potrerillo corresponderían a vasijas domésticas con evidencias de utilización para cocción. Pese a la ausencia de referencias cronológicas precisas, consideramos que la abundancia de tiestos marleados descriptos podría corresponder a una ocupación de momentos tardíos del primer milenio o principios del segundo milenio. En cambio, para el caso de La Cañadita la escasez de restos recuperados no permite realizar inferencias de ese tipo. Adicionalmente, la presencia de estructuras de tipos rectangular o semi- 
rectangular en ambos casos reforzaría la idea de ocupaciones tardías. Sin embargo, la alusión a monolitos podría ser consecuente con ocupaciones del primer milenio (Cremonte, 1996:57-58).

A falta de indagaciones más precisas, se podría considerar tentativamente a los sitios observados por Cremonte, como ocupaciones multicomponentes que fueron re-utilizadas diacrónicamente en distintos momentos de la historia prehispánica. Al respecto, el valle de Anfama es una estrecha cuenca encajonada entre cerros de gran altura con pendientes acentuadas, lo cual implica que los sectores propicios para el asentamiento humano sean relativamente escasos y que las ocupaciones hayan redundado en épocas pre y post hispánicas en las mismas locaciones del paisaje. Numerosas viviendas actuales parecen haber sido construidas sobre sitios arqueológicos de distintos periodos. Tanto en los perfiles generados por cortes de nivelación del terreno, como en los adobes de las construcciones o en las superficies con menor cobertura vegetal, se observan fragmentos de cerámicas Grises incisas (similares a las del primer milenio en áreas circundantes), Ordinarias lisas, Santamarianas y Famabalasto negro inciso, y artefactos líticos (en cuarcita, cuarzo y obsidiana).

También hemos registrado algunos tiestos cerámicos en poder de las distintas familias, sobre todo modelados y pintados, hachas líticas y numerosos bloques de piedra alargados (de unos 40 a $70 \mathrm{~cm}$ de largo y $10 \mathrm{~cm}$ de ancho) tallados con forma fálica, que rememoran a las huancas (anteriormente denominados "menhires" [García Azcárate 2000]) del valle de Tafí, pero de menor tamaño. Asimismo, hasta ahora, se han detectado tres grandes monolitos huancas en su posición original y numerosas rocas grabadas (móviles, semi-móviles y fijas) en las proximidades de las estructuras arqueológicas. Todo esto permite pensar en que la ocupación de la localidad fue intensa a lo largo de los últimos dos milenios. 


\section{Investigaciones arqueológicas realizadas}

Las prospecciones realizadas durante este periodo fueron destinadas a cubrir los sectores de altura media del área (entre 1800 y $2400 \mathrm{msnm}$ ), lo que ha permitido identificar vestigios arqueológicos que incluyen áreas de molienda con múltiples cavidades en sectores próximos a los ríos, unidades compuestas por recintos de planta circular, unidades compuestas por recintos cuadrangulares, muros aislados y conjuntos de depresiones con materiales en superficie. Los vestigios identificados fueron poco más de un centenar de estructuras arqueológicas que pueden integrarse en nueve "sitios" o locaciones de concentración de evidencias, que en su mayoría ya eran conocidos (al menos parcialmente) por los comuneros anfameños (Ver Figura 5): El Sunchal, Las Pavitas, Casa Rudi, Casa Pastor, La Perillita, La Laguna, La Larga, La Mesada y Mortero Quebrado. A continuación detallamos los trabajos realizados en cada una de esas ocupaciones entre 2014 y 2015, caracterizamos la evidencia material recuperada y exponemos una serie de interpretaciones sobre las prácticas humanas en el pasado, su relación entre sí y con el paisaje, y su dinámica temporal. 


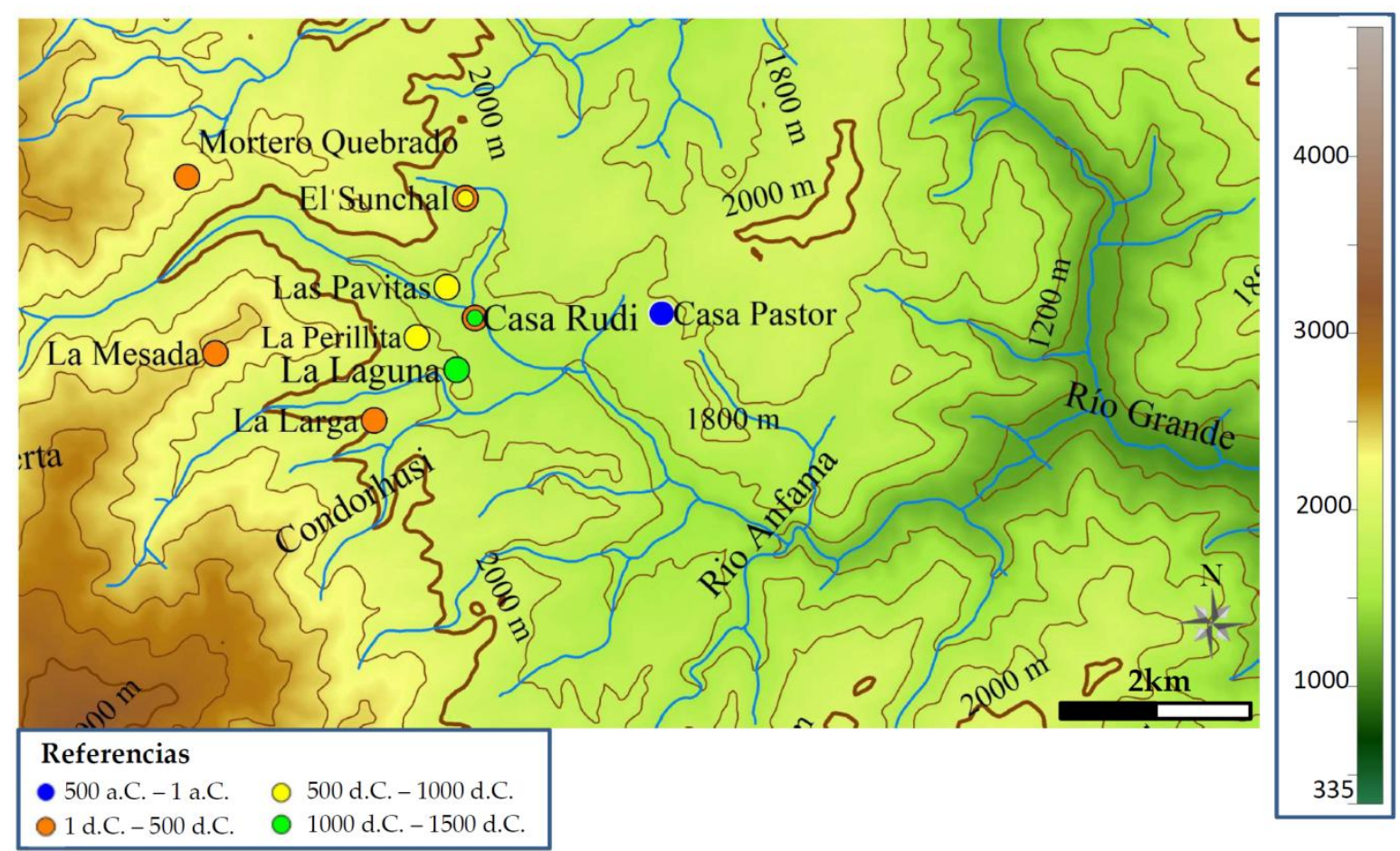

Figura 5. Mapa arqueológico de Anfama donde se muestran las ocupaciones consideradas en este informe.

\section{El Sunchal}

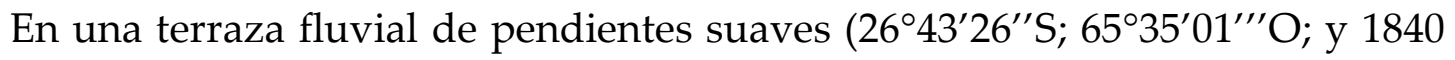
msnm) y cubierto por pastizales, muy próximo a la iglesia de Anfama y a la casa de Don Desiderio Masa y Doña Teresa Monasterio, se podían observar algunas depresiones y muros próximos a un puesto subactual ya abandonado. 


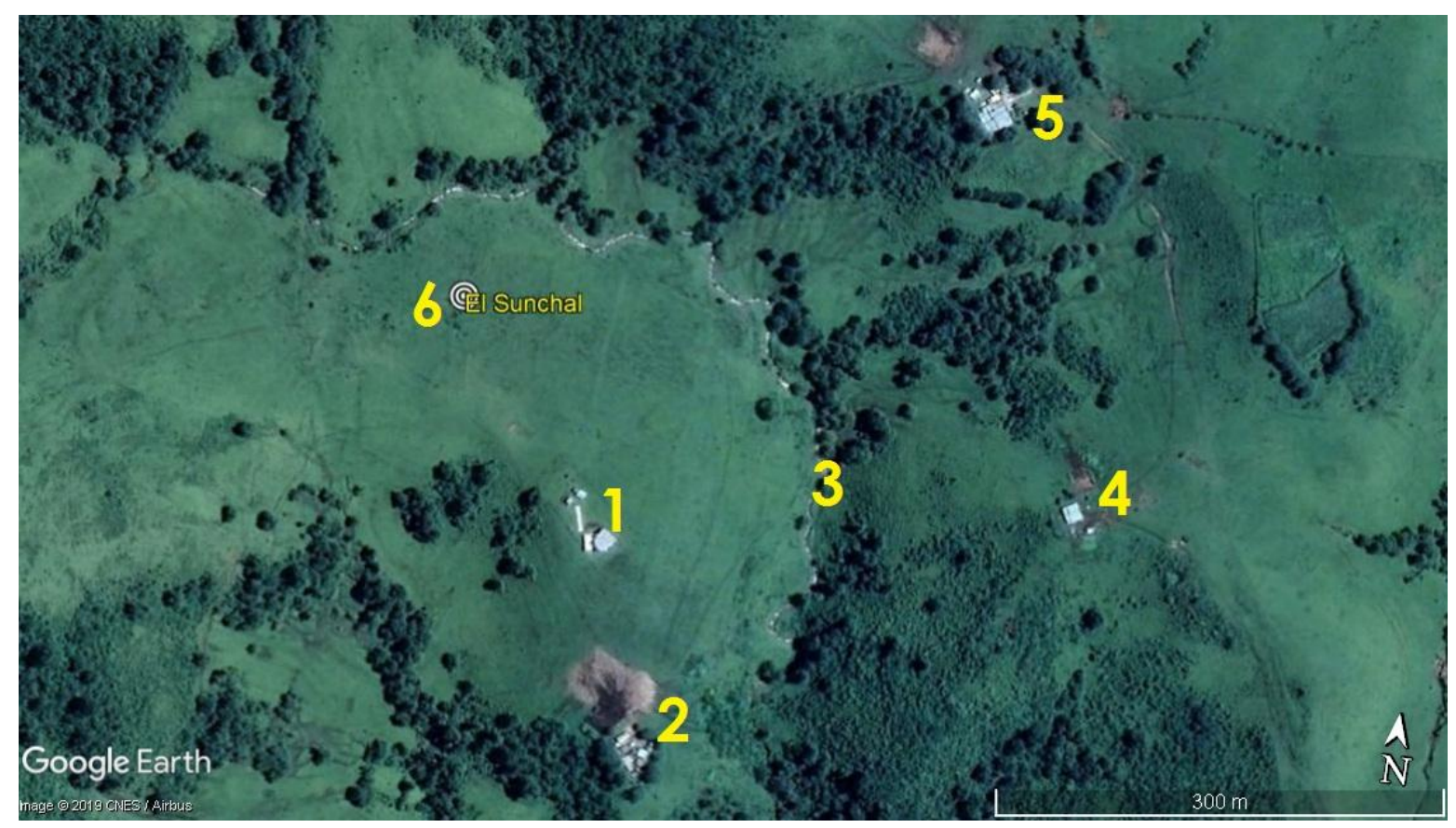

Figura 6. Toma aérea de El Sunchal. 1) Capilla de Anfama. 2) Puesto familia Maza. 3) Arroyo El Sunchal. 4) Puesto familia Natalia Aguilera. 5) Puesto familia Ragido. 6) Puesto subactual abandonado.

Las depresiones y muros conforman dos conjuntos distanciados entre sí por solo $10 \mathrm{~m}$. En uno de ellos, al que llamamos unidad U2, se identificó una roca grabada de unos $80 \mathrm{~cm}$ de largo la cual presenta en uno de sus extremos un motivo de dos círculos concéntricos con un punteado en su interior (Figura 7 y 8), y dos bloques con grabados hemiesféricos (Figura 9 y 10). En la superficie se observaban también algunos instrumentos de molienda fijos y móviles, con lo cual, decidimos realizar excavaciones sistemáticas en torno a la unidad U1, y en la estructura R01. Esta última constituye una depresión subcircular de unos $10 \mathrm{~m}$ de diámetro (Figura 6). Con el objetivo de sistematizar las intervenciones y generar un muestreo representativo, toda la superficie fue cuadriculada a través de una grilla de celdas de 1,5 m de lado. Para cubrir la totalidad se requirieron 18 columnas planteadas de Este a Oeste (denominadas desde A hasta Q) y 17 filas planteadas de 
Norte a Sur (denominadas con números del 0 al 16), definiendo 306 cuadrículas que ocupan una superficie de $688,5 \mathrm{~m}^{2}$. Las alturas de la superficie (respecto al punto 0) fueron registradas y a partir de eso se generó un modelo topográfico sobre el cual se fueron cargando los datos espaciales de las excavaciones. (Figura $11)$.

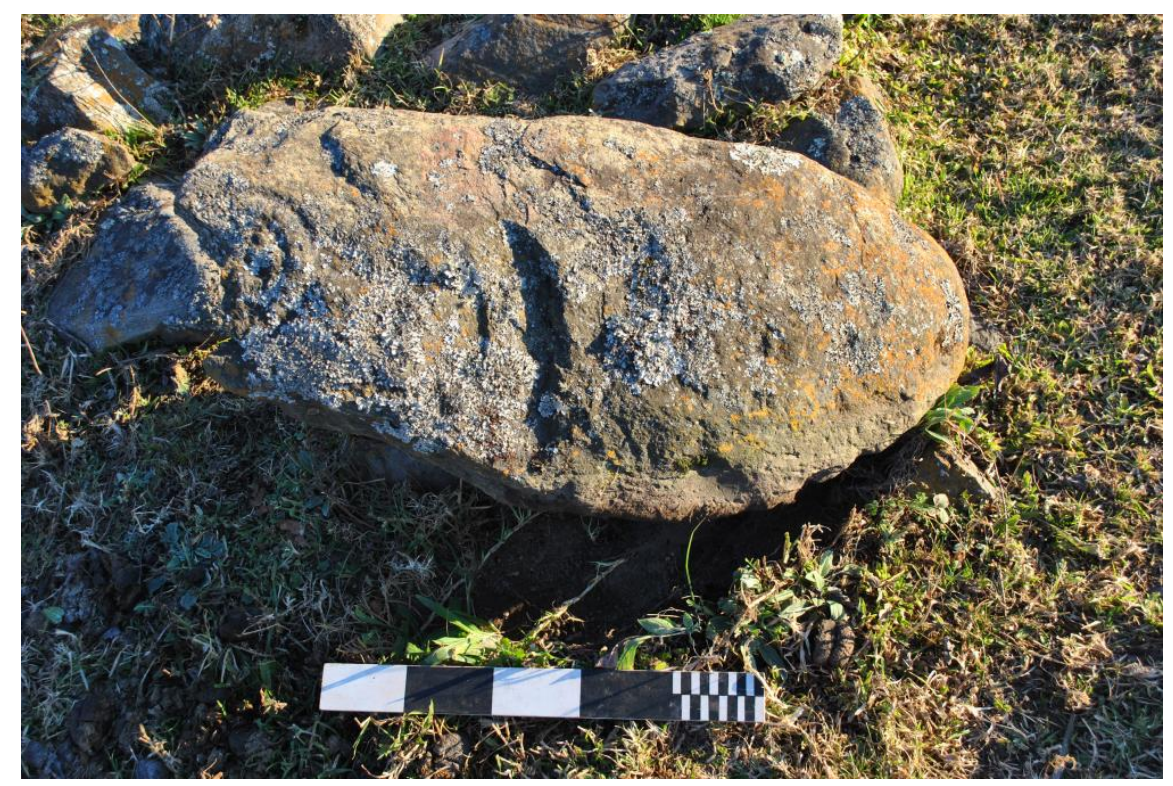

Figura 7. Bloque lítico móvil grabado, en el vértice izquierdo se observa el grabado. 


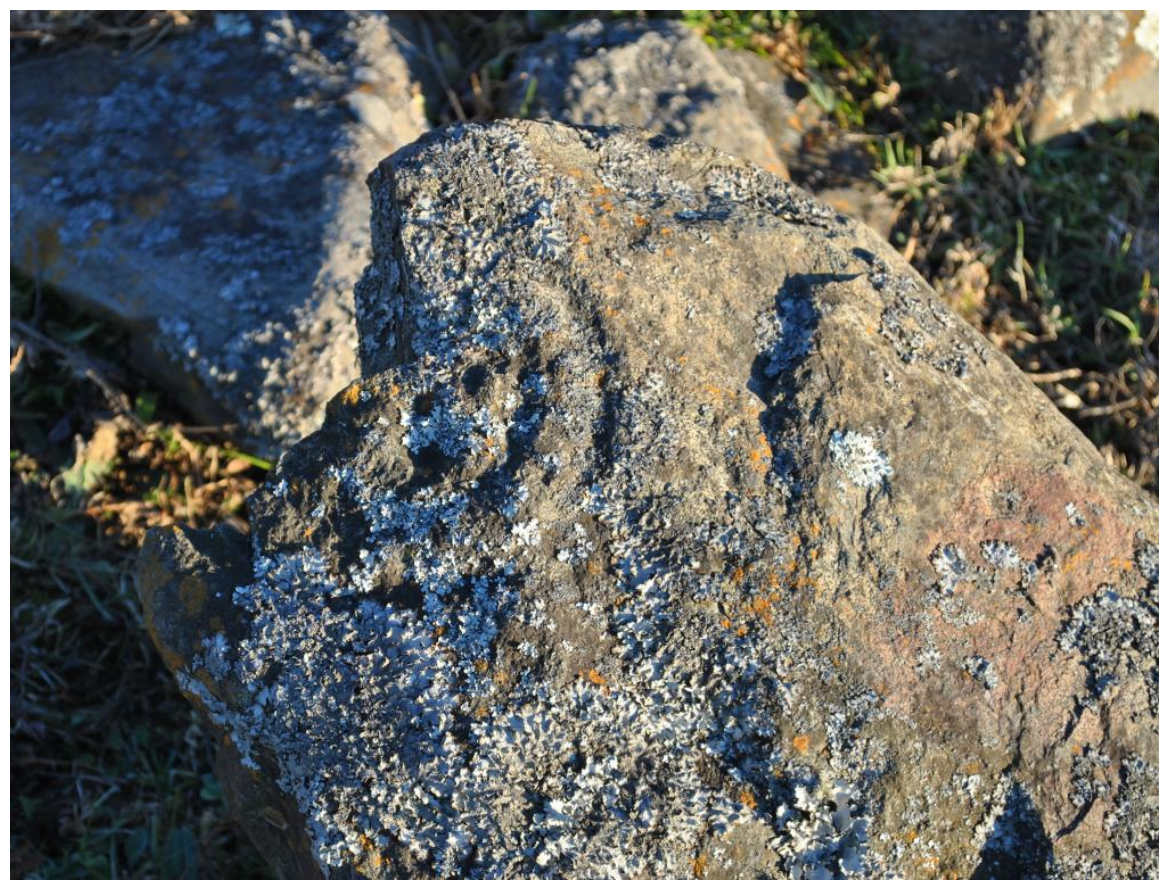

Figura 8. Detalle de motivos concéntricos y punteados grabados en la roca. 


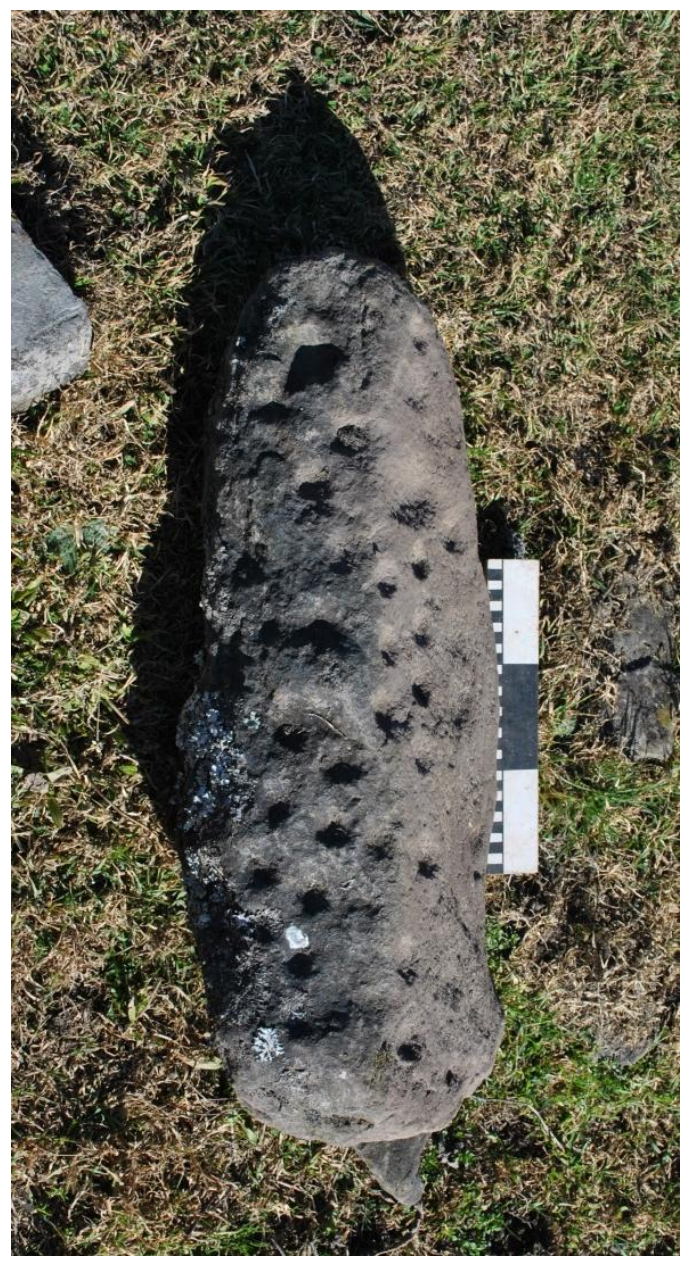

Figura 9. Roca grabada con cavidades hemiesféricas, la cual había sido incluida en un muro subactual.

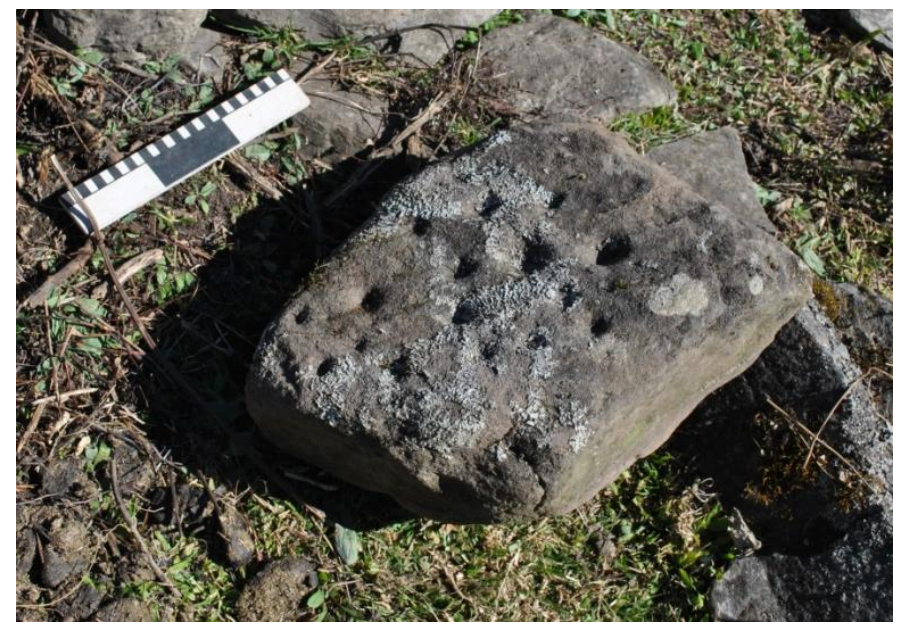

Figura 10. Roca grabada con cavidades hemiesféricas. 


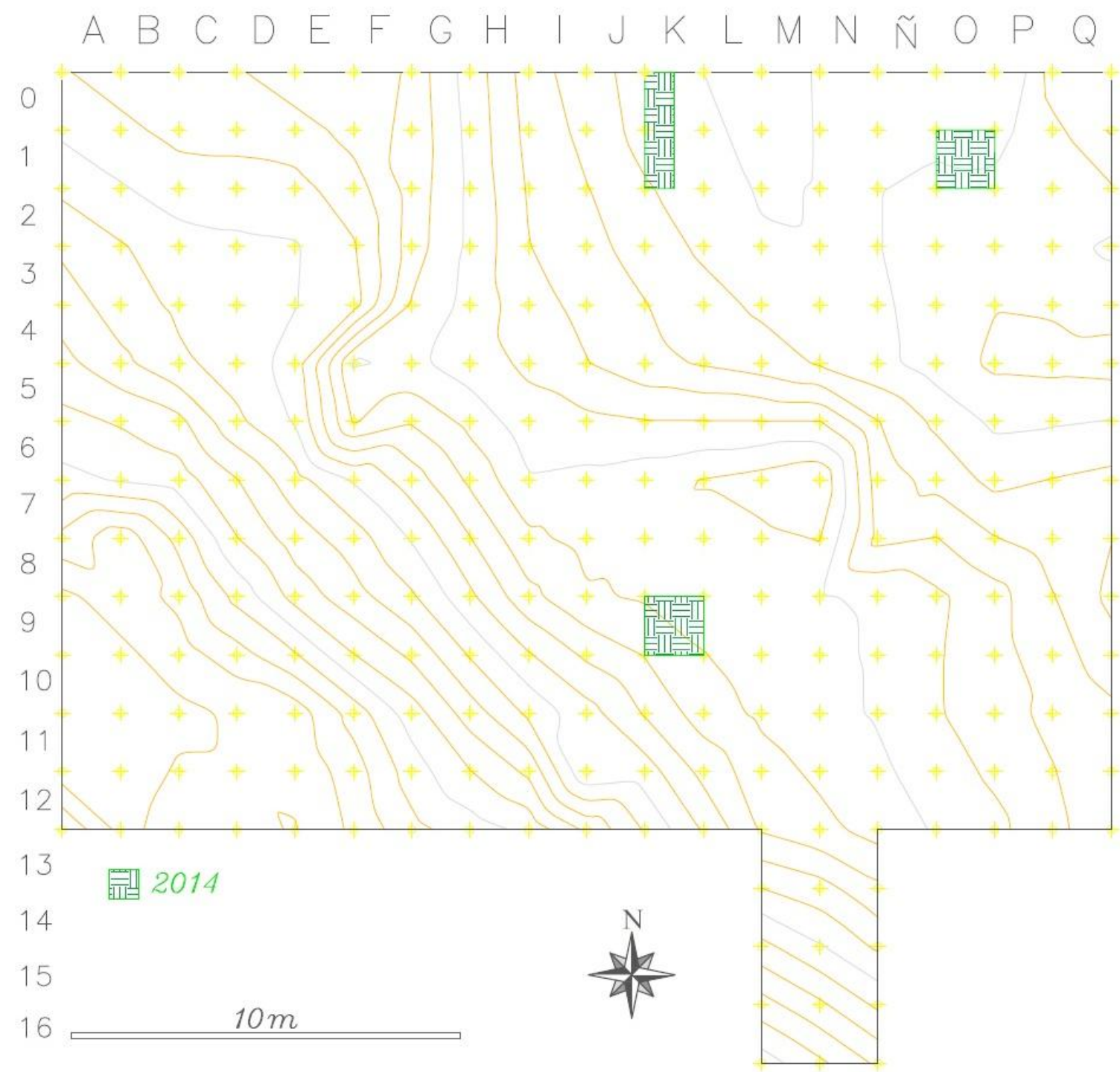

Figura 11. Cuadriculado del sitio R1- El Sunchal. En verde, espacios excavados en Octubre de 2014.

En su excavación de la cuadrícula K9 se identificaron cinco estratos naturales. Los dos primeros contenían materiales culturales entre los que se destacaban una punta de flecha triangular escotada de obsidiana y un fragmento de cerámica Santamariana bicolor (Figura 14). Estos materiales se habrían introducido en momentos posteriores a la ocupación principal del sitio, junto con otros como un fragmento de vidrio, evidenciando procesos de migraciones verticales. 


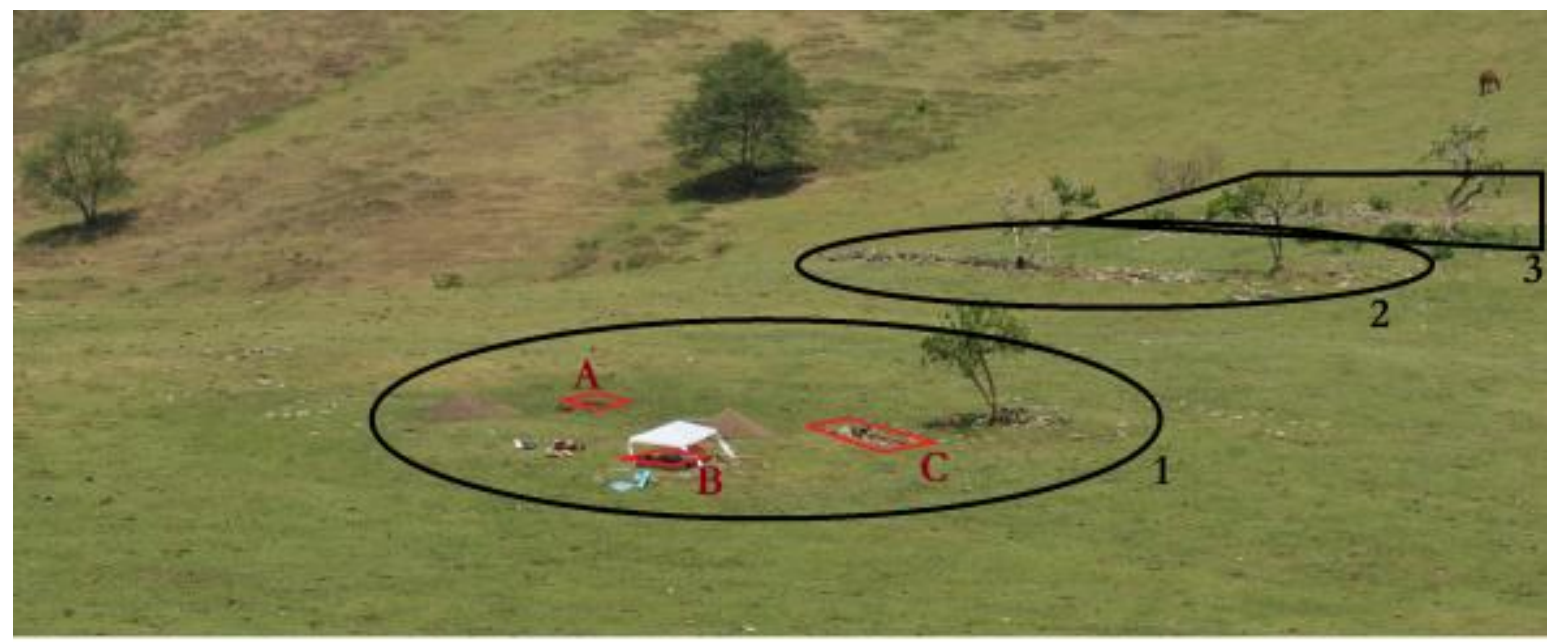

Figura 12. Vista de El Sunchal y detalles de sondeos. Arriba: 1) Unidad U1; A) Sondeo K9 en la porción central del recinto U1R1; B) Sondeo 01 en sector externo de recinto U1R1; C) Sondeo K0K1 transversal al muro perimetral de U1R1. 2) Unidad U2; 3) Unidad Puesto subactual.

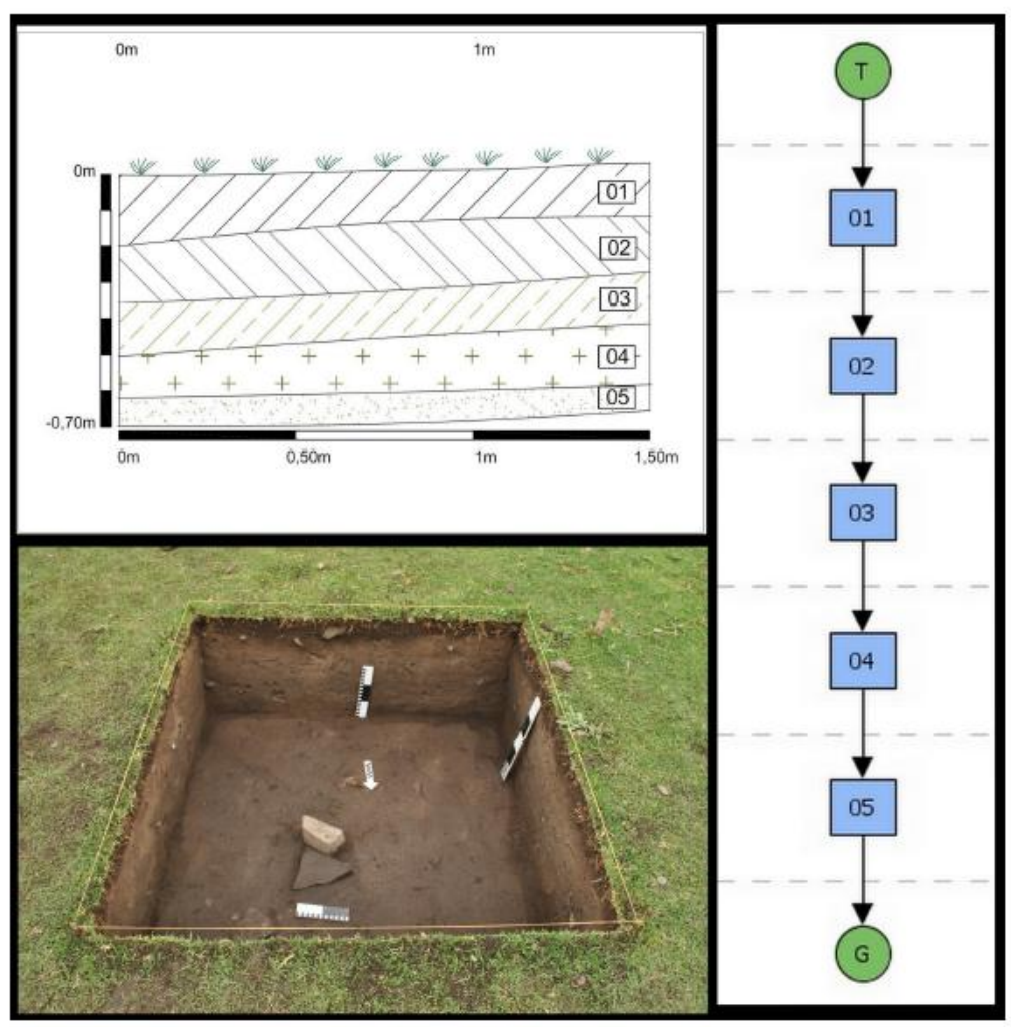

Figura 13. Representación del perfil norte del sondeo K9, cierre de excavación y secuencia estratigráfica siguiendo matriz de Harris (1991). 


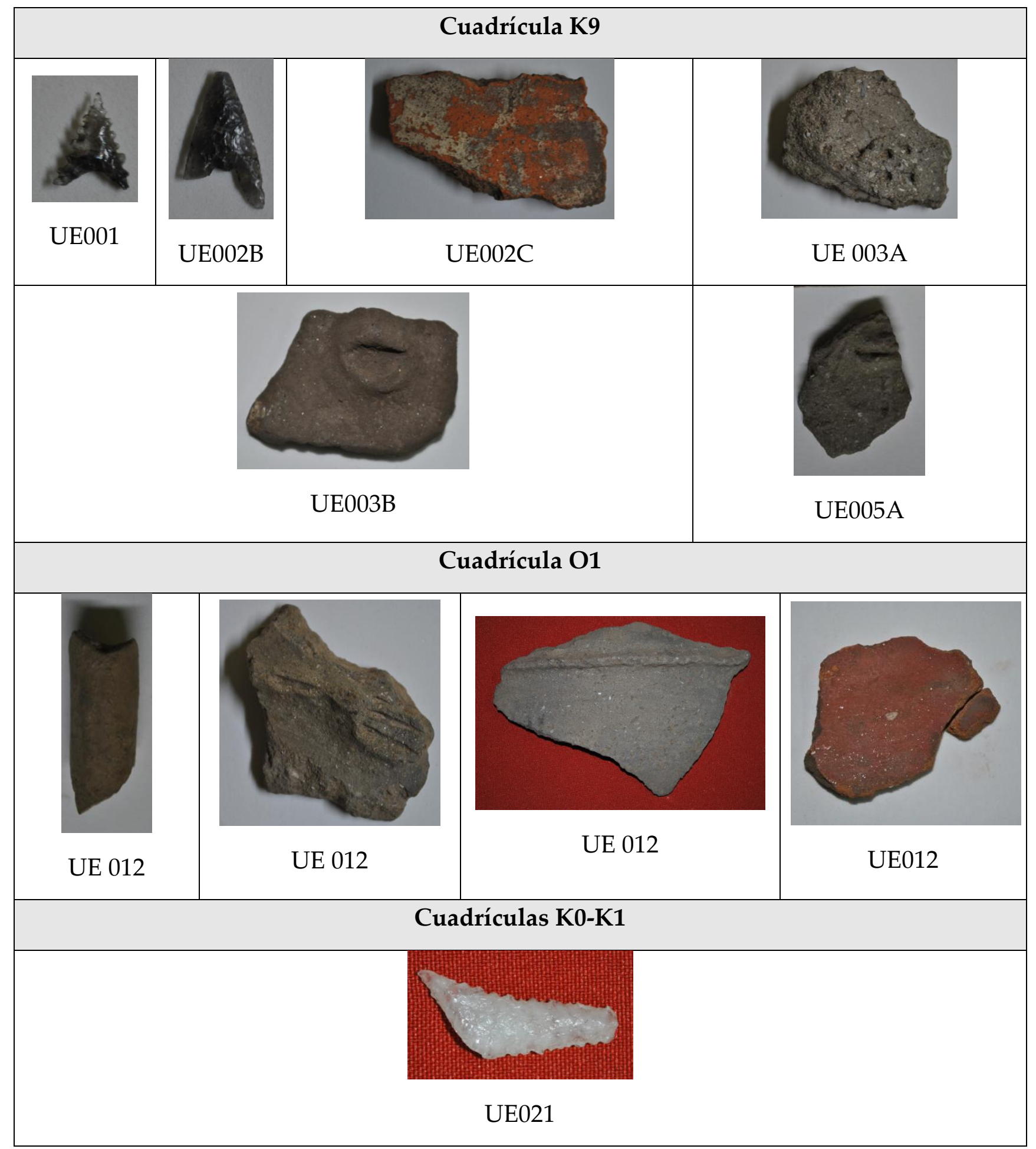

Figura 14. Algunos fragmentos cerámicos y puntas de flecha halladas en distintas Unidades

Estratigráficas de los tres sondeos. 
Las unidades estratigráficas 03, 04 y 05 (Figura 13) no evidenciaron materiales intrusivos. El conjunto cerámico se componía en su mayoría casi absoluta por grupos ordinarios sin engobes ni pinturas. En la base del sondeo, a unos $65 \mathrm{~cm}$ de la superficie, se identificó un gran tiesto de cerámica ordinaria alisada por marleado en posición horizontal. Por debajo se identificó un estrato estéril, fino, sumamente compacto y de color amarillento posiblemente loéssico, a partir del cual se cerró la excavación.

En la cuadrícula O1, que ocupaba el talud exterior de la depresión en su lado este, se identificaron cuatro estratos, en los cuales se recuperó un interesante conjunto de restos materiales, siendo las unidades 012 y 013 las que mayores concentraciones artefactuales evidenciaron (Figura 15). Entre ellas se destaca el conjunto de cerámica ordinaria que presenta algunas decoraciones, en su totalidad motivos modelados e incisos aplicados al pastillaje, con representaciones antropomorfas (ojos, manos, cejas o rostros), y motivos geométricos como punteados, triángulos o líneas. El material lítico, constituido predominantemente por cuarzo, cuarcita roja y en menor medida obsidiana, induce a pensar en estrategias tecnológicas expeditivas. Los instrumentos formales recuperados se reducen a puntas de flecha de obsidiana y de cuarzo. En este mismo conjunto se extrajeron muestras de material vegetal carbonizado, una de las cuales fue datada en $1744 \pm 27$ AP, AA105485, calibrado entre 249-308 y 319-408 d.C. (con 95\% de posibilidades). 


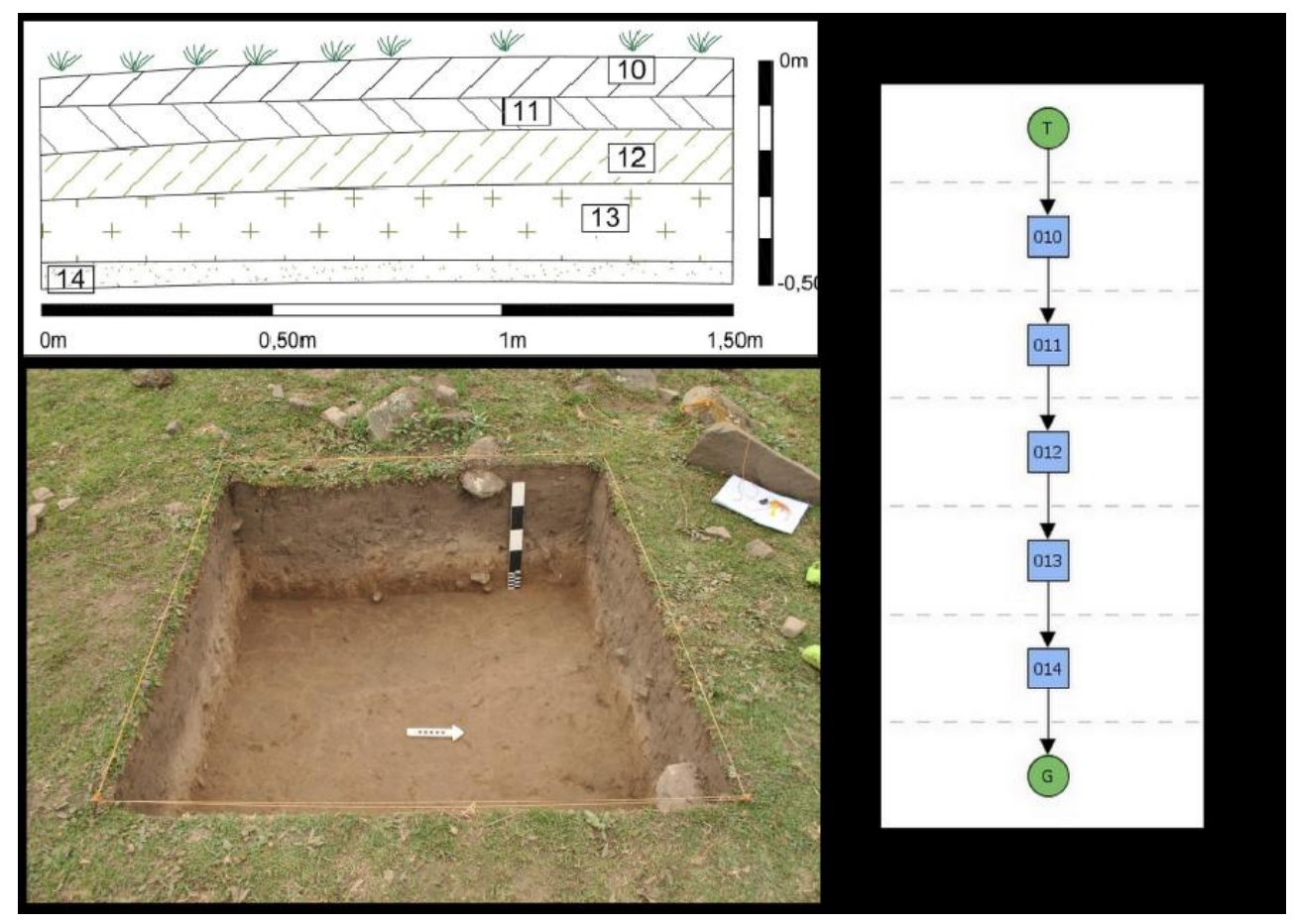

Figura 15. Representación del perfil norte de la Cuadrícula O1, cierre de excavación y secuencia estratigráfica siguiendo matriz de Harris (2001).

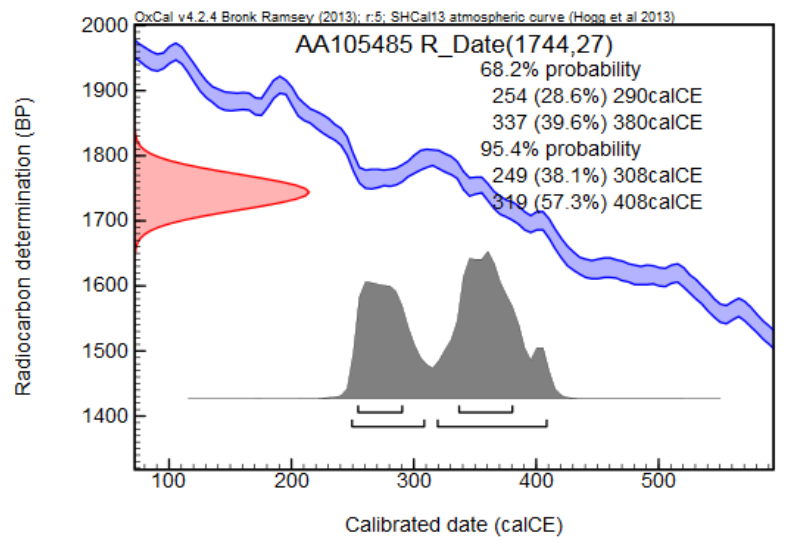

Figura 16. Calibración del Fechado Radiocarbónico de El Sunchal recuperado de UE 012, ESuU1R01 Cuadrícula O1. 
La tercer excavación intervino las mitades oeste de las cuadrículas K0-K1, constituyendo una superficie de $3 \mathrm{~m} \times 1 \mathrm{~m}$ fue planteado de manera transversal al "muro" perimetral de R01. La densidad artefactual fue ciertamente escasa y se pudo caracterizar una muy baja inversión de trabajo en la construcción del paramento que solo se parece ser la base de una estructura realizada con materiales perecederos sin una gran solidez arquitectónica (Figura 17).



Figura 17. Representación del perfil norte de las cuadrículas K0-K1, cierre de excavación y secuencia estratigráfica siguiendo matriz de Harris (2001).

Los materiales hallados permiten proponer que la estructura R01 de El Sunchal constituyó un espacio doméstico, construido mediante el cavado de un pozo y utilizando para la construcción materiales vegetales perecederos. La informalidad de esta construcción posibilita relativizar el grado de sedentarismo de sus ocupantes, aspecto interesante a considerar en una población del primer 
milenio, en principio asimilable a las englobadas dentro del "Formativo" (Olivera 2001).

\section{Las Pavitas}

En un sector próximo a la sede de la comunidad $\left(26^{\circ} 44^{\prime} 11^{\prime \prime} S\right.$; $65^{\circ} 35^{\prime} 20^{\prime \prime \prime} \mathrm{O}$; y $1730 \mathrm{msnm}$ ) y a las viviendas de Rudecindo y Adolfo Chocobar, se encuentra el sitio llamado "Las Pavitas", el cual constituye una zona plana e inclinada a pocos metros del cauce del río Anfama (figura 18). En algunos lugares perimetrales de esta porción plana se disponen algunos muros lineales de piedra, que parecen contener el terreno, aunque su grado de conservación es muy bajo. En la parte más alta se identificó una alteración en el terreno con algunas concentraciones de rocas visibles en superficie que parecen formar un círculo mayor (R029) y dos círculos menores adosados.

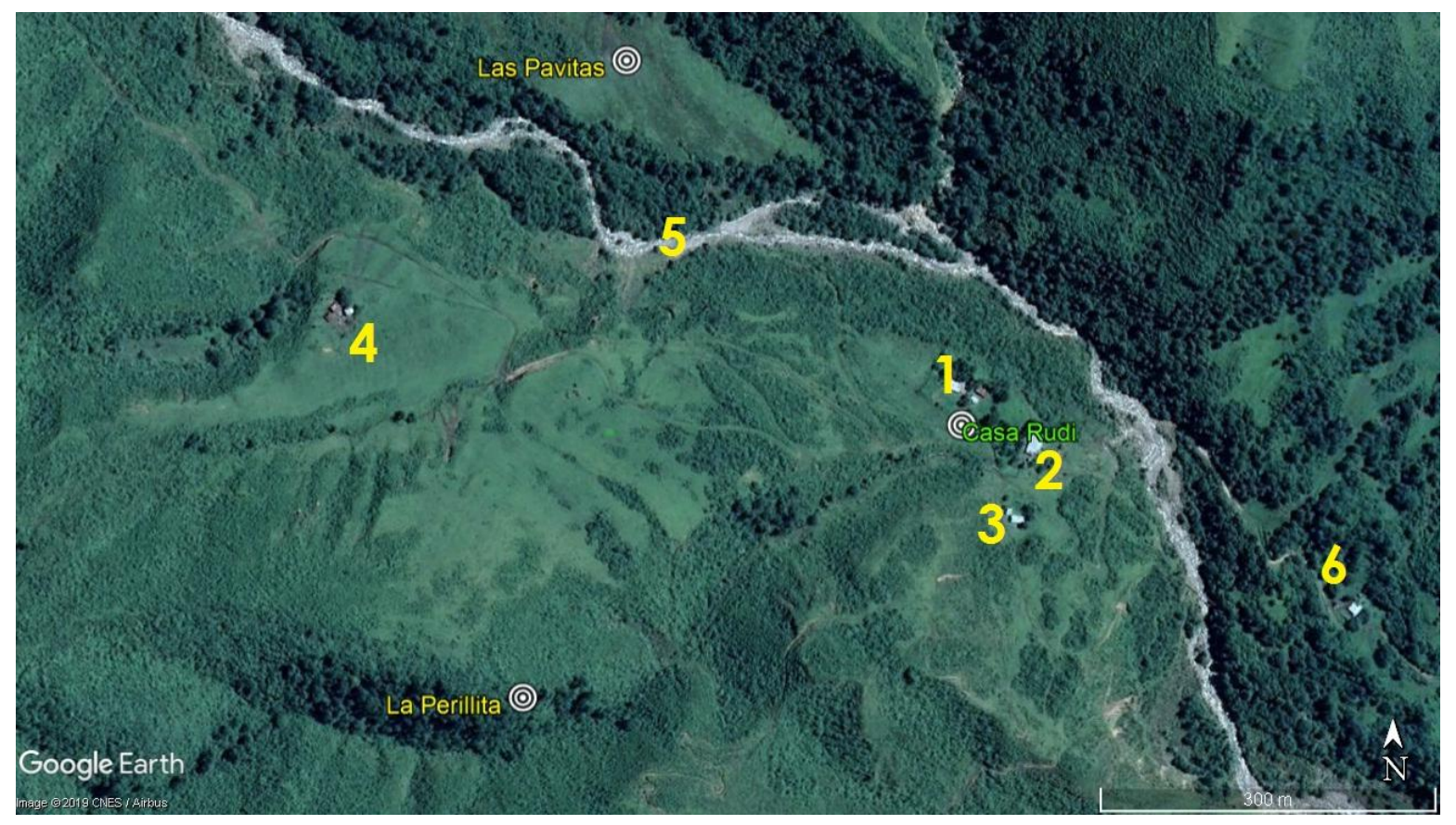

Figura 18. Toma aérea de los sitios Casa Rudi, Las Pavitas y La Perillita. 1) Puesto familia Rudecindo Chocobar. 2) "Puesto familia Adolfo Chocobar. 3) Sede de la Comunidad. 4) Puesto subactual abandonado. 5) Río Anfama. 6) Puesto familia Ricarda Aguilera. 
Para identificar los contextos materiales de la ocupación e indagar sobre la cronología y dinámica de prácticas de su formación realizamos dos sondeos en R029: el sondeo A, en la porción central; y el sondeo B, alineado al anterior, pero sobre el muro que cerraba por el lugar más bajo, en el lado sur del recinto.

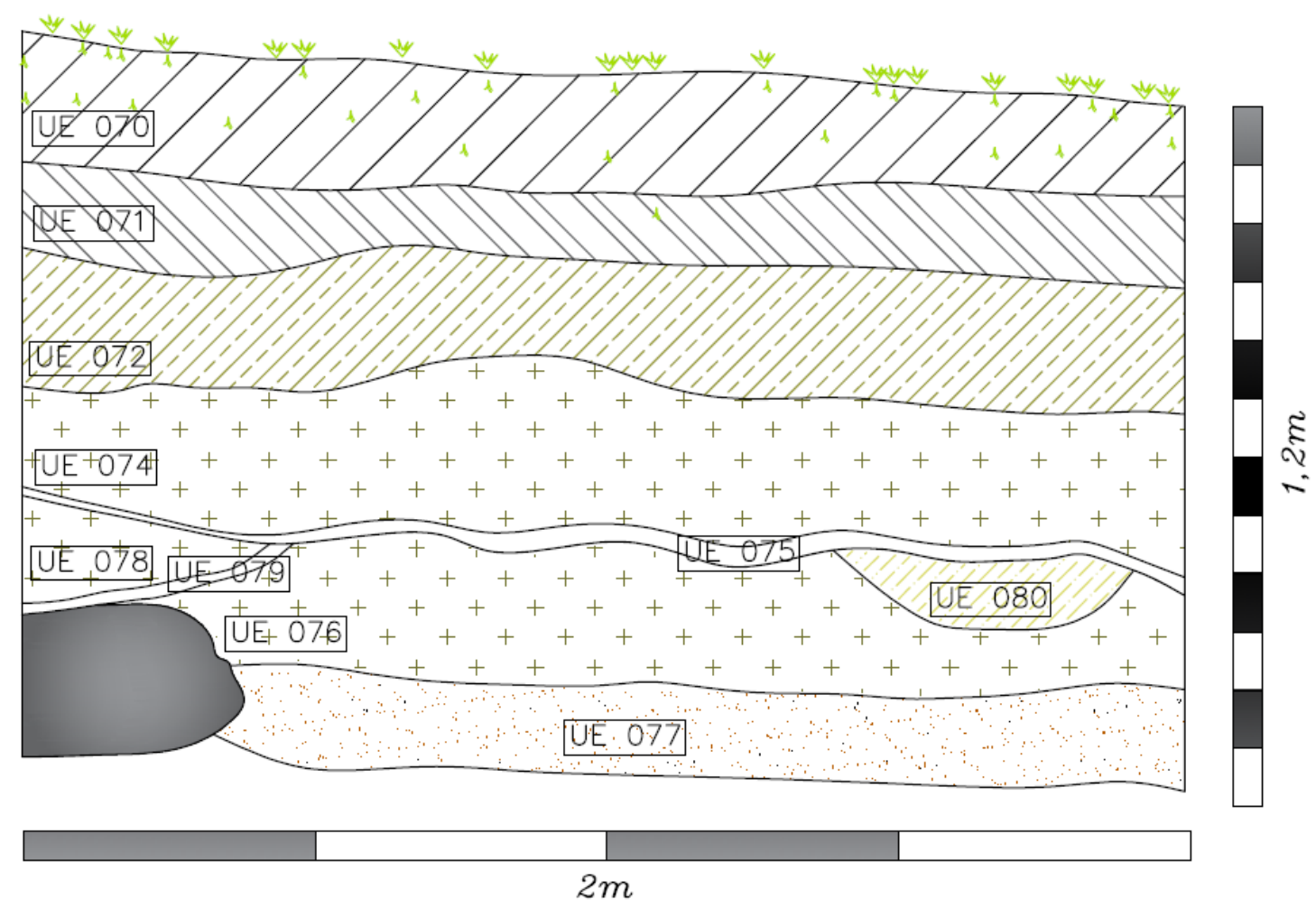

Figura 19. Estratigrafía del Perfil Norte de Sondeo A de LP U1 R029.

El Sondeo A permitió identificar siete estratos naturales, hasta la base estéril ubicada a 1,50 m. Los estratos en donde se identificó mayor concentración de materiales culturales fueron el 074, 076, 077 y 078, que se caracterizaban por presentar sedimento arenoso, de color claro y estar separados entre sí por delgadas capas de un material más fino y oscuro (Figura 19). La cerámica predominante se caracteriza por ser ordinaria, con abundancia de inclusiones micáceas de tamaño mediano a grueso, cocciones en atmósferas oxidantes (no siempre completas) y sin decoraciones. Solo algunos grupos muy minoritarios presentan engobes rojos (menores al 3\% del conjunto). En el único fragmento con decoraciones identificado 
se observó una pequeña aplicación modelada con una representación prosopomorfa que incluye boca, nariz, ojos y lágrimas marcadas con surcos lineales (Figura 20). Dentro del conjunto lítico se observaron mayormente núcleos y lascas de cuarzo y cuarcita, y en menor medida de sílice.
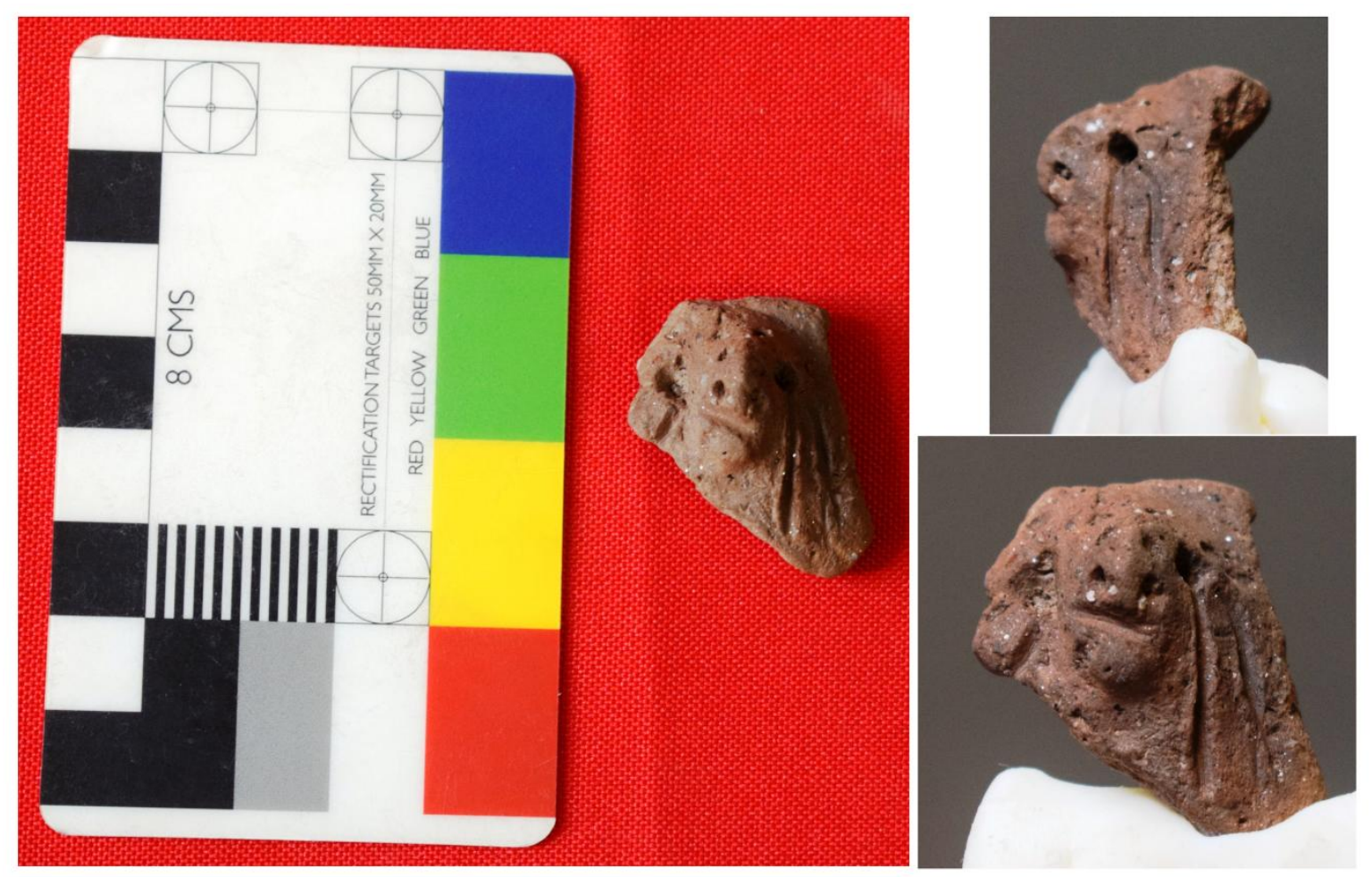

Figura 20. Aplicación prosopomorfa obtenida en la UE73.

El sondeo B, planteado sobre el muro sur, permitió reconocer las características arquitectónicas del paramento. El conjunto artefactual no fue tan denso como en el Sondeo A y la potencia arqueológica fue también menor reconociéndose el piso ocupacional a unos $0,50 \mathrm{~m}$. El muro reconocido no tiene gran altura, siendo solo una hilera de piedras de marcada compactación y solidez, constituyendo quizás la base de una estructura de grandes dimensiones de materiales perecederos (Figura 21). 


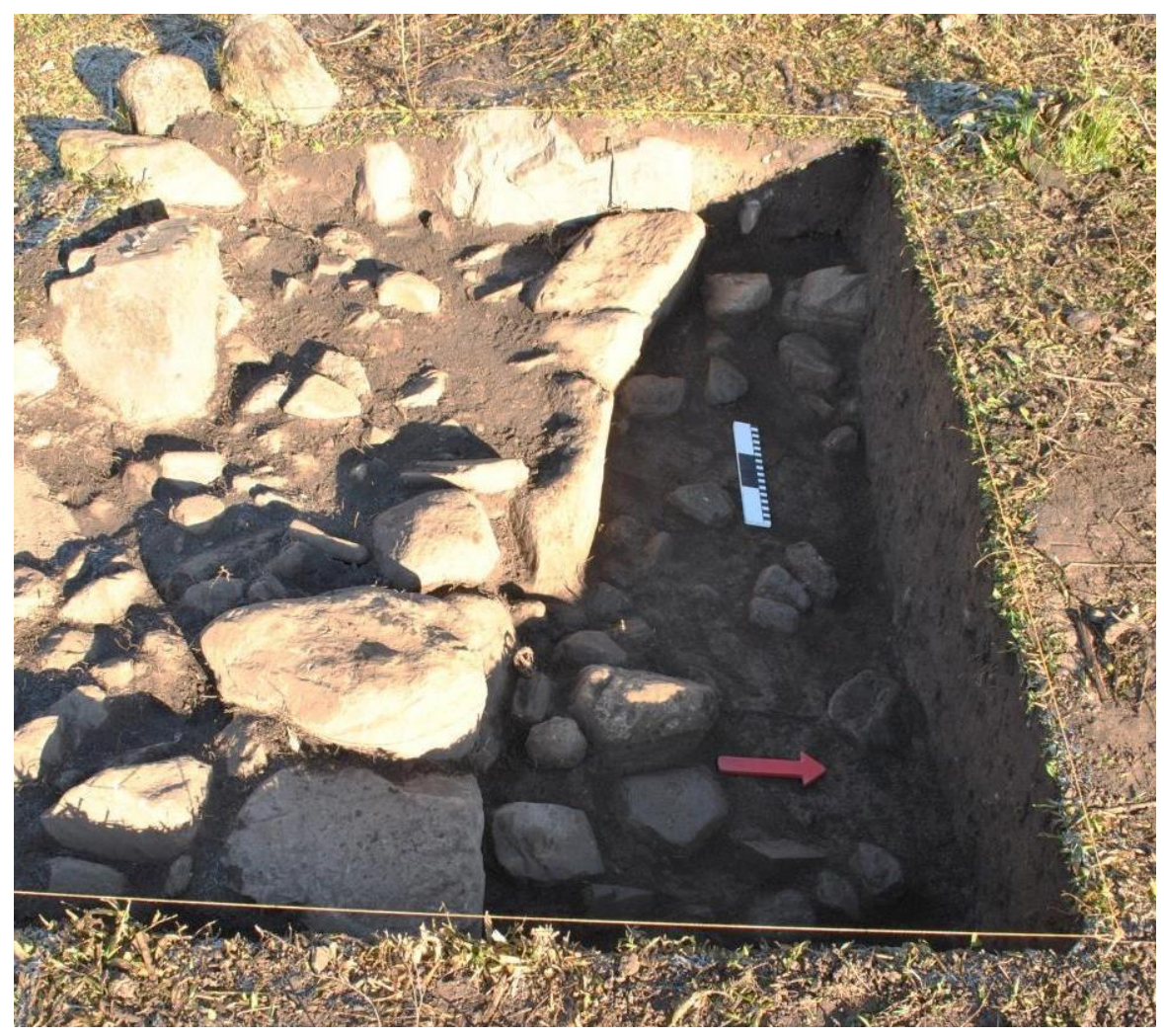

Figura 21. Proceso de excavación de Sondeo B, donde se puede identificar el sólido pero bajo muro que cerraba la Estructura R029 por el sur.

Las características constructivas y depositacionales identificadas, es decir baja inversión de trabajo en la arquitectura y estratos con concentraciones de materiales culturales separados por finas capas sedimentarias, hacen pensar que la ocupación en este espacio pudo haber sido estacional, lo cual es reforzado por las condiciones de severas inundaciones de este sector que se producen en las épocas estivales. Adicionalmente los materiales recuperados permiten pensar en una ocupación del primer milenio de la Era.

\section{La Perillita}

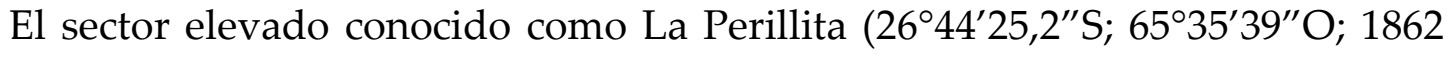
msnm) presenta unidades arquitectónicas formales pero en su mayoría constituidas por recintos subrectangulares grandes y pequeñas estructuras 
circulares (figura 22). En las tareas de prospección identificamos tres unidades constructivas, cubiertas por un denso monte de saucos.

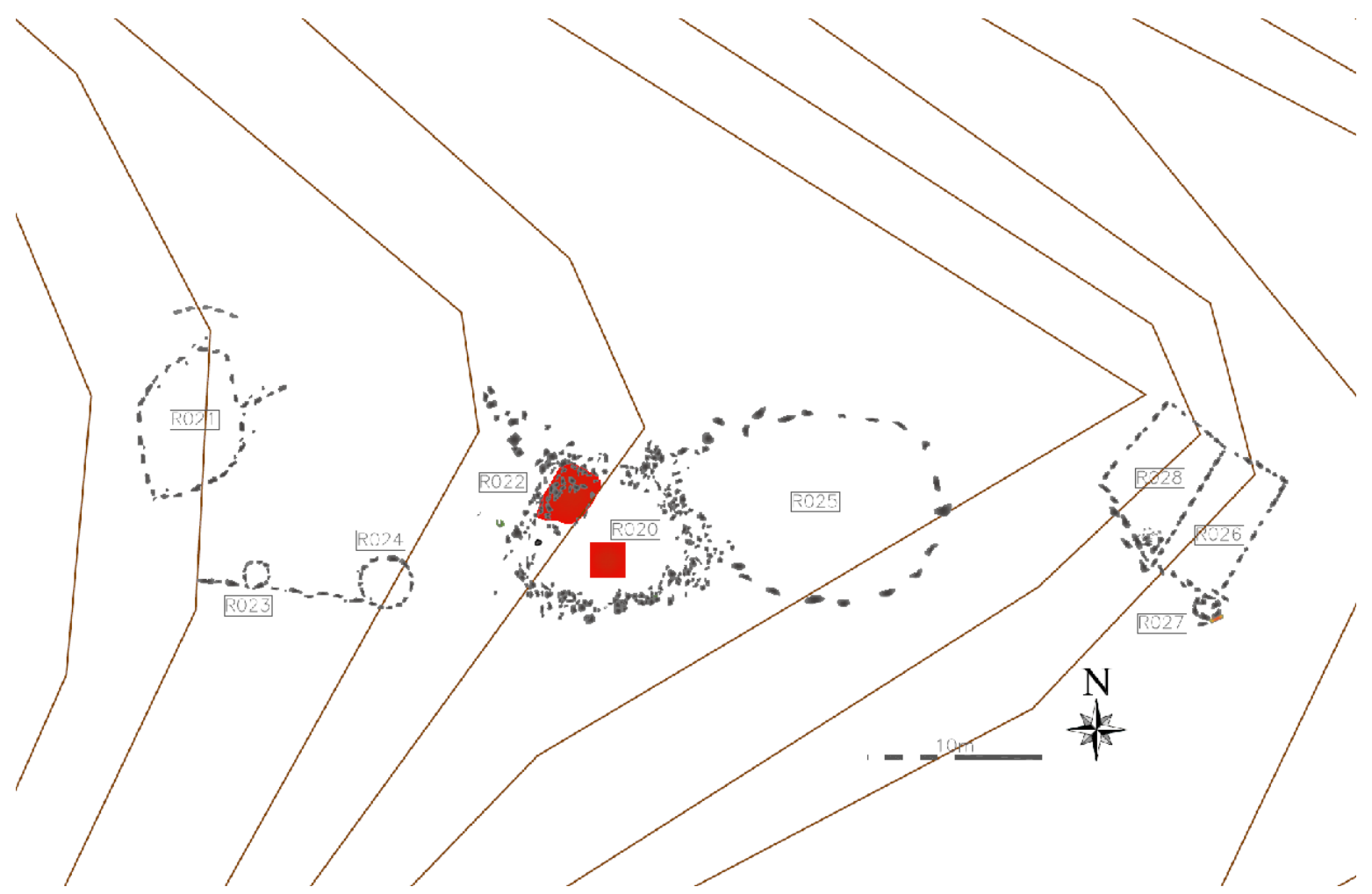

Figura 22. Planimetría de La Perillita donde se pueden identificar las tres unidades arquitectónicas relevadas. En rojo se destacan los sondeos realizados.

En el muro perimetral del R 027, un pequeño recinto circular adosado a R028, conformando la unidad arquitectónica U3, pudimos identificar un bloque lítico de unos $80 \mathrm{~cm}$ de largo que presentaba en una de sus caras un rostro antropomorfo (Figura 23). El diseño se confeccionó mediante una combinación de acanaladuras pulidas sobre la cara plana de la roca. Esta escultura tiene grandes reminiscencias con las encontradas durante el primer milenio en el valle de Tafí, tradicionalmente llamadas "menhires" y hoy entendidas como huancas, es decir el doble de piedra de un ancestro (García Azcárate, 2000). 


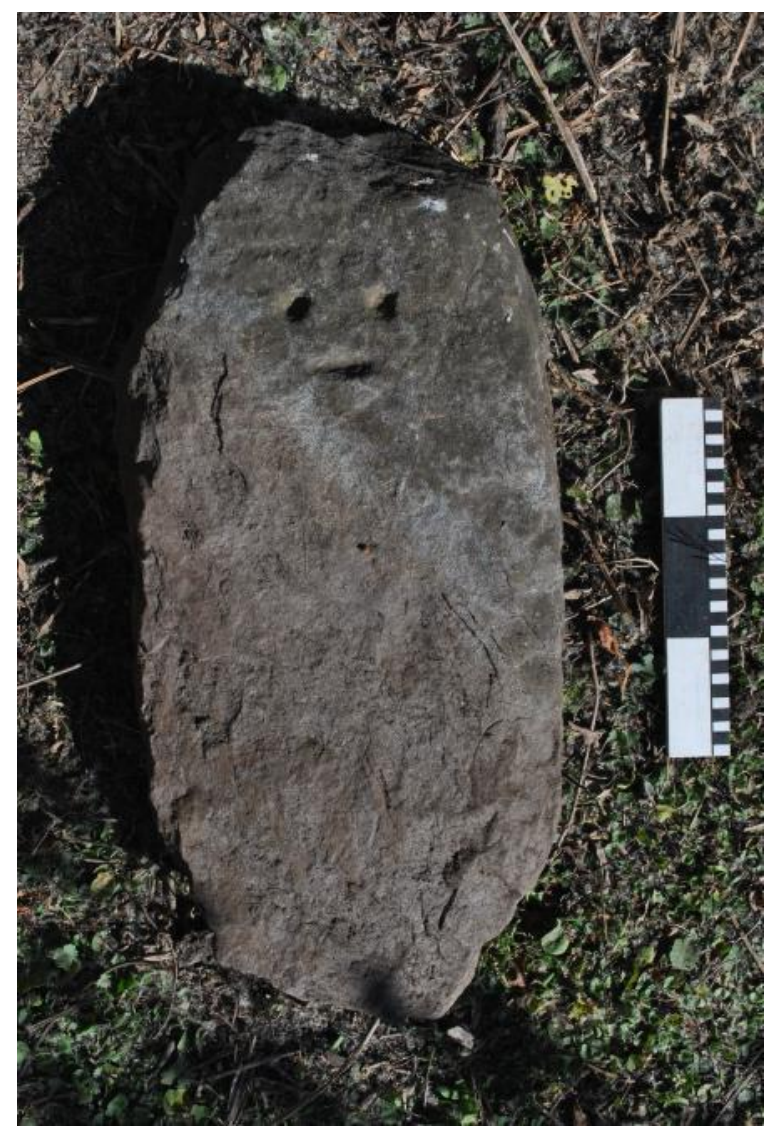

Figura 23. Roca decorada con motivo antropomorfo ("mascariforme") recuperado en La Perillita.

Considerando las características arquitectónicas visibles y la existencia de varios instrumentos de molienda en superficie decidimos realizar excavaciones en la Unidad U2 de La Perillita. Para esto fue necesario desmontar la zona lo que permitió exponer adecuadamente la totalidad de los muros que conformaban este conjunto, identificando tres recintos: uno central de planta subrectangular y anchos muros (R022), con una pequeña estructura incluida (R020) en su esquina Noroeste. Hacia el Este se adosa linealmente un recinto más grande, de muros más delgados y planta oval (R025). Decidimos realizar un sondeo en R020 (Sondeo 1), ubicado contra el muro sur en la porción media del recinto, y otro que cubriera completamente la estructura incluida: R022. 
El Sondeo 1 se planteó en una cuadrícula de $2 \mathrm{~m} \times 2 \mathrm{~m}$. En el nivel superficial (UE050) se registraron algunos tiestos de cerámica ordinaria, lascas de cuarcita roja y obsidiana. En el estrato siguiente (UE051) se registraron numerosos fragmentos cerámicos, algunos de ellos de gran tamaño. Casi todos presentaban muy mal estado de conservación con todas sus superficies ausentes, exponiéndose el antiplástico mayormente grueso y heterogéneo. La remoción de ese estrato permitió establecer que el mismo apoyaba en parte sobre la roca madre, y solo en algunos puntos sobre un estrato de sedimento muy compacto amarillento (UE052) que parecía estar rellenando y emparejando la superficie de la roca madre para ser habitada (figura 24). En este estrato se identificaron algunos fragmentos de cerámica en bastante mejor estado de conservación que los hallados en UE051.

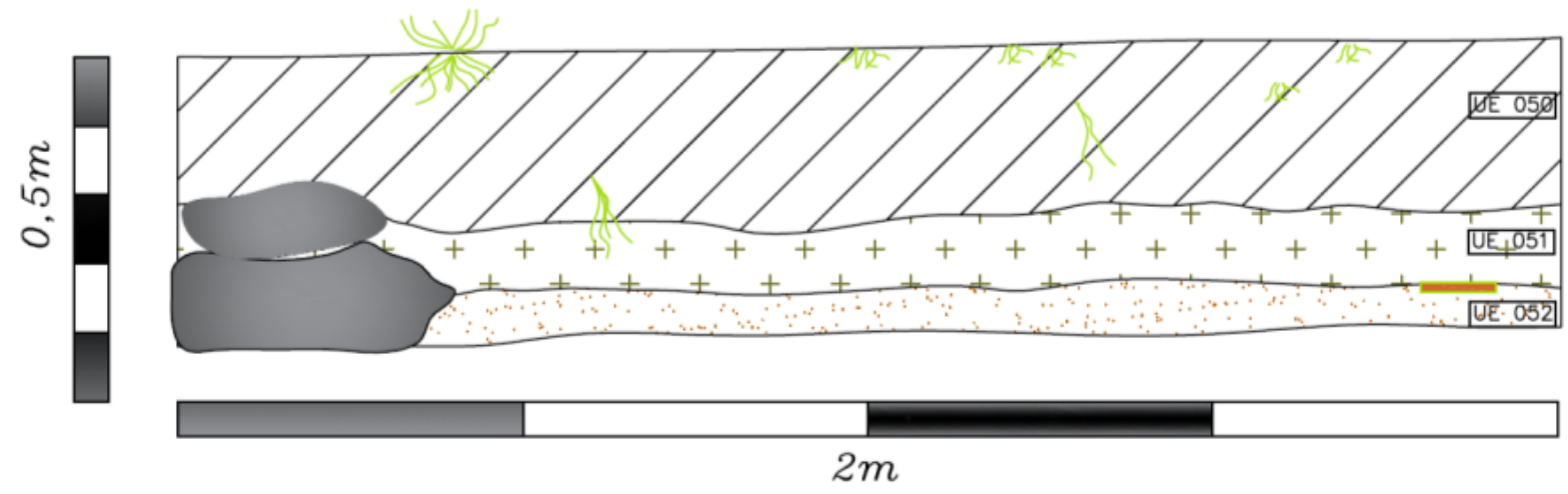

Figura 24. Estratigrafía del perfil norte del Sondeo 1 de LP R022.

La excavación del recinto incluido R020 intentó identificar sus características constructivas y el conjunto artefactual depositado en su interior, para interpretar tanto el funcionamiento de la unidad arquitectónica, como las prácticas humanas realizadas. El proceso de remoción de sedimentos se vio severamente complicado por los derrumbes presentes lo que a su vez impidió un claro reconocimiento de estratos presentes. No obstante, la excavación de los sectores más próximos al muro de R022 permitió inferir sus características constructivas. Si bien no pudimos 
exponer un lienzo regular, se recuperaron grandes cantidades de bloques tabulares muy delgados (no más de 0,10 $\mathrm{m}$ de espesor), alargados (promedio de 0,70 $\mathrm{m}$ de largo y 0,40 m de ancho), con sus aristas evidenciando tareas de talla, los cuales se encontraban caídos sobre otras rocas o sobre los sedimentos alineados entre sí (Figura 25). Esto lleva a pensar que los mismos se habrían clavado en el piso, para conformar la cara externa del paramento y darle uniformidad. Esta técnica constructiva, sin embargo, no habría otorgado una gran solidez al muro, el cual se habría derrumbado.

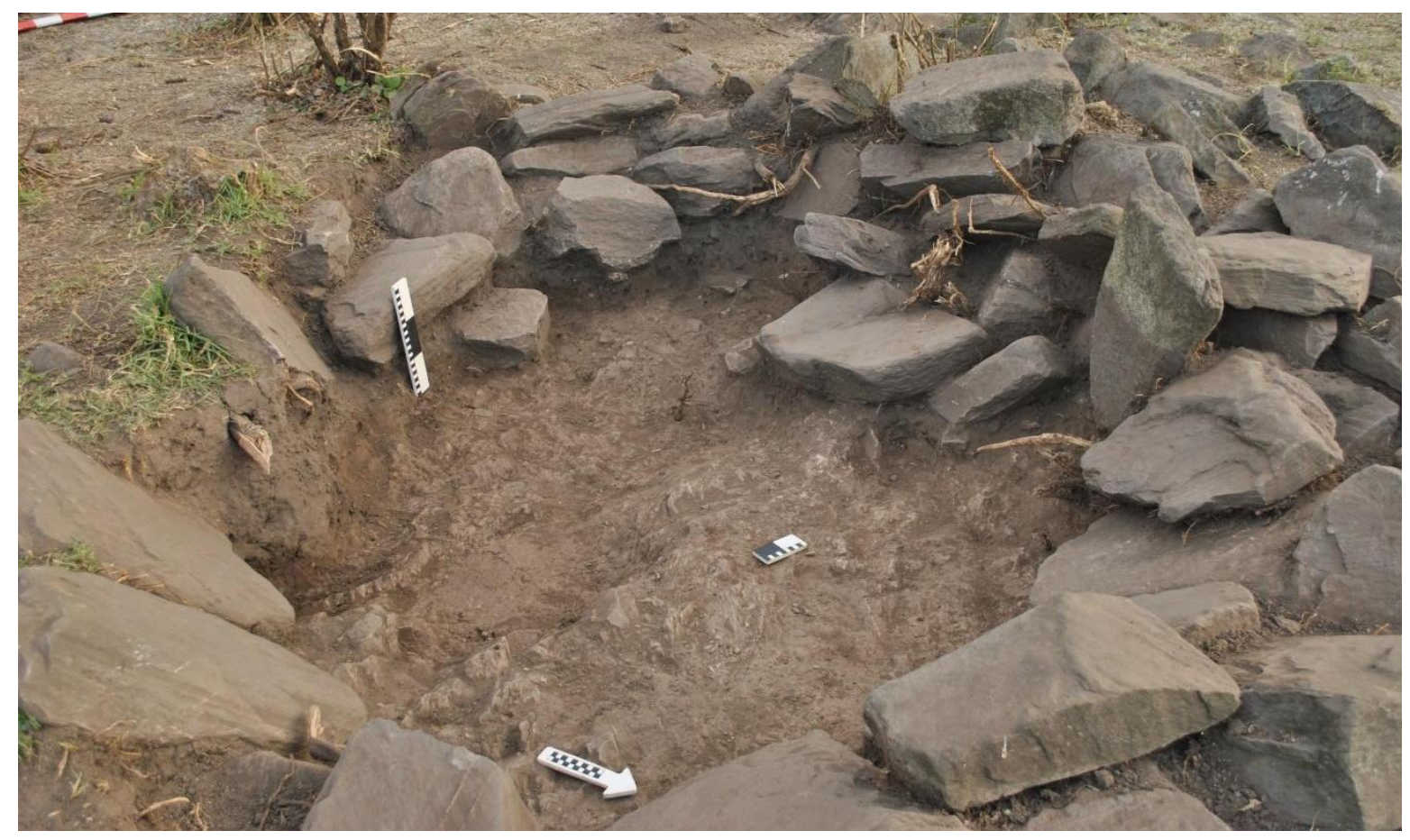

Figura 25. Vista del R020 excavado en su totalidad. Hacia la derecha, se observa el muro del R022, el cual se caracteriza por ser bastante ancho e incluir numerosos bloques líticos tabulares con marcas de talla en sus aristas. Hacia la izquierda se observan las rocas que presuntamente habrían formado el rasgo que dividía el espacio interior formando el recinto incluido R020.

En cuanto a los restos líticos se identificaron instrumentos en distinto grado de formatización y lascas de cuarzo, cuarcita, gravauca, obsidiana y sílice. Macroscópicamente las obsidianas obtenidas allí no serían provenientes de la 
fuente de Ona-Las Cuevas, pero correspondería realizar estudios de DRX para determinar con exactitud su origen (Figura 26).
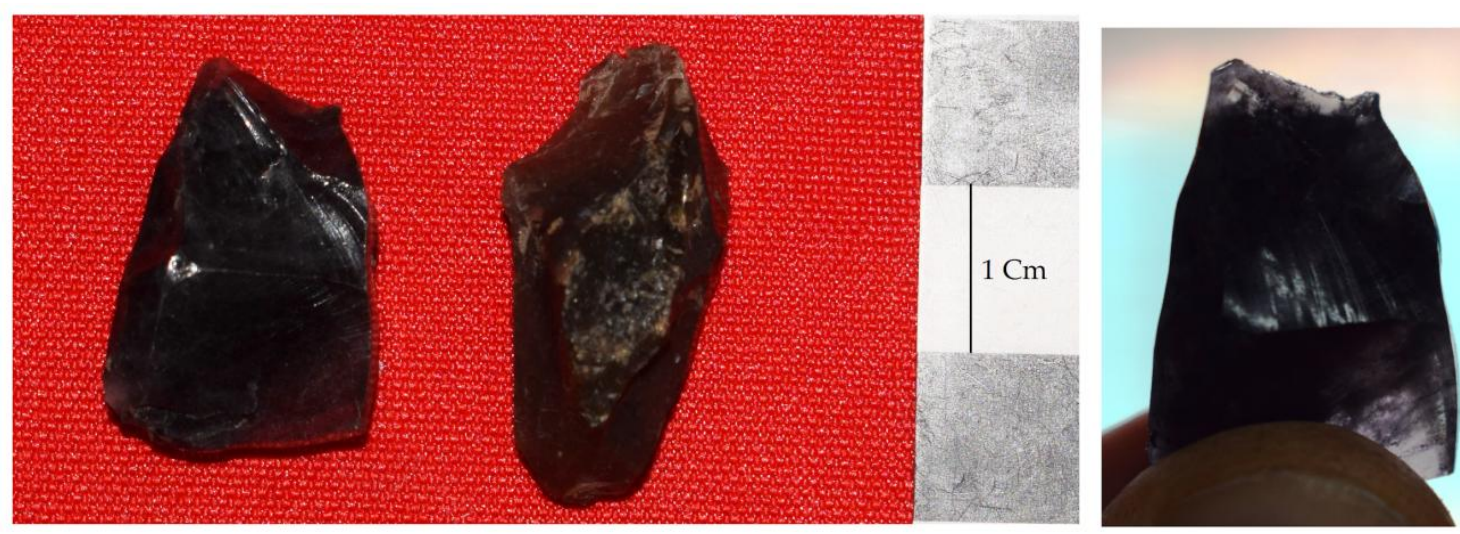

Figura 26. Lascas de obsidiana obtenidas en la UE 31B. En la imagen derecha se observa el cuerpo opaco y oscuro de las mismas.

Los conjuntos cerámicos recuperados también están formados preponderantemente por grupos ordinarios caracterizados por antiplásticos muy gruesos y superficies irregulares (Figura 27, algunos con evidencias de exposición al fuego), lo cual refuerza la idea de un proceso de formación de sitio caracterizado por una prolongada exposición de artefactos en superficie y un lento proceso de depositación, el cual solo generó una delgada cobertura de no más de 0,40 m de espesor sobre los pisos ocupacionales. Este mismo hecho tuvo como consecuencia la nula conservación de materiales vegetales, lo que impide la realización de fechados radiocarbónicos.

Las características constructivas de las estructuras identificadas y la preparación de la roca madre, rellenada con UE052, así como las características morfológicas del conjunto cerámico recuperado, permiten pensar que este espacio fue utilizado como ámbito residencial, aunque resulta difícil de evaluar hasta dónde fue ocupado de manera constante, o como un eslabón dentro de un circuito de movilidad estacional. 

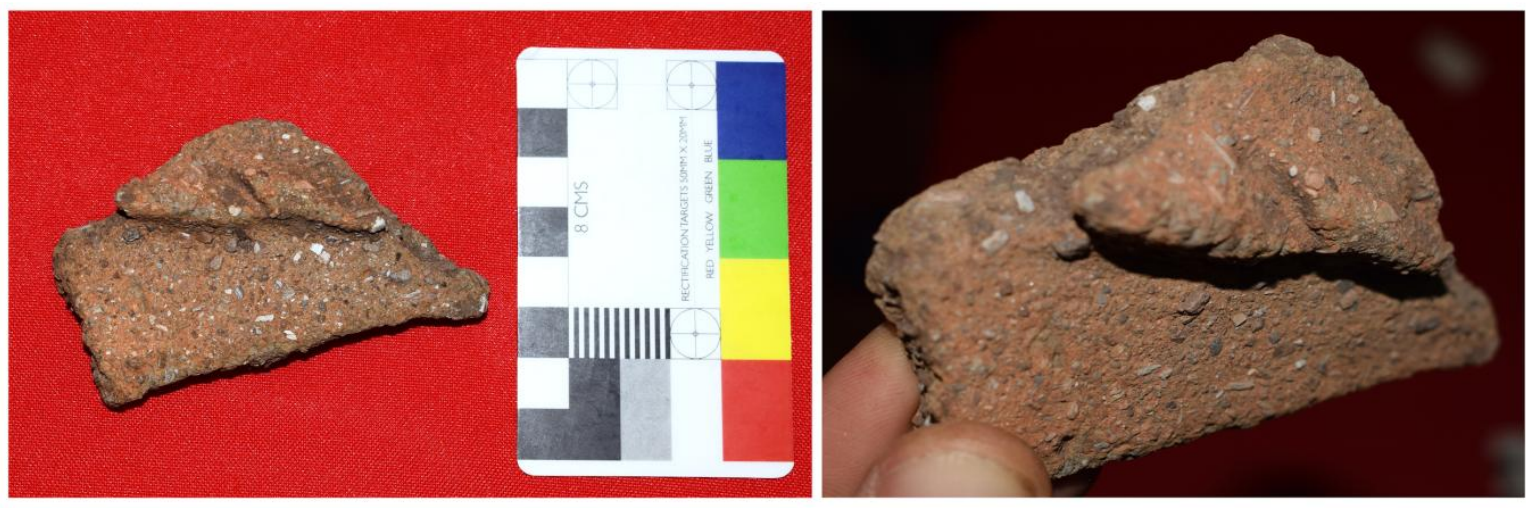

Figura 27. Aplicación de bandas al pastillaje recuperada en la UE 31C

\section{Casa Rudi}

El sitio Casa Rudi (2644'21"S; 65³5'09”O; $1694 \mathrm{msnm}$ ) ubicado en las inmediaciones de las viviendas de las familias de Rudecindo y Adolfo Chocobar, no presenta arquitectura en superficie pero sí evidencia distintos indicios de actividad humana, entre los cuales se destacan dos concentraciones de instrumentos de molienda fijos, próximos al río, y una gran cantidad de materiales arqueológicos, especialmente cerámica, visibles en los cortes realizados para nivelar la construcción de las dos casas, en los adobes de sus muros, y también fragmentos en poder de la familia, los cuales incluyen cerámica, dos cabezales de hachas, un instrumento de molienda pasivo (un molino plano) y una pequeña talla lítica acanalada en uno de sus extremos, formando un motivo fálico (Figura 28). 




Figura 28. Artefactos líticos y de cerámica que se encuentran en poder de Rudecindo y Adolfo

Chocobar.

Si bien no se realizaron aún allí trabajos de excavación se destaca la aparición de materiales cerámicos correspondientes a los estilos propios del Periodo de Desarrollos Regionales del Valle de Yocavil, especialmente Santamariano Bicolor y Famabalasto Negro Inciso. 


\section{Casa Pastor}

Por solicitud de Griselda y Pastor Chocobar asistimos a su vivienda (264 $\left.44^{\prime} 20^{\prime \prime} \mathrm{S} ; 65^{\circ} 33^{\prime} 54^{\prime \prime} \mathrm{O} ; 1765 \mathrm{msnm}\right)$ para identificar un rasgo arquitectónico que estaba emergiendo en la entrada de su vivienda debido al pisoteo cotidiano de personas y animales (Figura 29). La gran cantidad de material arqueológico que la familia tenía en su poder y que había sido encontrado in situ, entre los cuales se encontraba material cerámico ordinario, instrumentos de molienda fijos y semifijos, una talla lítica con acanaladura formando un motivo fálico (Figura 30); y también, la progresiva exposición del rasgo arqueológico en superficie que ponía el contexto en un creciente riesgo, nos llevó a realizar un sondeo exploratorio de $3 \mathrm{~m}$ por 1,5 m de modo de cubrir la totalidad de la estructura emergente.

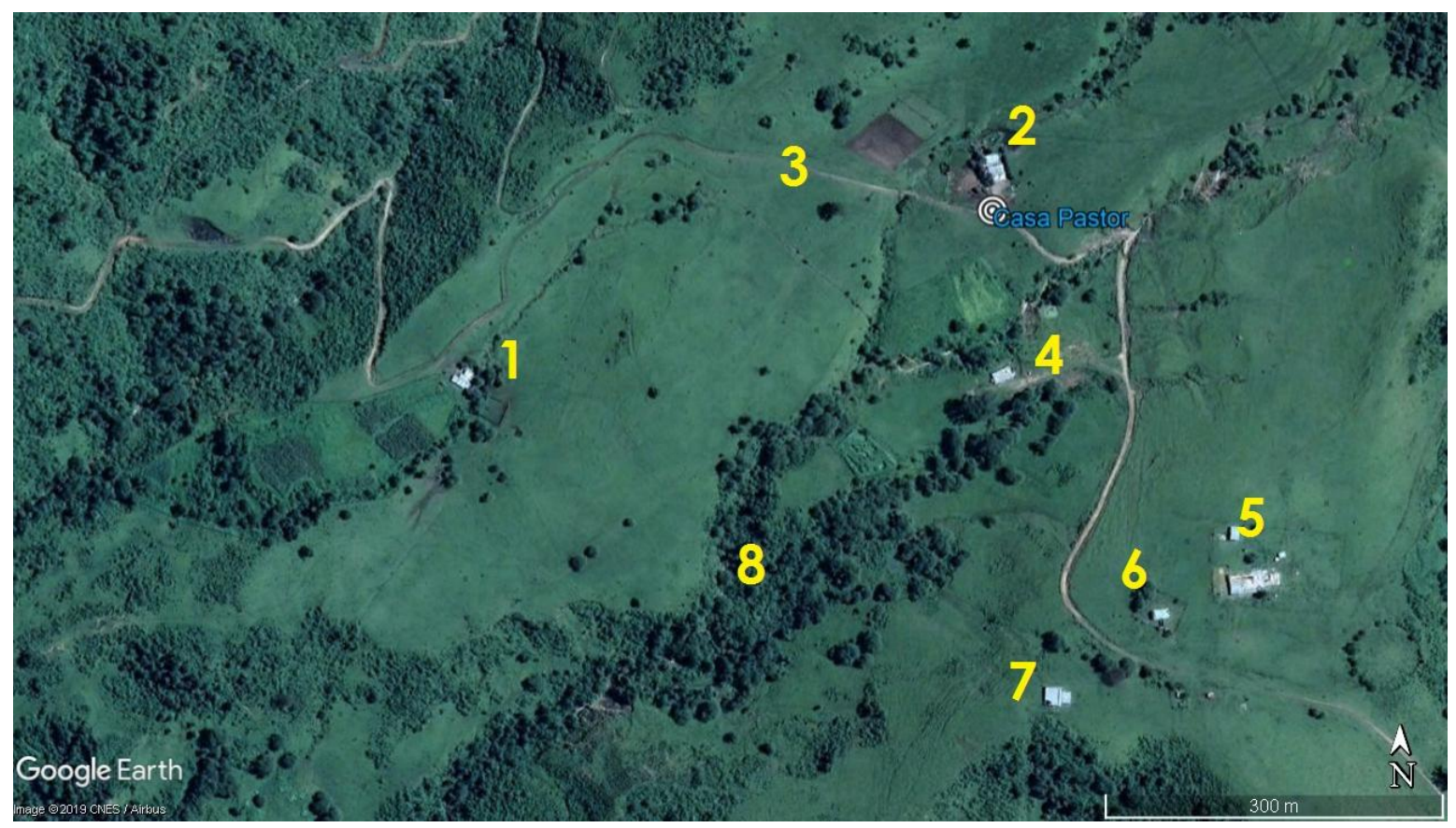

Figura 29. Toma aérea del sitio Casa Pastor. 1) Puesto familia Augusto Aguilera. 2) Puesto familia

Pastor Chocobar. 3) Camino Ancho. 4) Puesto familia de Lilia Guerra. 5) Escuela. 6) Dispensario. 7) Puesto subactual abandonado. 8) Arroyo estacional. 


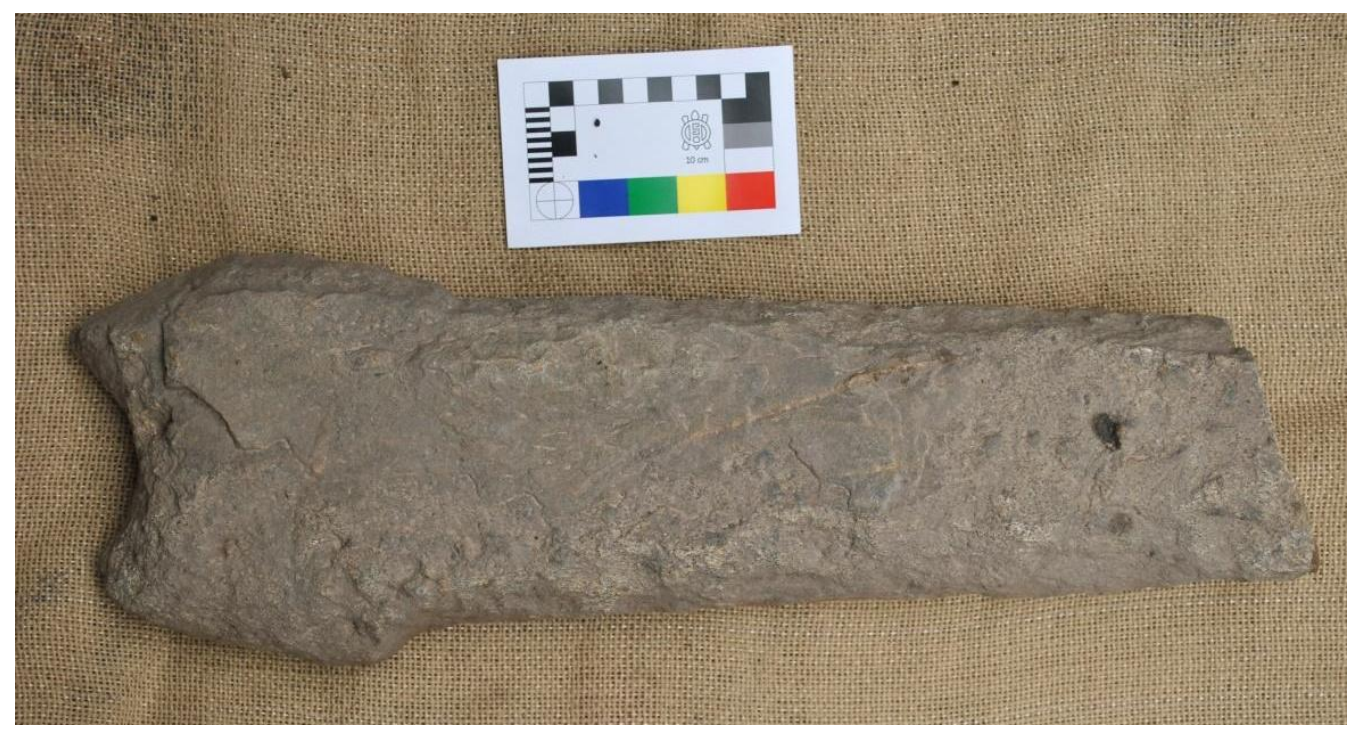

Figura 30. Talla lítica recuperada por la Familia de Pastor Chocobar en las tareas de excavación de su vivienda. Su morfología fálica sigue las líneas de otras registradas en Casa Rudi y en poder de otros comuneros y podría vincularse a la búsqueda de fertilidad de los campos agrícolas y a la representación de un ancestro importante, muy similar a los llamados menhires del valle de Tafí.

Las capas superficiales ya habían sido removidas hace tiempo en la construcción de la vivienda por lo cual rápidamente se comenzaron a registrar hallazgos. Solo se removió en principio una delgada capa superficial (UE150), luego de la cual (en una variación de 0,05 m a 0,10 m) se detectó un nuevo estrato de color naranja (UE151) en cuya remoción se recuperaron una serie de tiestos de tamaños variables y manos de moler. La remoción de este nivel permitió descubrir una porción importante del muro que la familia Chocobar había identificado y establecer que en mismo formaba parte de una construcción de importantes dimensiones, subyaciendo a la totalidad de la vivienda actual. La construcción consiste en un muro muy bajo de una hilada de piedras muy uniforme, sólida y compacta (Figura 31), quizás conformando la base de una estructura constituida mayormente con material perecedero. 


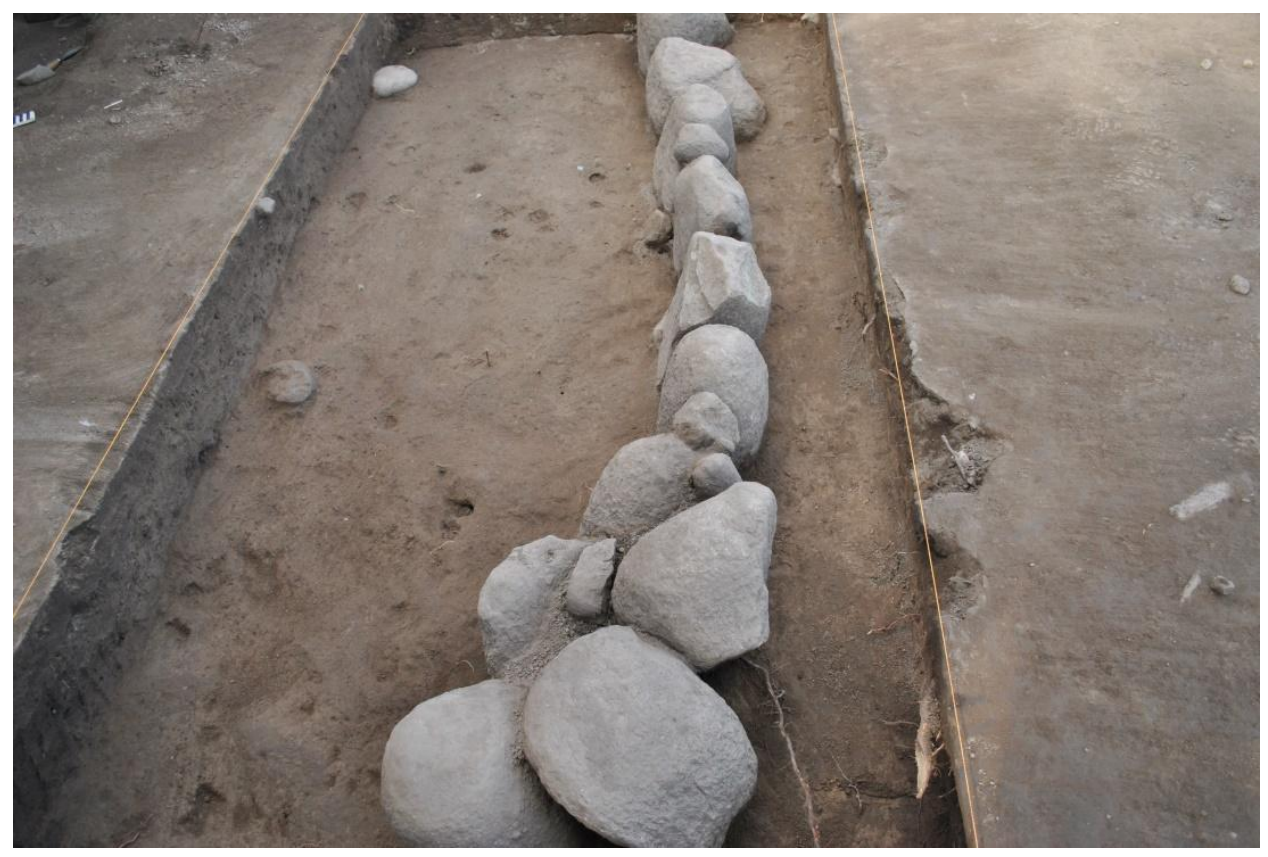

Figura 31. Vista lateral del sondeo realizado en Casa Pastor. Se puede observar el muro expuesto en las tareas de excavación.

La existencia del muro delimitó un espacio intramuros (UE151B) y un extramuros (UE152). La excavación de 151B permitió seguir registrando material cerámico predominantemente ordinario de poca dureza y muy alterado. Además en este estrato se recuperó un grano de chañar (Geoffroea decorticans) carbonizado el cual fue datado en 2137 \pm 31 AP, AA107303, lo que equivale a Cal. (95\% de posibilidades) 340-325 a.C. y 204-50 a.C. Esto ubica a la ocupación de Casa Pastor en unos siglos antes de la Era Cristiana, siendo el fechado más temprano registrado hasta este momento en la zona (Figura 32). 

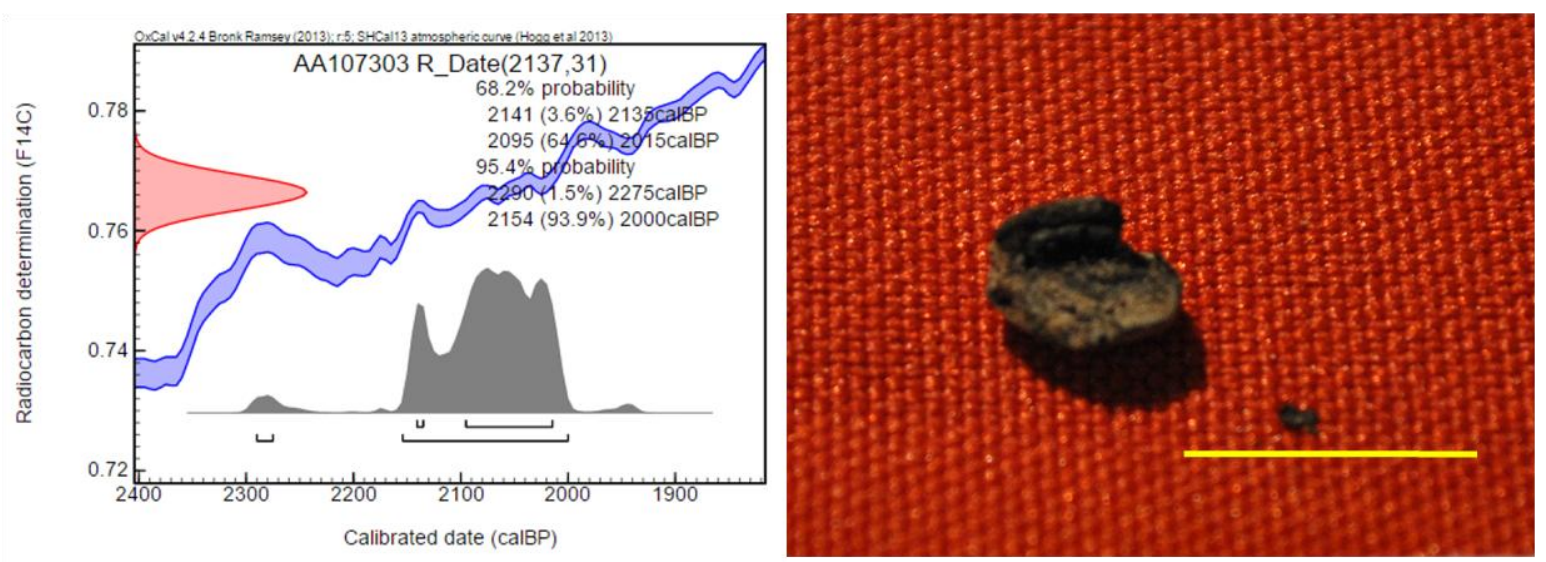

Figura 32. Calibración del Fechado Radiocarbónico de Casa Pastor, realizado sobre chañar

(Geoffroea decorticans) carbonizado recuperado de UE 151B, CPaU1 Sondeo (imagen derecha, escala de $2 \mathrm{~cm}$.)
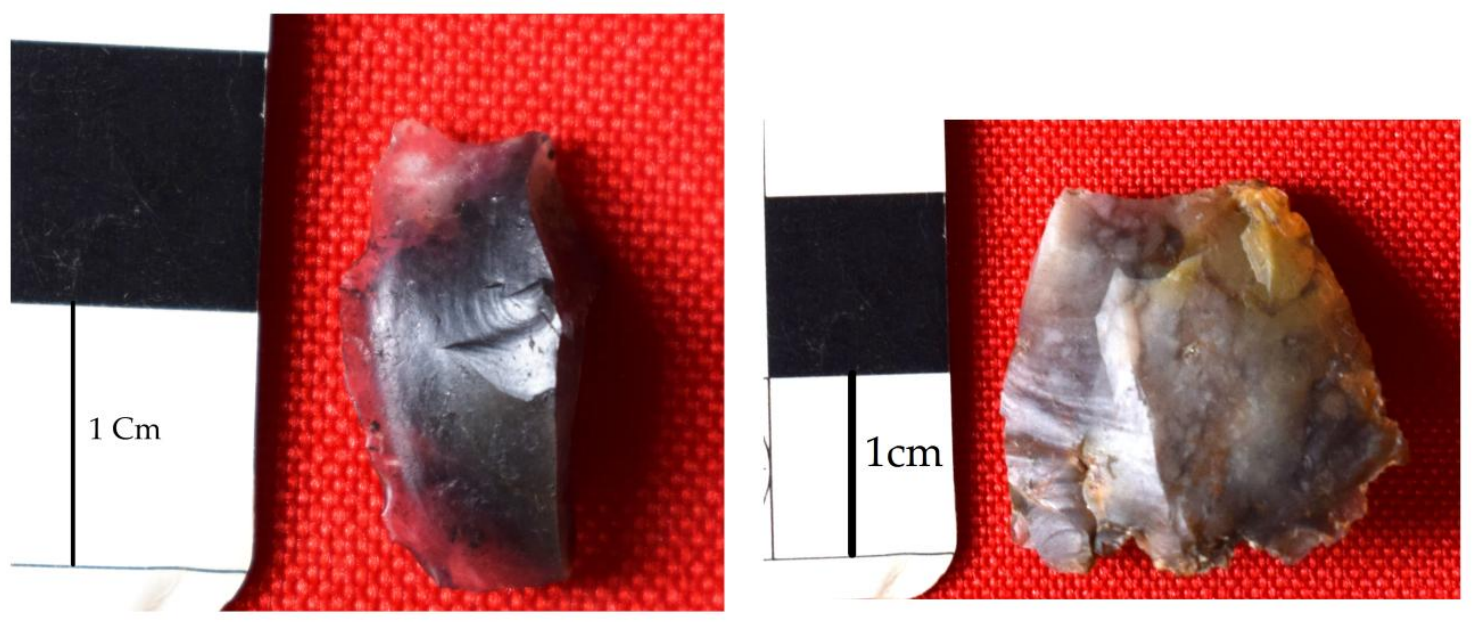

Figura 33. A la izquierda lasca de obsidiana. A la derecha deshecho de sílice. Ambos fueron recuperados en la UE $151 B$

La cerámica es en su totalidad ordinaria, con antiplásticos generalmente gruesos y ocasionalmente alisados muy cuidados. En relación a los conjuntos recuperados en otros sitios asignables al primer milenio de la Era no se observa aquí la presencia de engobes de color rojo, los cuales podrían ser un gesto técnico de aparición más tardía, tampoco se detectaron fragmentos de estilos tempranos como Vaquerías. En dos de los fragmentos se identificaron decoraciones, uno presenta una aplicación circular al pastillaje sobre la cual 
se observan dos líneas incisas verticales, y otro posee una pequeñísima y sutil representación de camélido (Figura 34), única hasta el momento en Anfama y que recuerda a una de las huancas observadas en el sitio Mortero Quebrado.
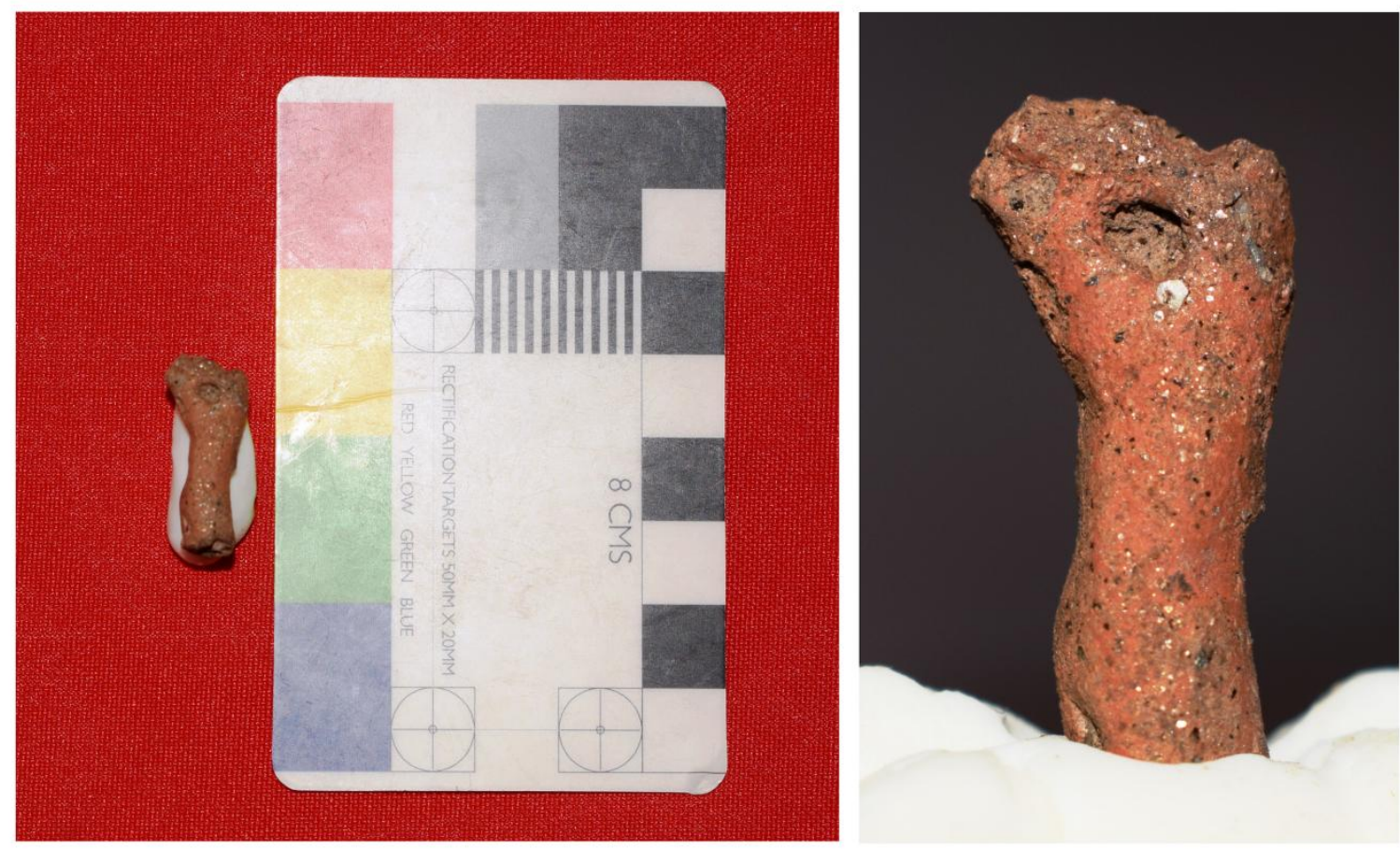

Figura 34. Representación de camélido recuperada en la UE 151.

La estructura excavada en Casa Pastor muestra un patrón constructivo interesante con cierta inversión de trabajo materializada en la técnica constructiva que incluye una base compuesta por pequeñas rocas alineadas y el resto de la estructura probablemente realizada en materiales perecederos de los cuales no han quedado vestigios en la actualidad. Esto se asemeja bastante a lo registrado en Las Pavitas y El Sunchal, y quizás remite a estrategias de cierta movilidad, lo cual deberá ser corroborado en nuevas intervenciones y contratado con el análisis de otras líneas de evidencia. Esto sería también relevante si consideramos la antigüedad establecida, ya que podría pensarse como una práctica relevante en momentos de transición de economías más orientadas a la extracción hacia 
estrategias más productivas. Aún así, la imposibilidad de continuar las excavaciones por tratarse del ingreso a la vivienda actual, limitan las posibilidades de ampliar las indagaciones en esa fase transicional, al menos hasta que se identifique otro sitio contemporáneo.

Un aspecto muy rescatable de este trabajo, además de la rica base de datos construida, fue la posibilidad de compartir con comuneros y sobre todo con los estudiantes de la escuela algunas de las prácticas científicas que se aplican en arqueología para realizar las investigaciones aspecto que puede tener consecuencias muy productivas en otros casos similares.

\section{Mortero Quebrado}

El sitio Mortero Quebrado se ubica al Noroeste de la localidad de Anfama a $2400 \mathrm{msnm}\left(26^{\circ} 43^{\prime} 65^{\prime \prime} \mathrm{S} ; 65^{\circ} 37^{\prime} 05^{\prime \prime} \mathrm{O}\right.$, Figura 35). En el filo de cumbre del cerro, se encuentran distribuidas a lo largo de $500 \mathrm{~m}$ siete unidades arquitectónicas cuya construcción remite a los conjuntos residenciales erigidos y habitados durante el primer milenio de la era en el Valle de Tafí y regiones aledañas (Berberián y Nielsen 1988; Sampietro y Vattuone 2005; Salazar 2011; Di Lullo 2012; Oliszewski 2017; Aschero y Ribotta 2007; Scattolin 2010). Estas estructuras están constituidas por entre tres y ocho recintos, con una construcción de planta circular de gran dimensión en la porción central (mayor a 10 m de diámetro) a la cual se adosan otras de menor tamaño, también circulares (Figura 36). Si bien en superficie no se observa cerámica, son notorios los instrumentos de molienda pasivos y los bloques de piedra decorados, algunos con combinaciones de pequeñas cavidades circulares y otra tallada en busto representando un camélido. Los fechados radiocarbónicos obtenidos de material proveniente de dos unidades residenciales, permiten fijar la ocupación del sitio en la primera mitad del primer milenio de la Era (entre el 80 DC y el $530 \mathrm{DC})$. 


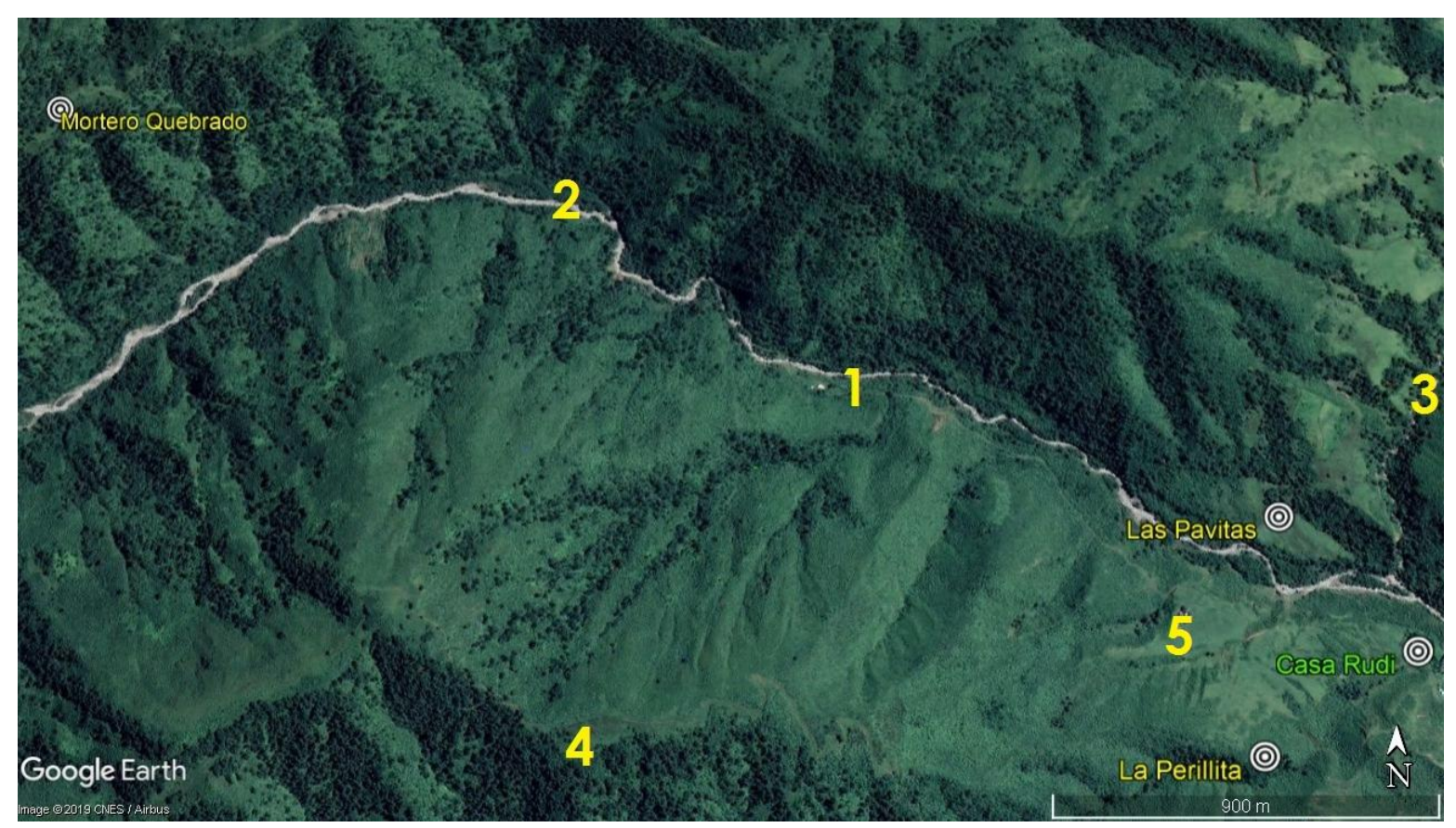

Figura 35. Toma aérea de Mortero Quebrado. 1) Toma de agua y piletas de filtrado. 2) Río Anfama. 3) Arroyo El Sunchal. 4) Cuesta de Anfama. 5) Puesto subactual abandonado.

Las tareas de relevamiento y mapeo permitieron reconocer las características visibles en superficie de las unidades arquitectónicas, así como una gran cantidad de instrumentos de molienda en superficie, lo que ha dado su nombre actual al área. Decidimos sondear dos recintos de planta circular adosados a estructuras de mayores dimensiones. Seleccionamos en R34 de la U2 y el R46 de la U4. De las dos intervenciones, el R34 permitió identificar un interesante conjunto de materiales domésticos entre los que se destacaban dos puntas de flecha de obsidiana, grandes fragmentos de cerámica ordinaria y una importante cantidad de material vegetal carbonizado. Contrariamente, el registro de R46, fue casi nulo. Por esta razón, en la campaña siguiente decidimos ampliar la excavación de R34, el cual fue intervenido en área en toda la mitad sur. 


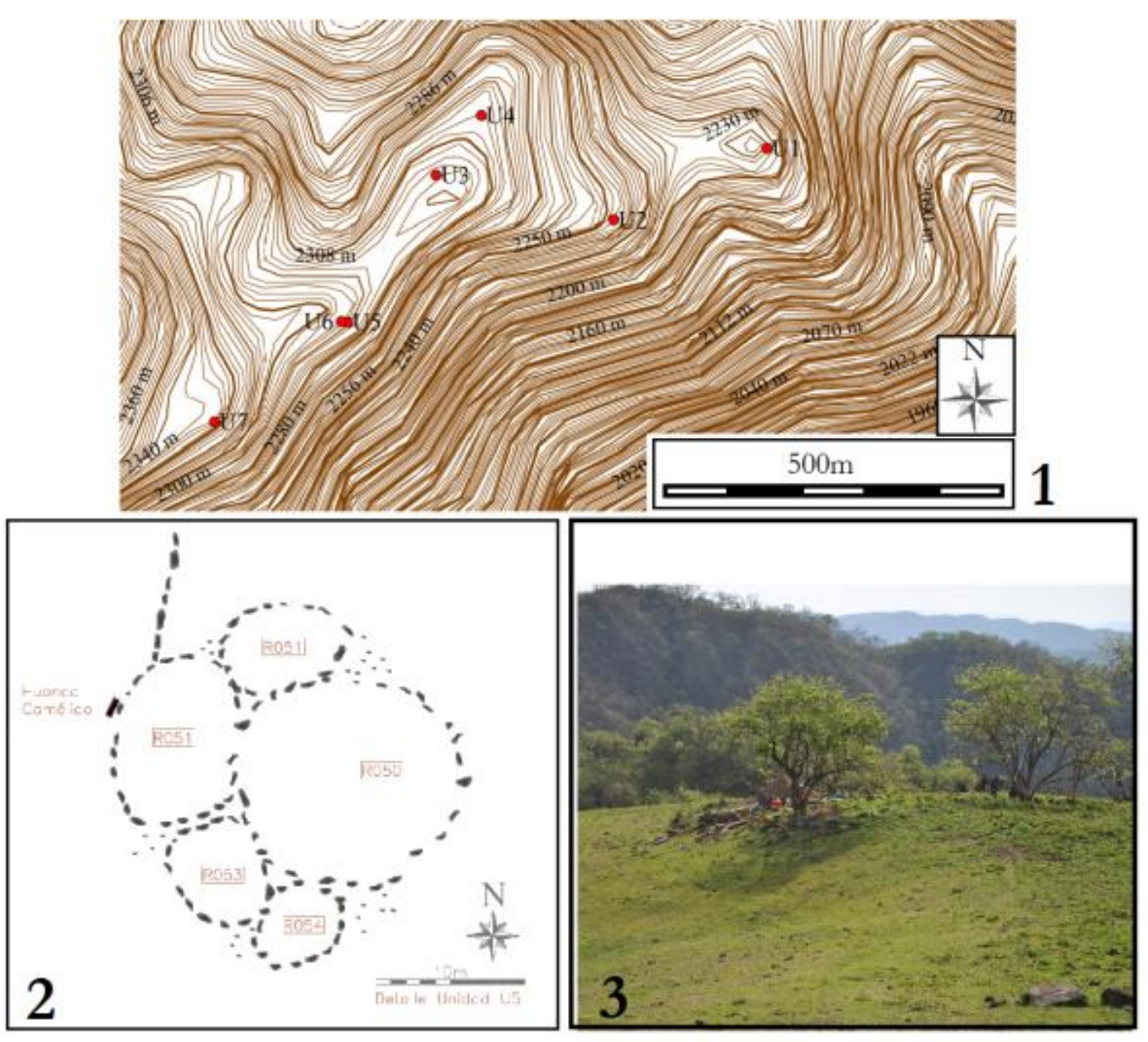

Figura 36. Mortero Quebrado. 1) Distribución de Unidades Residenciales en el sitio Mortero Quebrado; 2) Plano de Planta de unidad arquitectónica MQ-U05; 3) Vista de Unidad arquitectónica MQ-U02.

La excavación del R34, estructura lateral de 6 m de diámetro de la Unidad U2 (Figura 37), permitió identificar un contexto asociado a la realización de prácticas de procesamiento, cocción y consumo de alimentos. En la porción central del recinto se detectó la presencia de un fogón en cubeta, con gran cantidad de materiales carbonizados en su interior y con una gruesa capa de material arcilloso 
termoalterado en su base. La base de este fogón fue datada en 1725 \pm 20 AA107302, es decir aproximadamente en el 350 d.C. (Figura 38).

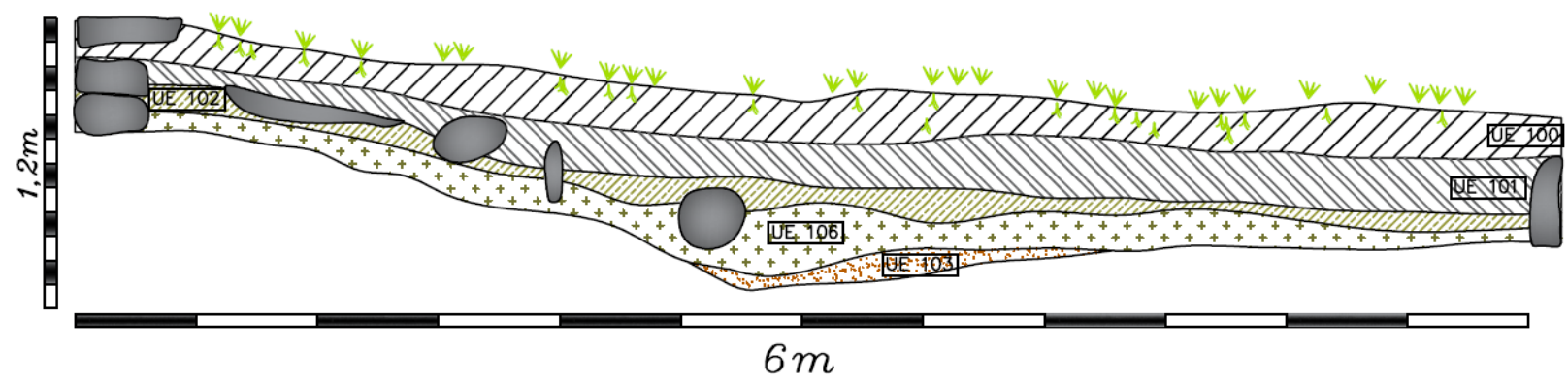

Figura 37. Estratigrafía del perfil Norte de la mitad sur de MQ U2 R01.

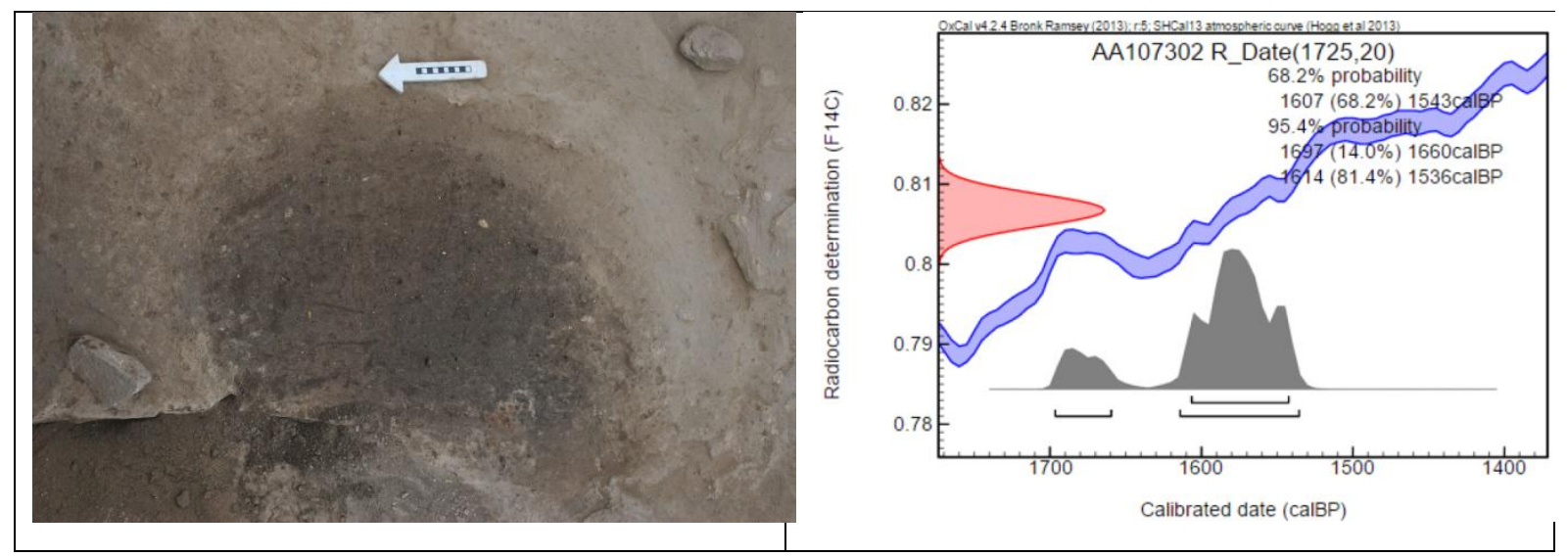

Figura 38. Fogón en cubeta registrado en MQ U2 R34 y Calibración del Fechado Radiocarbónico de Mortero Quebrado, realizado sobre material vegetal leñoso carbonizado.

En torno a este rasgo, se encontraron manos de moler, molinos planos pequeños y restos cerámicos con las paredes carbonizadas, algunos de grandes dimensiones, que corresponden a ollas de siluetas simples y restringidas con cuello y bordes evertidos. En este recinto, fue identificado un macrorresto carbonizado de maíz (Zea mays). El análisis de microrrestos vegetales dio como resultado la presencia de almidones identificados con maíz (Zea mays), poroto tarwi (Lupinis mutabilis Sweet), algún tipo de tubérculo (probablemente Oxalis tuberosa) y silicofitolitos de zapallo (Cucurbita sp.) (Figura 39). 


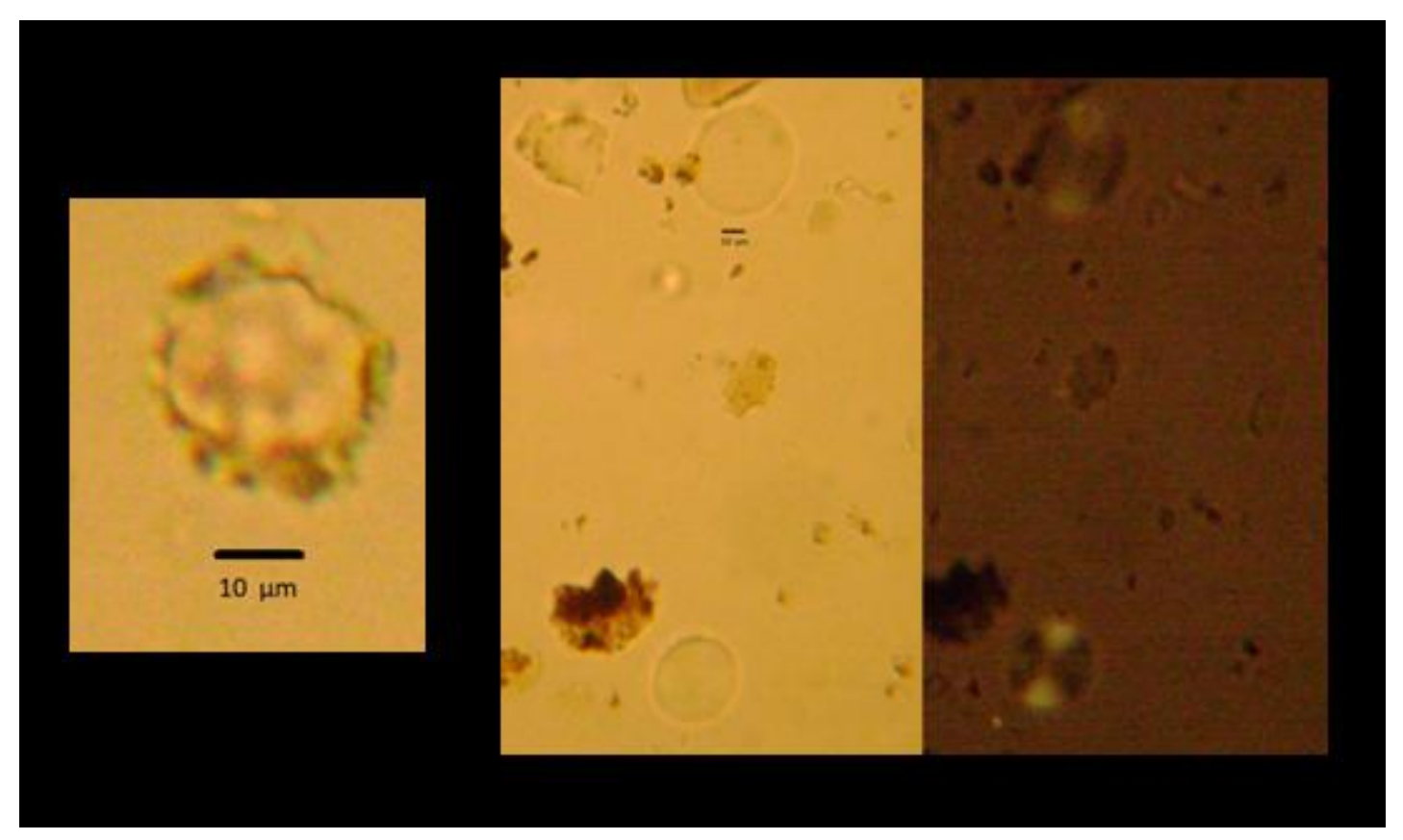

Figura 39. Izquierda: silicofitolito de zapallo (Cucurbita sp.). Derecha: granos de almidón de poroto (Lupinis sp.).

Los muros de la estructura se constituyen de gruesas acumulaciones de piedras de diversos tamaños que hacia el interior tienen una cobertura de grandes lajas que habrían dado uniformidad a los paramentos. La puerta que lo comunica con el recinto central del conjunto es una amplia abertura de $90 \mathrm{~cm}$.

Un elemento destacable registrado en esta excavación fue una importante cantidad de rocas talladas (Figura 40). Solo en la mitad excavada del recinto se recuperaron seis bloques con distintos tipos de decoraciones (tanto talla en busto como bajorrelieves) algunos de ellas aparentemente no concluidas o incluso fracturadas en proceso de tallado/pulimento, depositadas en muros y derrumbes del recinto, junto a un conjunto de percutores, alisadores y yunques líticos. Estos hallazgos, en principio destacan la importancia de este tipo de rocas en la cosmovisión de los habitantes del sitio, pero a su vez nos ofrece un contexto de producción de los mismos de los cuales casi no hay evidencias en el Noroeste 
Argentino. El uso de rocas talladas como huancas es un fenómeno suficientemente conocido en numerosos contextos espaciales del NOA durante el primer milenio, pero poco se sabe de sus contextos de producción, de las personas que los ejecutaban y de los motivos que llevaba a hacerlos, lo cual convierte a Mortero Quebrado en un espacio sumamente importante para el estudio de esta problemática.

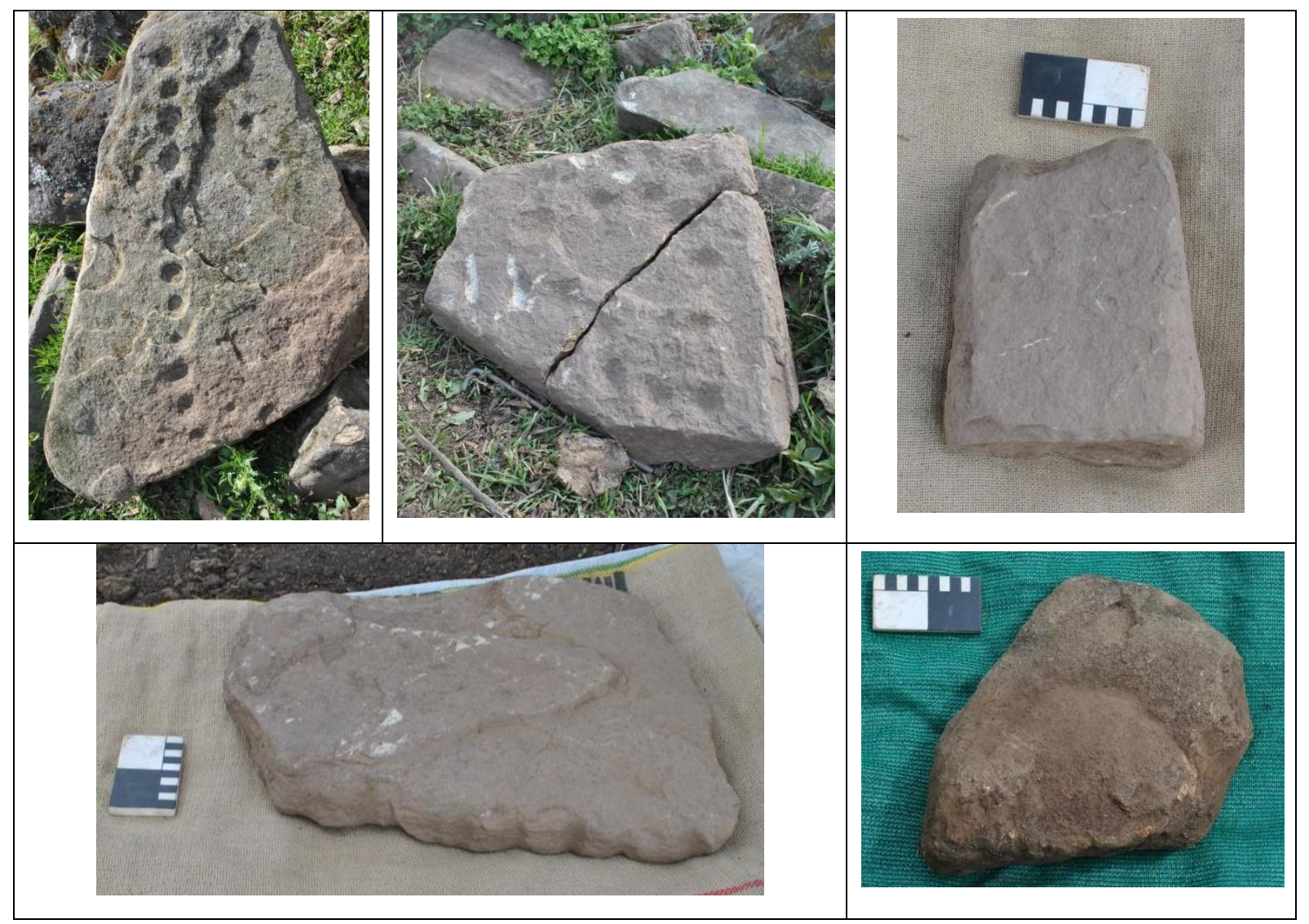

Figura 40. Algunas de las rocas talladas en busto y bajo relieve halladas en R34.

\section{La Larga}

La Larga presenta siete unidades arquitectónicas $\left(26^{\circ} 44^{\prime} 53^{\prime \prime} \mathrm{S}\right.$; $65^{\circ} 35^{\prime} 34^{\prime \prime} \mathrm{O}$; 1845 msnm, Figura 41) de piedra de un patrón similar al registrado en Mortero Quebrado. En el centro de las unidades se ubica un recinto de grandes dimensiones, de planta circular o subcircular, en torno a las cuales se disponen, 
adosadas, otras estructuras de morfología similar y menor tamaño. Si bien el estado de conservación de los muros no parece ser el mejor, en superficie se pueden observar numerosos instrumentos de molienda o fragmentos de los mismos.

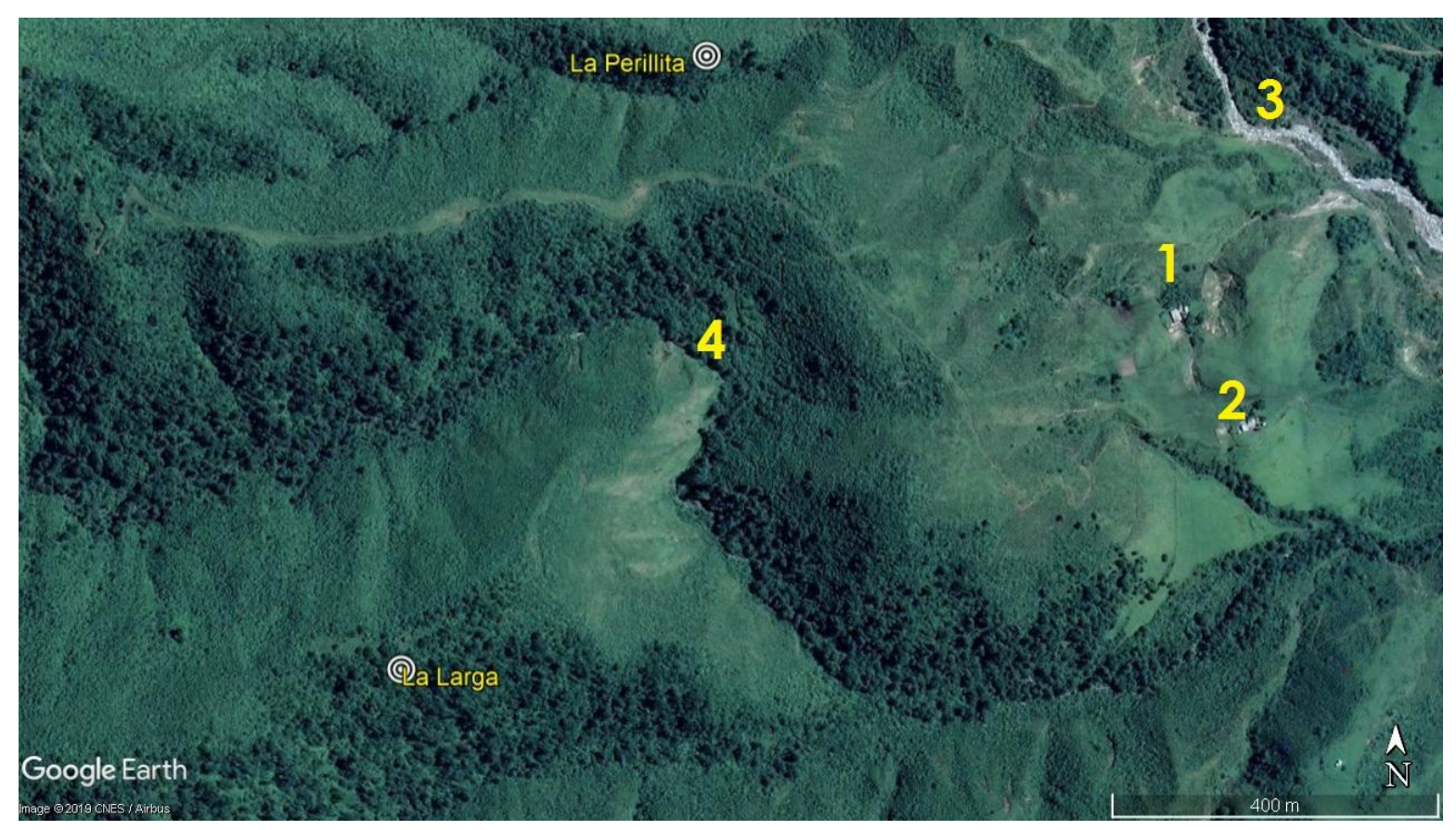

Figura 41. Toma área sitio La Larga. 1) Puesto familia Plácido Chocobar. 2) Puesto familia doña Inés. 3) Río Anfama. 4) Arroyo Condorhuasi.

En este lugar realizamos un relevamiento con GPS, brújula y cinta métrica de todas las estructuras visibles en superficie. Posteriormente decidimos realizar dos sondeos en el R66 de la U2, pero lamentablemente los resultados no fueron muy positivos debido a la poca depositación de sedimentos y a la fuerte actividad destructiva de las raíces de las plantas que cubren este lugar.

Los materiales líticos recuperados incluyeron lascas e instrumentos de cuarzo y cuarcita, y un pequeño fragmento de obsidiana que sería macroscópicamente asignable a la fuente de Ona-Las Cuevas (Figura 42). En tanto, 
los fragmentos cerámicos recuperados son de factura ordinaria, antiplásticos medianos a gruesos, mayormente de cocción oxidante, y sin que se observe ninguna decoración en ellos.
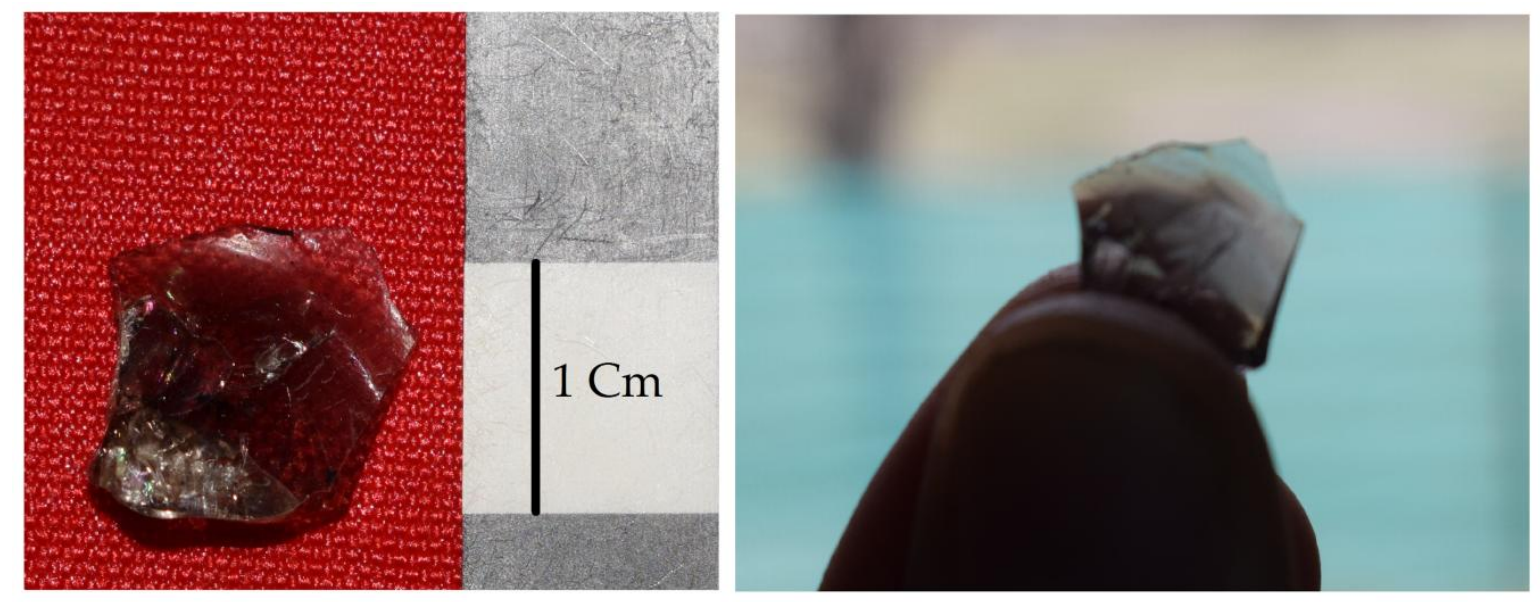

Figura 42. Obsidiana posiblemente asignable a la fuente Ona Las Cuevas. Obtenida en la UE 66.

\section{La Mesada}

La Mesada (26⒋ $44^{\prime} 47^{\prime \prime}$; 65 $65^{\circ} 37^{\prime} 17^{\prime \prime} \mathrm{O}$; 2386 msnm, Figura 43) uno de los sitios ya descritos por Quiroga (1899) muestran unidades muy similares a las de Mortero Quebrado combinando recintos circulares pequeños con recintos circulares centrales de grandes dimensiones a la manera de patios. Ambos sitios si bien están separados por el cauce del Río Anfama son intervisibles.

Debido a la distancia con Anfama y la relativa escasez de agua en esa ubicación aún no hemos podido llevar a cabo ningún estudio. 


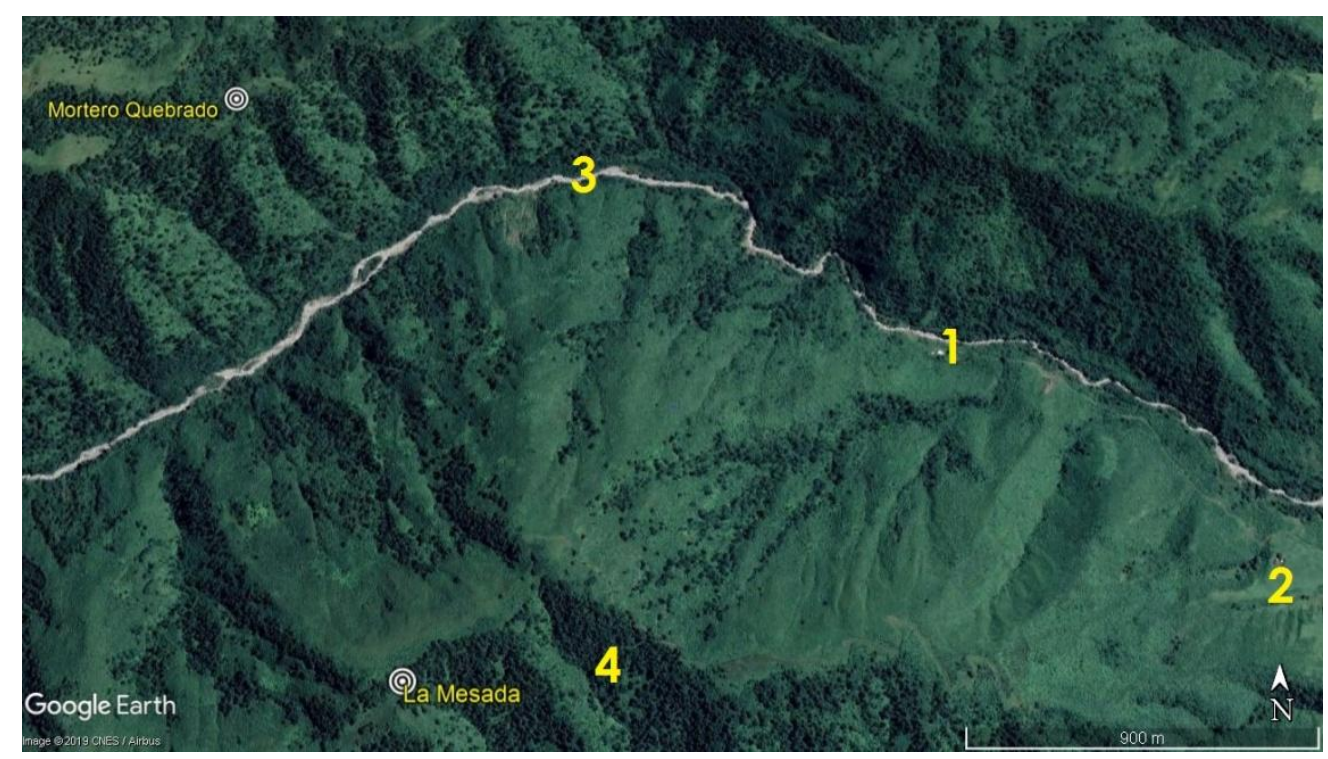

Figura 43. Toma aérea de La Mesada. 1) Toma de agua y piletas de filtrado. 2) Puesto subactual abandonado. 3) Río Anfama. 4) Cuesta de Anfama.

\section{Aspectos cronológicos de la materialidad}

La construcción de una secuencia cronológica precisa, aspecto clave para la interpretación de las dinámicas de los procesos sociales materializados en un paisaje con múltiples ocupaciones como el analizado aún adolece de la carencia de dataciones absolutas. Por otra parte, los indicadores temporales relativos, especialmente los estilos cerámicos con asignaciones cronológicas certeras que proceden de valles como el de Tafí o Yocavil, resultan de relativa aplicabilidad. Solamente hemos identificado estilos con cronologías claras en uno de los sitios, Casa Rudi, en el cual se presenta un conjunto asignable al Período de Desarrollos Regionales. El resto de las ocupaciones parecen pertenecer a momentos previos al año 1000 d.C. Esta afirmación procedía exclusivamente, hasta hace tiempo, de algunas características de los conjuntos arquitectónicos, similares a los del primer milenio en el valle de Tafí, a los conjuntos cerámicos caracterizados por una gran preponderancia de grupos ordinarios y la escasez casi absoluta de decoraciones, 
reduciéndose las mismas a algunos motivos modelados que representan en la mayor parte de los casos algunas partes del cuerpo humano, especialmente rostros, ojos, cejas y manos.

Uno de los aportes más importantes de nuestras investigaciones ha sido comenzar a generar datos precisos sobre la temporalidad de la ocupación humana en Anfama. Es así que pudimos realizar las primeras tres dataciones radiocarbónicas del área en los sitios Casa Pastor, El Sunchal y Mortero Quebrado.

Las implicancias que se desprenden de estos datos son sumamente relevantes tanto para el mundo académico como para la Comunidad Indígena:

-La ocupación originaria de Anfama se remonta, al menos, a cuatro siglos antes de la Era. Dicha ocupación tiene una fuerte continuidad, atravesando el llamado Periodo Formativo (500 a.C.-1000 d.C.), el Periodo de Desarrollos Regionales (1000 d.C. - 1500 d.C.), el periodo Colonial, evidenciado por las crónicas hispánicas, y el Republicano, lo cual queda reflejado en la historia oral de los comuneros.

-La contemporaneidad de los fechados de Mortero Quebrado y El Sunchal (próximos al 350 d.C.), dos sitios que en principio reflejan lógicas de uso del paisaje muy distintas introduce una serie de preguntas muy relevantes que intentaremos responder en el futuro: ¿Eran esos lugares ocupados por la misma gente? Si era así ¿Cómo se explican construcciones tan distintas? ¿Cómo se vincularon entre ellas? Si no era así ¿Cómo hacían estos grupos para convivir en este mismo espacio? ¿Cuáles eran sus relaciones?

-En los conjuntos cerámicos la homogeneidad de los materiales recuperados es marcada. En todos los sitios excavados hasta el momento, la cerámica se corresponde con grupos asignables estilísticamente al primer milenio de la Era, y 
similares a los de otros sectores del área sudcalchaquí (González y Núñez, 1960; Heredia, 1974; Berberián y Arguello, 1988; Cremonte, 1996 y 2003; Palamarczuk et al., 2007; Salazar et al., 2008; Maldonado et al., 2011; Oliszewski, 2011), los cuales habrían sido utilizados en actividades domésticas cotidianas de almacenamiento, cocción y servicio de alimentos. Los conjuntos se caracterizan por la preponderancia casi absoluta de fragmentos toscos, con antiplásticos gruesos, cocciones en atmósferas oxidantes (muchas de ellas incompletas), y decoraciones casi nulas. Cuando se observaron decorados estos fueron engobes de color rojo, aplicaciones circulares al pastillaje, motivos lineales simples incisos, y representaciones prosopomorfas.

-No se han detectado por el momento estilos cerámicos del primer milenio de origen presumiblemente alóctono como Vaquerías, Condorhuasi, Ciénaga, o Aguada. Sin embargo, sí se han observado estilos de amplitud regional más marcada asignables al segundo milenio como Santamariano bicolor, tricolor y Famabalasto negro grabado, los cuales proceden de colecciones de comuneros del valle o se observan en los adobes de sus casas.

-En los conjuntos líticos en tanto destaca la presencia mayoritaria de recursos que serían de origen local como cuarzo y cuarcita, y en menor grado de gravauca y sílice, los cuales habrían sido utilizados siguiendo estrategias expeditivas (Binford, 1979; Nelson, 2001). Adicionalmente, destaca en casi todos los sitios la utilización de obsidiana de origen no local, las características macroscópicas de los fragmentos parecen indicar la proveniencia de la mayoría de los restos de las fuentes de Ona-Las Cuevas (en la puna catamarqueña). La presencia de este recurso alóctono inserta a Anfama en redes de intercambio y/u obtención más amplias, de hasta cientos de kilómetros de extensión. 


\section{Algunas reflexiones iniciales}

Las características del registro arqueológico descrito posibilitan generar una serie de reflexiones iniciales sobre la variabilidad del registro arqueológico prehispánico de Anfama.

En primer lugar observamos un fuerte predominio de las ocupaciones del primer milenio por sobre otros periodos. La mayoría de los sitios identificados serían ámbitos residenciales, distribuidos de manera muy dispersa en el paisaje. Estos se habrían diferenciado en al menos dos modalidades de habitar: una que parecería responder a patrones sedentarios, con componentes que poseen una relativamente alta inversión de esfuerzo constructivo; y otra que respondería a estrategias de movilidad más acentuadas, con construcciones más informales.

Las instalaciones más formales se ubican generalmente en zonas de cumbre, las cuales presentan terrenos levemente horizontales y posibilitan el establecimiento de construcciones en zonas con pendientes promedio muy pronunciadas. En estos espacios, la arquitectura presenta gruesos muros de rocas, especialmente de las lajas de la zona con las cuales se generan lienzos sumamente parejos.

En segundo lugar, es interesante remarcar la constante relación entre unidades residenciales y esculturas líticas con formas fálicas, antropomorfas, zoomorfas y geométricas, las cuales remiten a las huancas del valle de Tafí y podrían entenderse como marcadores territoriales, en su constante alusión a los ancestros.

El paisaje aldeano emergente durante el primer milenio habría estado salpicado de viviendas, parcelas de cultivo (sin demasiada inversión en infraestructura) y jardines en cercanías a las unidades residenciales, las cuales 
habrían caracterizado a un ámbito marcado por la descentralización de las decisiones y la heterogeneidad de colectivos involucrados. 


\section{Entrevistas para el registro de la Historia Oral y el Saber Comunitario.}

Los trabajos del equipo también incluyeron una serie de entrevistas con comuneros que sirvieron para conocer y registrar tradiciones, saberes ancestrales y problemáticas de la comunidad. En esta oportunidad incluimos por un lado la realizada a Daniel Chocobar, y por otro a Teresa Monasterio y Desiderio Maza.

Daniel es un joven músico local, no vidente, hijo de Pastor y Griselda Chocobar y actualmente cursa el profesorado en música en la ciudad de San Miguel. También forma parte del conjunto "Esperanza chamamecera" el cual actúa habitualmente en las fiestas de Anfama y otras localidades vecinas. En tanto, Teresa y "Dechi" poseen un puesto donde se realizan habitualmente tareas agrícola-ganaderas, las cuales son realizadas por ellos mismos de sol a sol pese a su avanzada edad (ocasionalmente cuentan con la colaboración de algún nieto).

Entrevista a Daniel Chocobar (Julio de 2014) por Gonzalo Moyano (también se encuentran Cecilia Argañaraz y el tío del entrevistado Adolfo Chocobar quienes realizan algunas acotaciones)

Gonzalo: Bueno Daniel ya hemos estado charlando un rato con vos, sobre tu vida, ahora dejaríamos registrada tu historia.

Daniel: Si señor.

G: Podes contarnos, ¿cómo te llamas? ¿Cómo se compone tu familia?

D: Bueno, entonces primero voy a presentarme, yo soy Daniel Chocobar. Y bueno soy originario de aquí, de la zona. Somos 8 hermanos. Me gusta que ustedes vengan y nos demuestren lo que ustedes saben hacer. Y nosotros también demostrarle lo mejor, y que se vayan con un lindo recuerdo de la zona.

G: Bueno Daniel, nosotros además sabemos que sos músico, y por ahí nos gustaría que nos cuentes ¿Cómo bajaste a la ciudad?, ¿Cuánto hace que bajaste?, ¿Por qué bajaste? 
D: Bueno yo en primer lugar baje por intermedio de mi salud, del problemita de salud que tuve. Pequeño problema que yo venía hace 2 años atravesando. Y bueno, de esto se me dió, como dice el dicho, por tras de una piedra grande llega algo que nunca espera uno. La esperanza que no se ha de perder nunca. Y a mí, por intermedio de unos amigos tucumanos míos, que son músicos, como ser el dúo “La Yunta" que presentaron su disco en Cosquín, no sé si ustedes se enteraron. También "Miti Miti" y "Mono" Villafañe, y un colaborador y amigo, y amigo de la comunidad indígena de la zona. Por intermedio de ellos yo fui a estudiar a Tucumán. Y por intermedio de un profesor que yo tuve hace 11 años en la escuela braille. Porque yo estuve en la escuela braille hace 11 años por dos semanas. Y lo poco que aprendí bueno, fui perdiendo un poco contacto, y hace dos años volví a tener contacto, y volví a re-aprender el sistema braille y ahora trabajamos con el alfabeto en braille. Y eso a mí me gusta, y ahora estoy haciendo la secundaria, y todo para terminar, y tenemos computadoras y muchas herramientas necesarias que tenemos. Ahora estoy de vacaciones por dos semanas. Y este año me puse las pilas, de hacer más trabajos, de aprender masajes terapéuticos, panadería y la música más que nada. 


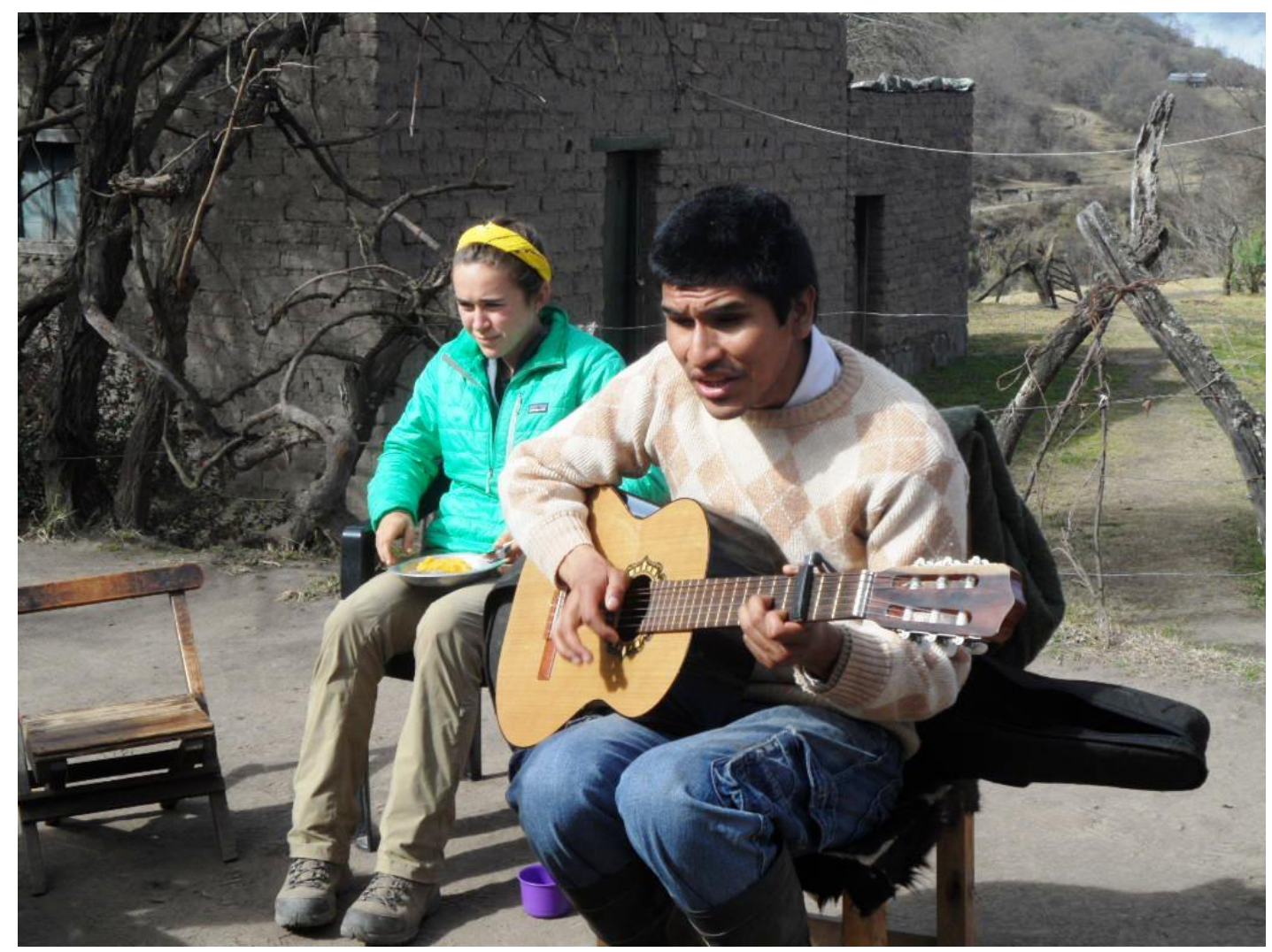

Figura 44. Dani Chocobar cantando su zamba.

G: ¿Y cómo empezaste con la música?

D: Empecé hace 15 años a hacer la música, porque yo desde chico. (Otra persona le apunta que desde los 7 años empezó con la guitarra) hacía bombos de cartón, se ríe. Una maestra de grado me regaló una guitarra hace 14 o 15 años de una fundación que se llamaba "Niños necesitados". Y bueno, y eso me hizo que aprenda más cosas, más canciones. Y a medida que pasaba el tiempo, fui quedando ciego del todo, me apagaron las luces, y Dios me dio el oído para seguir aprendiendo más canciones, y más cosas, y de tener más éxito en la música y seguir con lo que vengo haciendo. Y componer canciones, yo tengo canciones compuestas por mi autoría, y todavía no las grabé, eso es lo que tengo soñado. Y yo hace seis o siete años que aprendí a tocar el acordeón, formé una banda, y la banda está compuesta por siete músicos. Uno que es compañero de la escuela de allá de la ciudad, y seis de acá de la zona. Bueno, hace siete años primero se formó 
con el acordeón, al poco tiempo que aprendí acordeón empezamos a formar el grupo, yo y mis dos tíos, hasta que incluimos un guitarrero, después a él, estuvo mi otro primo que también tocaba la guitarra y ahora está mi hermano, que es músico también, y es güirista. Primero estuvo mi hermana que ahora no está, y que está con mi abuela. Tocaba también el güiro. Hasta que se incluyó él, y así seguimos el grupo. El grupo se llama los "Chamameceros de Anfama" (NdE: Ahora "Esperanza Chamamecera"). Y nosotros, mas yo que tengo más escenario, y digamos salí, conozco de escenarios, como estoy relacionado con muchos artistas y eso es lo mejor para mí.

G: A pesar que tocas el acordeón, también tocas muy bien la guitarra. ¿Nos podes tocar la zamba que tocaste hoy a la mañana?

D: Si como no.

Adolfo Chocobar: El violín también toca y el órgano.

Cecilia Argañaraz: Si Rudi nos dijo que toca como 6 instrumentos.

G: Es una orquesta completa el hombre.

D: Esta zamba la compuse hace poco, la que estuve cantando hace un rato.

\section{Adentro}

Por el cerro voy cantando esta zamba tucumana Porque me siento contento cuando se enamora mi alma Porque me siento contento cuando se enamora mi alma

Cuando me voy por Anfama, La Ciénaga y San José

Con mi guitarra templada vengo a cantarte otra vez

Con mi guitarra templada vengo a cantarte otra vez Cuando pasé por La Junta, Mala Mala y El Alisal Seré libre como el viento en aquel bello lugar Seré libre como el viento en aquel bello lugar 


\begin{abstract}
Adentrito
Qué lindo es poder cantarte debajo de las estrellas

Un sendero de esperanza por donde dejo mis huellas

Un sendero de esperanza por donde dejo mis huellas

Adiós pueblito serrano, con mi mano te diré

Perfumadito de azares, algún día volveré

Perfumadito de azares, algún día volveré

Cuando pasé por La Junta, Mala Mala y El Alisal

Seré libre como el viento en aquel bello lugar

Seré libre como el viento en aquel bello lugar
\end{abstract}

D: Esa es de mi autoría.

G: Por ahí nos podes contar cómo la música te ayudo a superar tus problemas. Y cómo te permitió tener ciertas experiencias en la ciudad.

D: A pesar de todo estoy consiguiendo más amistades, y me buscan, o me contratan desde fiestas familiares hasta festivales, a beneficios de algo también, como a mí me gusta hacer campaña con todo y con la música por supuesto. Hay artistas que se basan y no sé, y no sé cómo explicarlo, pero yo tengo el agrado y me gusta la música. Me gusta de todo. Yo creo que sin esto, no seríamos nada.

G: ¿Hoy todavía te seguís formando? ¿Cómo fue tu formación aquí en Anfama?

D: Hasta EGB3, secundario básico.

G: ¿Hiciste la primaria acá y el secundario básico?

D: Si

G: ¿Y ahora estás terminando el secundario?

D: Si, allá en la ciudad.

G: ¿Y cómo es tu relación con la comunidad? ¿Hace cuánto que sos comunero? 
D: Hace siete años más o menos que somos comuneros. Y me gusta su historia, lo que cuentan ellos. Lo que es.

G: Vos ahora nos contaste que estás de paseo...

D: Si estoy de paseo sí.

G: ¿Venís siempre en las vacaciones?

D: Hace cuatro meses que no venía. Vengo siempre. A veces dejando, pero una o dos veces al mes, así, sucesivamente. También salimos cuando hay eventos, a veces, hay alguna falta, a veces salgo yo a representar a la comunidad a donde vamos. El mes pasado hubo una fiesta en Tafí del Valle, del Inti Raymi, ahí estuve presente representando a la comunidad. De aquí no fueron por razones climáticas.

G: ¿Qué te representa a vos ser comunero? ¿Te sentís originario? ¿Y cómo sentís ser parte de la comunidad?

D: Me siento contento de mi parte, porque me gusta.

G: ¿Qué pensás que puede aportar el trabajo que venimos a hacer nosotros?

D: Puede aportar algo importante para la zona.

C: Yo te quería preguntar, porque hoy a la mañana Rudi (NdE: Rudecindo Chocobar) nos estuvo contando mucho tiempo sobre toda su historia, de lucha, de cómo se forma poco a poco esta consciencia de poder ser una comunidad y todo lo que fue la vida anterior. Y yo te quería preguntar calculo que vos habrás sido chico cuando comienza todo esto ¿Cómo lo viviste? ¿Cómo te llegó eso?

D: Yo tendría 16 años. Me llegó, porque querían formar, de todo el lío que había, y eso digamos de venir gente de afuera y adueñarse de acá del lugar, no podía ser. Mejor a que se forme y luchemos. Para que digamos, no venga gente de afuera. Y que nos quite lo nuestro. Porque eso todo es nuestro y de nadie más.

C: Muchas gracias por la respuesta y la zambita.

D: Gracias a ustedes por venir aquí a la zona y que visiten mi casa, las puertas de mi casa siempre estarán abiertas para lo que necesiten ustedes, y bienvenidos sean. 
G: Muchas gracias.

Entrevista a Teresa Monasterio y Desiderio Maza (Julio de 2015). Por Rocío Molar y Stefanía Chiavassa Arias, también se encuentra Julia Maza (nieta de los entrevistados). El escrito sigue el orden de la entrevista y es un resumen de la transcripción realizada en base a lo que hablamos fundamentalmente con Teresa y Desiderio. Julia se encargó de mostrarnos los elementos y las estructuras que nos iban describiendo y nos ayudó a tomar fotografías.

La familia Masa-Monasterio, compuesta por Desiderio y Teresa, su hijo Miguel, y sus nietos Carlitos y Julia, tienen una explotación agrícola-ganadera a pequeña escala. En los espacios de cultivo se siembra maíz y en las inmediaciones del hogar tienen más de 200 ovejas, gallinas, algunas cabras y vacas, y una pequeña huerta que trabajan los más jóvenes.

Decidimos hacerle una entrevista a esta familia principalmente por dos cuestiones. Por un lado, porque en el establecimiento tienen lugar diversas actividades productivas tanto agrícola-ganaderas como manufactureras. Por otro, porque la familia mantiene activa una pirgua o estructura de almacenaje para conservar maíz, de la cual nos interesaba conocer más para poder obtener información que nos permita interpretar el registro arqueológico. La entrevista por lo tanto se centró fundamentalmente en las actividades productivas cotidianas que realizan Teresa y Dechi.

El establecimiento se encuentra cerca de la Iglesia de Anfama y del sitio arqueológico El Sunchal. El núcleo residencial está compuesto por tres dormitorios, una cocina y un espacio para usos múltiples, encontrándose todas las habitaciones separadas por unos pocos metros. Dentro del perímetro de la residencia se encuentran un horno de barro, una estructura de almacenaje, un gallinero y una 
huerta. En la inmediatez del alambrado, hay un corral cuadrangular de $15 \mathrm{~m}$ x 25 m aprox., destinado al manejo de cabras y ovejas (figura 45).

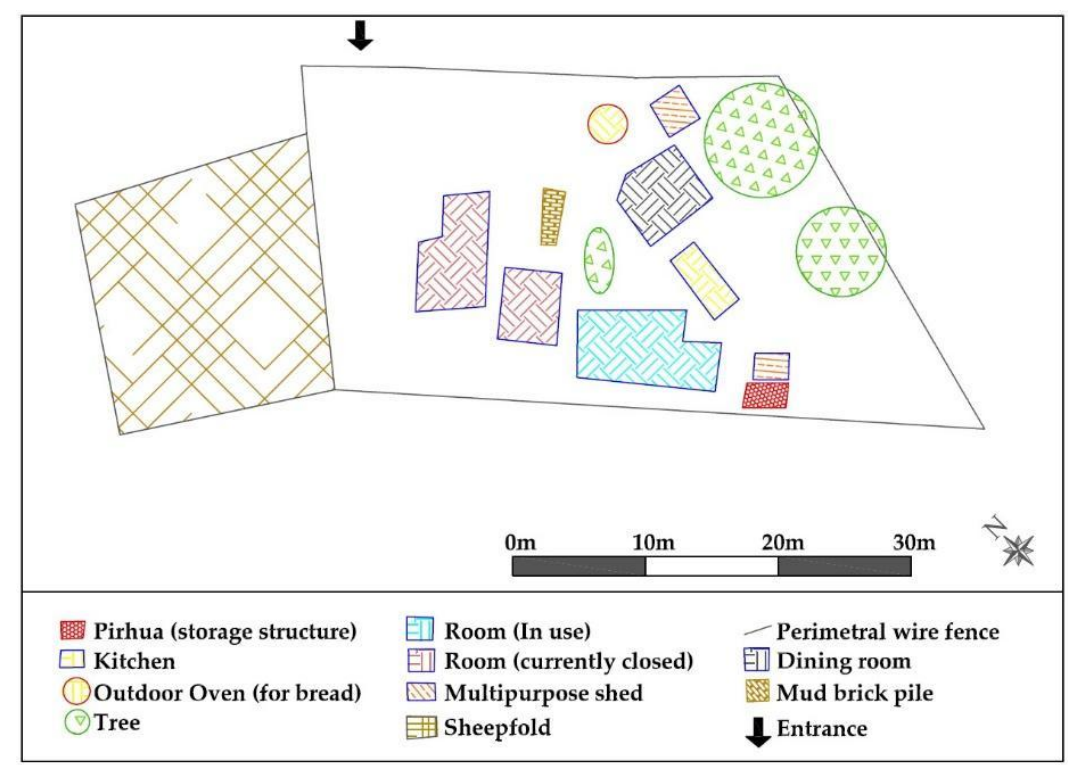

Figura 45. Gráfico de la organización espacial del establecimiento de Desiderio y Teresa.

Los campos de cultivo se encuentran a unos $700 \mathrm{~m}$. del área residencial. A principios de Octubre, Desiderio amontona el rastrojo de la cosecha anterior y lo prende fuego. Luego ara la tierra con dos bueyes y siembra el maíz que cosechará en Mayo (figura 46). 


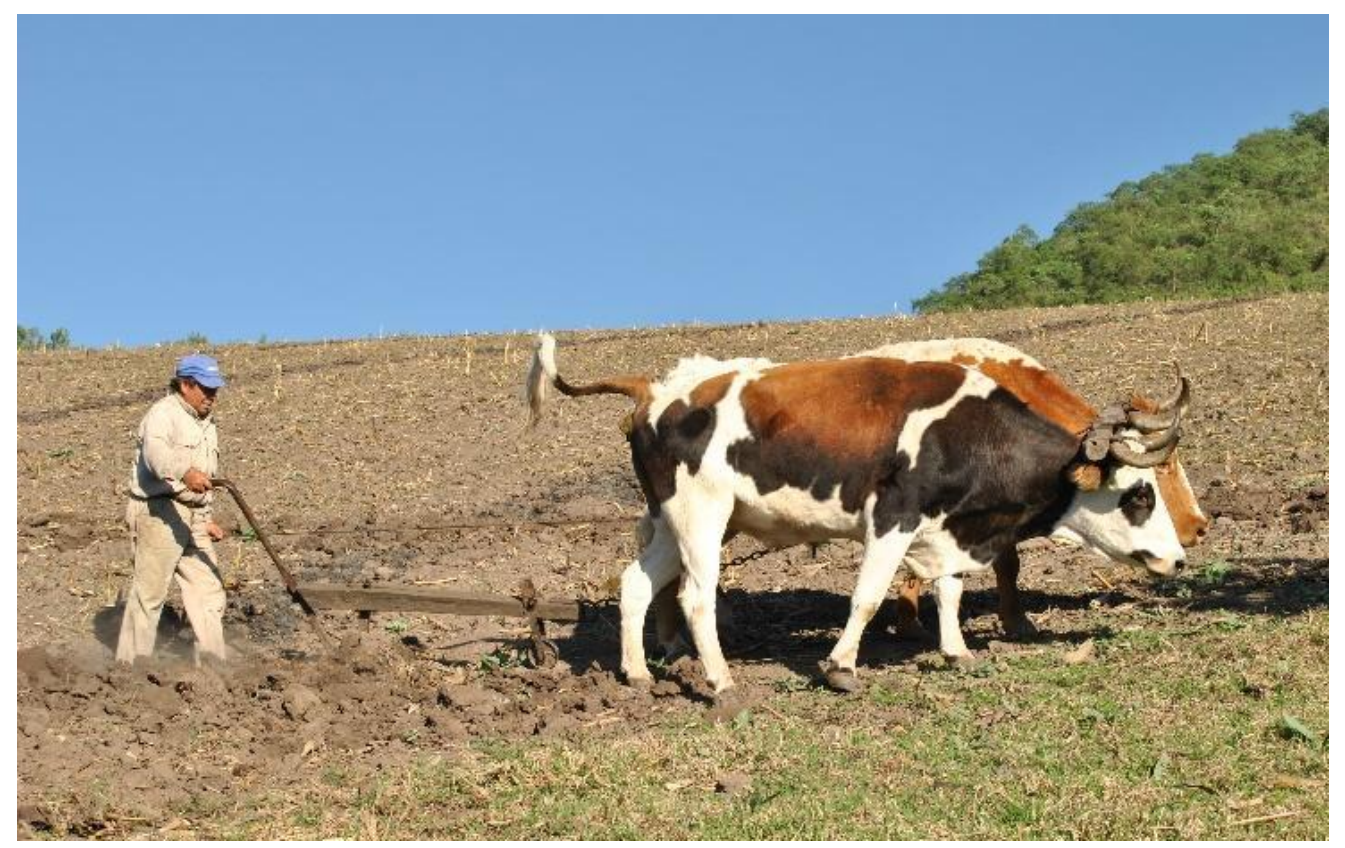

Figura 46. Don Desiderio arando con bueyes (Octubre de 2014).

Durante el invierno no se siembra nada porque el frío no permite que crezca ningún cultivo, por lo que se deja el rastrojo como protector del suelo. En otros momentos, sembraron zapallo angola (dejaron de hacerlo porque se lo comen las palomas) y cayote, pero actualmente prefieren centrarse únicamente en el maíz porque es lo que más se consume. Desiderio hace todo solo, porque los chicos se dedican a cuidar la huerta de hortalizas y a los animales. Sin embargo, se hacen un tiempo para ayudarlo en la cosecha. El maíz se recolecta cuando ya está bien seco y es trasladado en bolsones hasta la residencia. Por cosecha suelen obtenerse entre 25 y 30 bolsas de $50 \mathrm{~kg}$ cada una, dependiendo de las lluvias del verano. Si bien hay chuñas, loros, urracas y palomas que comen los granos cuando se están secando, esto no significa una gran pérdida y Desiderio dice que los animalitos también tienen derecho a comer. 
El maíz es colocado en el granero construido hace tres años. Está hecho con maderas y con unas varillas $\mathrm{u}$ horcones a los que llaman "lata o chapa de pobre" (figura 47).

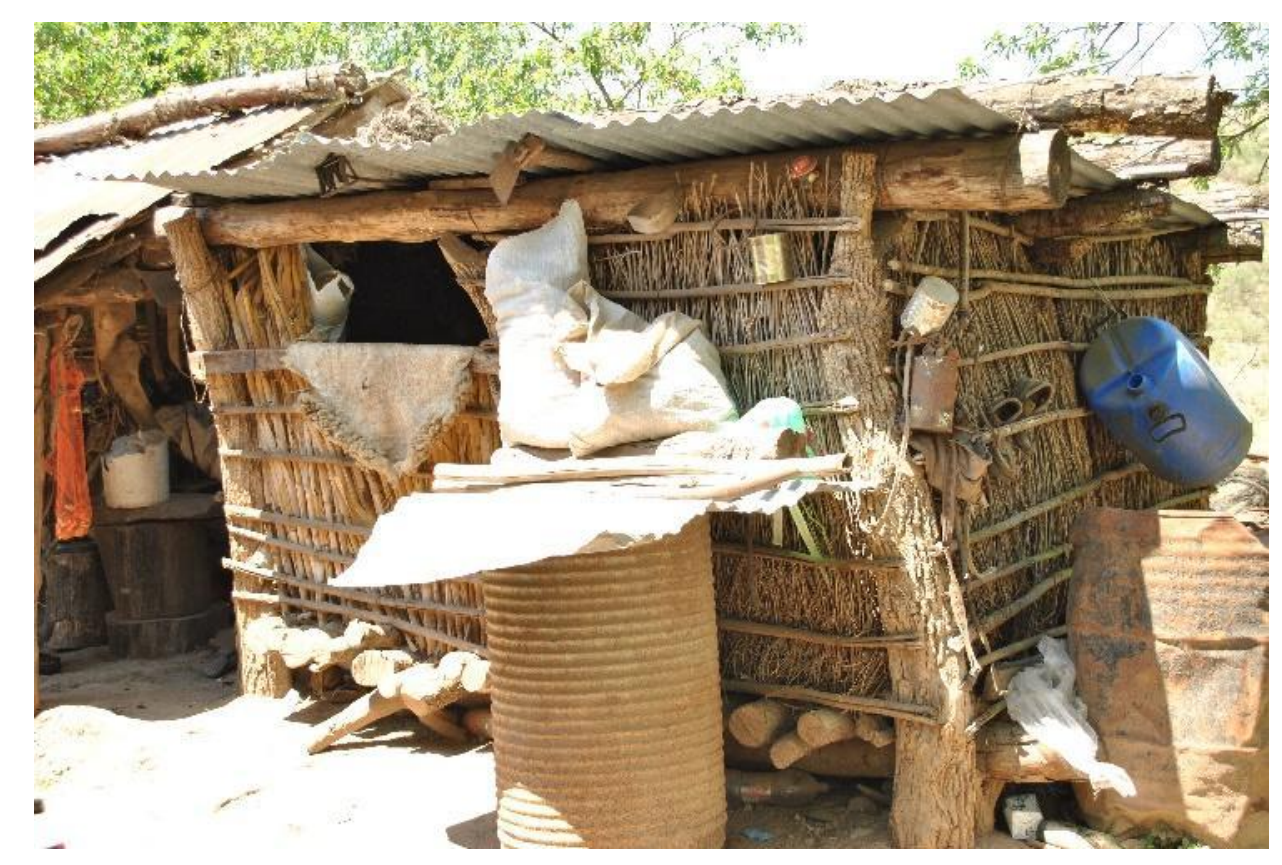

Figura 47. Pirgua o granero

El marlo se guarda entero porque si se tritura es atacado rápidamente por gorgojos y pirpintos. El tiempo de conservación es de unos cuatro o cinco meses desde la cosecha, porque en septiembre con el aumento de las temperaturas aparece el pirpinto a atacar los granos y prefieren dárselo a las gallinas antes que perderlo todo. Además del marlo, también se guarda la chala para hacer humitas. Algunos choclos incluso son guardados con las hojas para frenar el ataque de insectos, pero es preferible sacársela para que no conserven humedad y no se pudran. Una vez aireados y secos, son desgranados y molidos únicamente para consumo inmediato. El encargado de moler es Desiderio y con las harinas obtenidas Teresa realiza guisos, mazamorra y locro, e incluso panes. Los granos de 
maíz que van cayendo en el deshojado o que se consideran muy pequeños, son guardados en el capacho.

El capacho es una de las manufacturas que se realizan en este hogar. Es un recipiente hecho de cuero de vaca, al cual cuando aún está húmedo, lo cortan, lo cosen y lo llenan de arena para que tome forma. En este contenedor entran unos 15 kg de maíz que se destina a la alimentación de las gallinas (figura 48).

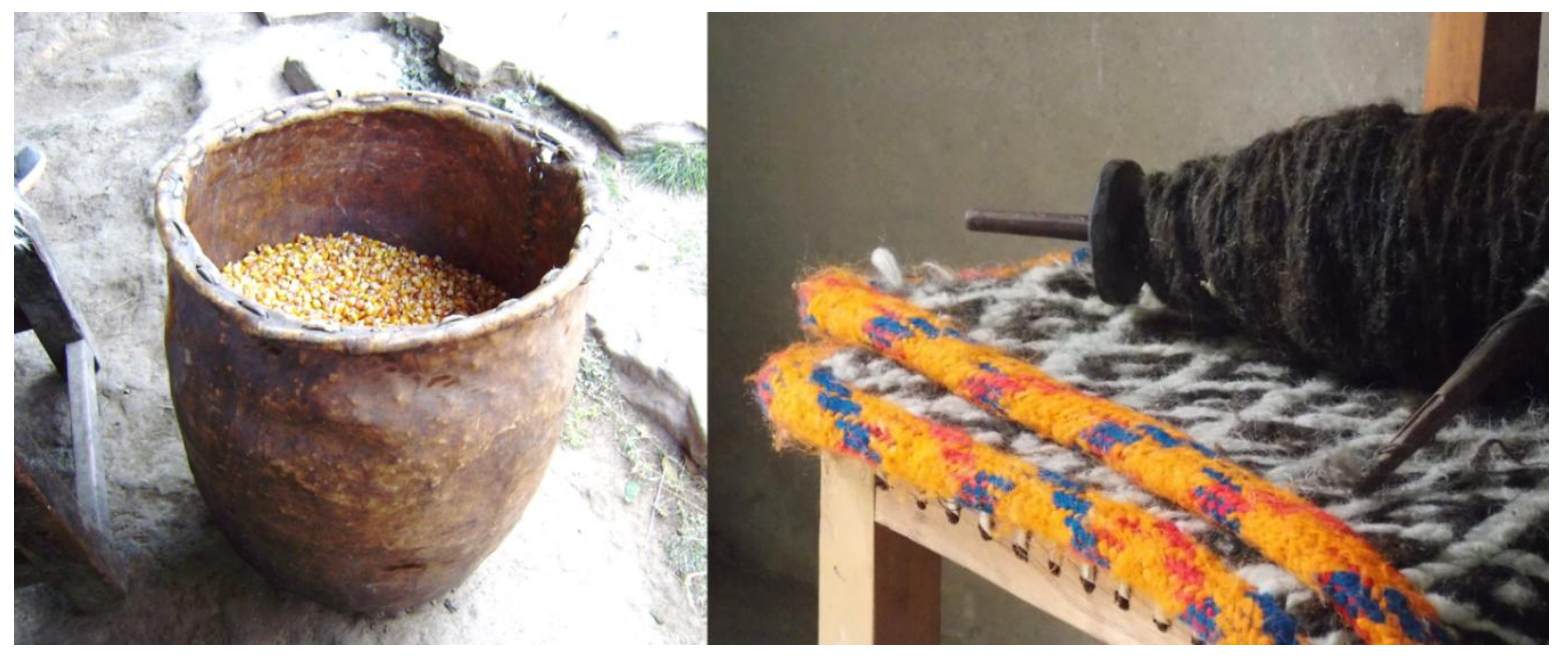

Figura 48. Algunos productos artesanales: Recipiente de cuero y lana hilada con Huso y tortero, sobre una sudadera.

La otra manufactura que aquí se produce, son los tejidos. Teresa obtiene la lana de las ovejas y la tiñe con tinta que compra en la ciudad. Cuando no tiene, utiliza como tintura la cáscara de nogal o el hollín de la chimenea. Con la lana hace mantas grandes para taparse y unas más pequeñas utilizadas para ensillar los caballos (figura 48). 


\section{Publicaciones}

Los trabajos académicos que se realizaron en función de estas primeras investigaciones fueron los siguientes:

Salazar, J., R. Molar, J. Montegú, G. Moyano, F. Franco, S. Chiavassa, V. Franco Salvi y J. López Lillo (2016). Arqueología de las ocupaciones prehispánicas en el bosque montano de las Cumbres Calchaquíes (Anfama, Tucumán). Actas del XIX CNAA, Tucumán, 2047-2054. Link

En esa primera síntesis se plantea una distinción entre los sitios de fondo de cuenca y de cumbre del valle. Se presenta de manera sintética parte del contenido vertido en este informe.

J. Salazar, V. Franco Salvi, R. Molar, G. Moyano, F. Franco, S. Chiavassa Arias. J. Montegú, P. Páez, y A. Vázquez Fiorani (2016). Historias y Patrimonios de Anfama. Una mirada desde la Arqueología, Córdoba: Secretaría de Extensión - UNC, 55 p. Link

Material de divulgación arqueológica elaborado para la Comunidad indígena tendiente a generar contenidos de Historia local consultables por las familias y en la escuela del valle. En él se desarrolla como habría sido la articulación de los pobladores originarios de Anfama con procesos prehispánicos de mayor rango espacial.

R. Molar y J. Salazar (2016).Trayectorias diversas a ambos lados del Cerro Pabellón. Aportes comparativos a la arqueología del primer milenio en Tafí y Anfama. Actas del XIX CNAA, Tucumán, 2089-2095. Link 
Este aporte traza líneas comparativas entre una unidad doméstica del sitio La Bolsa 1 (Tafí del valle) y otra del sitio Mortero Quebrado (Anfama).

Chocobar, R., G. Moyano y F. Franco (2016). De arrendatarios a comuneros: formas y lógicas de pisar el territorio en el valle de Anfama (Tucumán). Actas del XIX CNAA, Tucumán, 2255-2260. Link

Rudecindo Chocobar, cacique de Anfama, comparte con nosotros parte del proceso mediante el cual se conformó la comunidad indígena local a principios de la década del 2000.

J. Montegú (2016). Tecnología lítica y vida aldeana durante el primer milenio de la era en Anfama (Tucumán, Rep. Argentina). Actas del XIX CNAA, Tucumán, 14691475. Link

Se presentan las primeras hipótesis y resultados sobre la materialidad lítica de Anfama durante el primer milenio. 


\section{Bibliografía citada}

Antelo, C. y C. Navarro

2017 Avifauna de un camino rural de montaña en las Yungas de Tucumán (Argentina). Acta zoologica lilloana, 61, 3-14.

Aschero C. y E. Ribotta

2007 Usos del espacio, tiempo y funebria en El Remate (Los Zazos, Amaicha del Valle, Tucumán). En P. Arenas, B. Manasse y E. Noli (eds.): Paisajes y procesos sociales en Tafí del Valle. UNT: San Miguel de Tucumán, 79-94.

Berberián, E. y A. Nielsen

1988 Sistemas de asentamiento prehispánicos en la etapa formativa del Valle de Tafí. En E. Berberián (ed.): Sistemas de asentamiento prehispánicos en el Valle de Tafí. Comechingonia: Córdoba, 21-51.

Binford, L.

1979 Organization and formation processes: looking at curated technologies. Journal of anthropological research, 35 (3), 255-273.

Cabrera, A.

1976 Regiones fitogeográficas argentinas. En: Enciclopedia argentina de agricultura y jardinería, Tomo II, fascículo 1, Acme: Buenos Aires.

Capllonch, P., D. Ortíz, I. Ferro, A. Novillo, R. Ovejero, N. Aguilera, M. Costilla, y A. Zaccheo s/f Caracterización y diagnóstico del estado actual del ambiente físico y biológico de la reserva privada Las Queñuas. Inédito: San Miguel de Tucumán.

Cremonte, M. B.

1996 Investigaciones arqueológicas en la Quebrada de La Cienaga (Dpto. Tafí, Tucumán). (Tesis doctoral).UNLP: La Plata.

2003 Producción cerámica de la tradición Tafí. Estudios tecnológicos de la alfarería arqueológica de la Ciénega (Tucumán, Noroeste de Argentina). Revista do Museu de Arqueología e Etnología, 13, 57-74.

Di Lullo, E.

2012 La casa y el campo en la Quebrada de Los Corrales (El Infiernillo, Tucumán): Reflexiones sobre la espacialidad en el $1^{\circ}$ Milenio d.C. Comechingonia, 16, 85-104.

García Azcárate, J.

2000 Símbolos, piedras y espacios: una experiencia semiológica. En: M. Podestá y M. De Hoyos (ed.): Arte en las Rocas. Arte rupestre, menhires y piedras de colores en Argentina. 
Sociedad Argentina de Antropología: Buenos Aires, 73-83.

González, A. R., y V. Núñez Regueiro

1960 Informe preliminar sobre la investigación arqueológica en Tafí del valle (Noroeste de Argentina). Actas del XXXIV Congreso Internacional de Americanistas.

Heredia, O.

1974 Investigaciones arqueológicas en el sector meridional de las selvas occidentales. Revista del Instituto de Antropología de Córdoba, 5, 73-132.

López Campeny, S., A. Martel, J. Martínez y A. Romano

2005 Informe de resultados de la prospección arqueológica en la reserva privada la Queñoas. Inédito: San Miguel de Tucumán.

Maldonado, M., L. Neder, J. Roldán, y M. Sampietro Vattuone

2011 Caracterización geoambiental y cultural del período formativo en Selvas occidentales meridionales: sitio Horco molle (Dpto. Yerba Buena, Tucumán). Comechingonia, 14, 115131.

Nelson, M. C.

1991 The study of technological organization. Archaeological method and theory, 3, 57-100.

Oliszewski, N.

2011 Ocupaciones Prehispánicas en La Quebrada de los Corrales, El Infiernillo, Tucumán (ca. 2500-600 años AP). Comechingonia, 14 (1), 155-172.

2017 Las aldeas 'Patrón Tafí' Del sur de cumbres calchaquíes y norte del sistema del aconquija; Centro de Estudios Históricos Prof. Carlos S. A. Segreti. Comechingonia; 21 (1), 205-232.

Olivera, D.

2001 Sociedades agro-pastoriles tempranas: el Formativo Inferior del Noroeste Argentino. En E. Berberián y A. Nielsen (eds.): Historia Argentina Prehispánica., Brujas: Córdoba, 83126.

Palamarczuk, V., R. Spano, F. Weber, D. Magnífico, S. López, y M. Manasiewicz 2007 Soria 2. Apuntes sobre un sitio Formativo en el valle de Yocavil (Catamarca, Argentina). Intersecciones, 8, 121-134.

Quiroga, A.

1899 Ruinas de Anfama. El pueblo Prehistórico de la Ciénega. Boletín del Instituto geográfico Argentino, 95-123. 
Rohmeder, G.

1945 Paisaje natural y antropógeno en Tucumán, Antropogeografía general de la provincia de Tucumán. Gaea, Anales de la sociedad argentina de estudios geográficos, 7 (2), 293-316.

Sampietro, M., y Vattuone, M.

2005 Reconstruction of activity areas at a Formative household in northwest Argentina. Geoarchaeology, 20 (4), 337-354.

Salazar, J.

2011 Reproducción Social Doméstica y Asentamientos Residenciales entre el 200 y el 800 d.C. en el Valle de Tafí, Provincia de Tucumán. (Tesis doctoral). UNC: Córdoba.

Salazar, J., V. Franco Salvi, E. Berberián, y S. Cravero

2008 Contextos domésticos del valle de Tafí, Tucumán, Argentina (200-1000 AD). Werken, $10,25-47$.

Scattolin, M. C.

2010 La organización del hábitat precalchaquí (500 a.C.-1000 d.C.). En M. Albeck, M. C. Scattolin, y M. A. Korstanje (eds.): El hábitat prehispánico. Arqueología de la arquitectura y de la construcción del espacio organizado. Edi UNJu: San Salvador, 13-51, 